\title{
ESTUDO SOBRE A VIABILIDADE DA TOMOGRAFIA ELETROMAGNÉTICA NA MEDIÇÃO DO PERFIL DE VELOCIDADES DE ESCOAMENTOS MONOFÁSICOS EM DUTOS
}

\author{
Teodora Pinheiro Figueroa
}

Tese apresentada à Escola

de Engenharia de São Carlos, da

Universidade de São Paulo, como

parte dos requisitos para a

obtenção do título de Doutora em

Engenharia Mecânica.

ORIENTAdor: Prof. Dr. Paulo Seleghim Júnior

São Carlos

2005 
Todas as realizações e conquistas em minha vida são consequências da sabedoria, esforço, incentivo e da fé inabalável que minha mãe tinha em DEUS. À minha mãe, Marinalva Pinheiro $\mathbf{\dagger}$, dedico esta tese, pois ela sempre foi a razão de tudo na minha vida. 


\section{Agradecimentos}

Agradeço em primeiro lugar a DEUS por sempre estar presente em meu caminho. Ao meu orientador prof. Dr. Paulo Seleghim Jr. pela orientação, paciência e, por estar sempre disposto a ajudar com sua sabedoria e experiência.

À minha mãe Marinalva †, meu irmão Júnior, meu irmãozinho Samuel e a minha avó Maria José † pelo carinho e compreensão em todos os momentos.

Ao meu esposo Alessandro pela força e paciência no decorrer destes anos.

Ao meu amigo Alexander Cursino Guimarães pelo apoio e ajuda quando necessário. Ao meu amigo Eduardo José de Freitas pela força e amizade.

À prof $\stackrel{a}{\text {. }}$ Miriam Percia Mendes pela amizade e espírito de otimismo que sempre está presente em seu rosto.

À Ana Paula e todo o pessoal da secretaria da pós-graduação, pela atenção e simpatia no atendimento.

À Kelen, Fabiana, Gisleine, Luciana, Luciane e Beth pela verdadeira amizade. À Alice, a qual conheci por intermédio da Luciana, e que contribuiu muito com sua amizade, amor ao próximo e profissionalismo como assistente social do fórum de São Carlos, para que eu tivesse tranquilidade no decorrer destes últimos anos, em vista do falecimento da minha mãe e da responsabilidade que assumi como mãe para os meus dois irmãos.

À Grazieli e Renata pelo incentivo, carinho, atenção e riqueza de coração.

Ao Bruno pela amizade e atenção.

À Érica, Paulo, Graziela, Juliana pelo companheirismo no decorrer destes anos.

Ao Prof. Sérgio R. Fontes por acreditar em meu trabalho e pelo incentivo.

A todos os amigos do Núcleo de Engenharia Térmica e Fluidos.

Ao $\mathrm{CNPq}$ pelo apoio financeiro concedido durante o desenvolvimento deste trabalho. 


\section{Índice}

Lista de Figuras . . . . . . . . . . . . . . . iv

Lista de Tabelas . . . . . . . . . . . . . . . . . . vi vi

Lista de Símbolos . . . . . . . . . . . . . . . . vii

Resumo ........................ ix

Abstract ........................ $\mathrm{x}$

1 Introdução . . . . . . . . . . . . . . . . . . . . . . 1

2 Revisão Bibliográfica . . . . . . . . . . . . . . . . . . 3

2.1 Medidores de Vazão . . . . . . . . . . . . . . . . . . . . . . 3

2.1.1 Alguns Tipos de Medidores de Vazão . . . . . . . . . . . . 6

2.1.2 Medição e Controle de Vazão em Processos Industriais . . 15

2.2 Revisão histórica sobre Medidores Eletromagnéticos de Vazão . 17

2.3 Tomografia de Processos Industriais . . . . . . . . . . . . . . . . 27

3 Modelagem do Medidor Eletromagnético de Vazão . . . . . . . . . . . . . 30

4 Tomografia de Indutância Eletromagnética - EMT . . . . . . . . . . . . 34

4.1 Tomografia Eletromagnética \& Medidor Eletromagnético de Vazão 37

4.2 Técnica Numérica de Reconstrução Tomográfica Eletromagnética 39

5 Resolução do Problema Direto . . . . . . . . . . . . . . . . . . . . . 41

5.1 Adimensionalização . . . . . . . . . . . . . . . . . . . . 42 
5.2 Discretização da Equação Diferencial Parcial . . . . . . . . . . . . 43

5.3 Armazenamento . . . . . . . . . . . . . . . . . . . . . . . 49

5.4 Resolução do Sistema Linear . . . . . . . . . . . . . . . . . . . 50

5.4.1 Método Gradiente Bi-Conjugado Pré-Condicionado . . . . 51

6 Resolução do Problema Inverso . . . . . . . . . . . . . . . . . . . . . 53

6.1 Problema de Otimização . . . . . . . . . . . . . . . . . 55

6.2 Restrições . . . . . . . . . . . . . . . . . . . 5 55

6.3 Natureza das Variáveis . . . . . . . . . . . . . . . . . . 56

6.4 Mínimo Global . . . . . . . . . . . . . . . 56

6.5 Heurísticas de busca . . . . . . . . . . . . . . . 57

6.6 G.A. - Algoritmo Genético . . . . . . . . . . . . . . . 57

6.7 GEO - Algoritmo de Otimização Extrema Generalizado . . . . . . 65

6.8 MNRL - O Método de Newton Raphson Linearizado . . . . . . . 72

7 Resultados . . . . . . . . . . . . . . . . . . 75

7.1 Descrição do Problema Direto I . . . . . . . . . . . . . . . 75

7.2 Superfície de erro . . . . . . . . . . . . . . . . 77

7.3 Problema de Otimização I . . . . . . . . . . . . . . . . . . . . 79

7.3.1 Resultados da aplicação do G.A. - Algoritmo Genético . . 79

7.3.2 Resultados da aplicação do $\mathrm{GEO}_{\text {var }}$ - Algoritmo de Otimização Extrema Generalizado para $\tau=2.5 \ldots \ldots$. . . . . 83

7.4 Problema Direto II . . . . . . . . . . . . . . . . . . . . . . . . . 84

7.5 Problema de Otimização II . . . . . . . . . . . . . . . . . . . . . . 86

7.5.1 Resultados da aplicação do $\mathrm{GEO}_{\text {var }}$ - Algoritmo de Otimização Extrema Generalizado para $\tau=1.5 \ldots \ldots$. . . . 86

7.6 Problema Direto III . . . . . . . . . . . . . . . . . . . . . . . . . 89

7.7 Problema de Otimização III . . . . . . . . . . . . . . . . . . 90

7.7.1 Resultados da aplicação do $\mathrm{GEO}_{\text {var }}$ - Algoritmo de Otimização Extrema Generalizado para $\tau=2.0 \ldots . . \ldots 91$

7.8 Resultados Finais . . . . . . . . . . . . . . . . . . . . . . . . . 93

7.9 MNRL aplicado ao Problema de Otimização I . . . 93 
7.9.1 Resultados para o Problema de Otimização I . . . . . . . . 96 7.10 MNRL aplicado ao Problema de Otimização II . . 98 7.10.1 Resultados para o problema de Otimização II . . . . . . 99 7.11 MNRL aplicado ao Problema de Otimização III . . 102 7.11.1 Resultados para o problema de Otimização III . . . . . . . 103 8 Conclusão . . . . . . . . . . . . . . . . . . . . . 106 Referências Bibliográficas . . . . . . . . . . . . . . . . . 109 


\section{Lista de Figuras}

2.1 Seção Transversal do Tubo: $A$ é a área da seção transversal do tubo e $v$ velocidade do fluido . . . . . . . . . . . . . . . . . . . 4

2.2 Elemento de Superfície Generalizado em um Campo de Escoamento para Cálculo de Vazão . . . . . . . . . . . . . . . . . . . . . 4

2.3 Dispositivos Típicos para medir vazão em tubos . . . . . . . . . 6

2.4 Placa de Orifício . . . . . . . . . . . . . . . . . . . . . 7

2.5 Bocal ....................... . . 8

2.6 Venturi .............................. 9

2.7 Rotâmetro . . . . . . . . . . . . . . . . . . . 9 9

2.8 Turbina . . . . . . . . . . . . . . . . . . 11

2.9 Representação Física do Medidor Eletromagnético de Vazão . . 11

2.10 Perfil de velocidades desenvolvido . . . . . . . . . . . . . . . 15

2.11 Perfil de velocidades perturbado devido a curva . . . . . . . . 15

2.12 Medidor de Vazão de Campo Transversal . . . . . . . . . . . . . . 18

4.1 Diagrama de um típico Sistema de Tomografia Eletromagnética . 35

4.2 Modelo . . . . . . . . . . . . . . . . . . . 36

4.3 Objeto circular de ferrite . . . . . . . . . . . . . . 36

4.4 Objeto circular de alumínio . . . . . . . . . . . . . . . . . 37

4.5 Esquema do processo de reconstrução tomográfica . . . . . . . . . 38

4.6 Esquema geral de um problema de determinação de parâmetros 40

5.1 Malha em coordenadas polares . . . . . . . . . . . . . . . . 44

5.2 Malha em coordenadas polares . . . . . . . . . . . . . 47 
6.1 Esquema do problema inverso . . . . . . . . . . . . . . . . . 54

6.2 Exemplo de função não-convexa . . . . . . . . . . . . . . . 56

6.3 Estrutura Geral dos Algoritmos Genéticos . . . . . . . . . . . . 60

6.4 Desenho Cruzamento com apenas um corte (one-point crossover) . 62

6.5 Desenho Cruzamento com dois cortes (two-point crossover) . . . . 63

6.6 Exemplo de mutação para cromossomos binários . . . . . . . . . . 64

6.7 Algoritmos GEO . . . . . . . . . . . . . . . . . . 70

7.1 Malha em Coordenadas Polares . . . . . . . . . . . . 76

7.2 Função $v(r, \theta)$ para $\theta=0 \ldots \ldots \ldots \ldots$. . . . . . . . . 77

7.3 Superfície de Erro . . . . . . . . . . . . . . . 78

7.4 Curvas de Nível da Superfície de Erro . . . . . . . . . . . . . . 78

7.5 Resultados ótimos para a função de fitness e, variáveis $\alpha$ e $\mathbf{n}$. . . 82

7.6 Resultados ótimos para a função de fitness e, variáveis $\alpha$ e $\mathbf{n}$. . . 84

7.7 Influência dos parâmetros $\alpha, n$ e $a \ldots . \ldots . \ldots 85$

7.8 Resultados ótimos para a função de fitness e e variável $\alpha \ldots$. . . 88

7.9 Resultados ótimos para as variáveis $\mathbf{n}$ e a . . . . . . . . 88

7.10 Influência dos parâmetros $\alpha, n, a$ e $b \quad \ldots .90$

7.11 Resultados ótimos para a função de fitness e, variáveis $\alpha$ e $\mathbf{n}$. . . 92

7.12 Resultados ótimos para as variáveis a e b . . . . . . . . . . . 92

7.13 Resultados gerados pelo MNRL para $\epsilon$, variáveis $\alpha$ e $\mathbf{n}$. . . . 98

7.14 Resultados gerados pelo MNRL para $\epsilon$ e variável $\alpha$. . . . . . 100

7.15 Resultados gerados pelo MNRL para as variáveis $\mathbf{n}$ e a . . . . . 101

7.16 Resultados gerados pelo MNRL para $\epsilon$, variáveis $\alpha$ e $\mathbf{n}$. . . . . 104

7.17 Resultados gerados pelo MNRL para as variáveis a e b . . . . . 105 


\section{Lista de Tabelas}

2.1 Tabela Comparativa . . . . . . . . . . . . . . . . . . 13

2.2 Comparação de técnicas tomográficas elétricas . . . . . . . . . . 29

6.1 Correspondência entre os termos da Genética e do Algoritmo Genético 59

7.1 Tabela referente aos resultados obtidos com a aplicação do G.A. 81

7.2 Resultados obtidos com $G E O_{v a r}, \tau=2.5 \ldots \ldots$. . . . . . 83

7.3 Resultados obtidos com $G E O_{v a r}, \tau=1.5 \ldots \ldots$. . . . . . 87

7.4 Resultados obtidos com $G E O_{v a r}, \tau=2.0 \ldots \ldots$. . . . . . . 91

7.5 Aproximações geradas pelo MNRL . . . . . . . . . . . . . . . 97

7.6 Aproximações geradas pelo MNRL . . . . . . . . . . . . 100

7.7 Aproximações geradas pelo MNRL . . . . . . . . . . . . . . . 104 


\section{Lista de Símbolos}

$E E$ : eletrodos $E$ e $E$

$\overrightarrow{\mathbf{W}}$ : vetor peso

$W$ : função peso

$\vec{B}$ : vetor de indução magnética, ou vetor campo magnético

$B_{0}$ : componente do vetor campo magnético

$\vec{J}$ : vetor densidade de corrente

$\vec{E}$ : campo elétrico

$\vec{H}$ : vetor excitação magnética

$\vec{v}$ : vetor velocidade do fluido

$v$ : magnitude da velocidade do fluido

$v_{m}$ : velocidade média do fluido

S: sensibilidade do medidor de vazão

q: cargas presentes no fluido

Q: vazão

$(r, \theta)$ : coordenadas polares

$(\mathrm{x}, \mathrm{y})$ : coordenadas cartesianas

$D_{v}$ : domínio da função velocidade

r: raio

$\alpha$ : parâmetros da velocidade

$\alpha_{0}$ : aproximação inicial para $\alpha$

$n$ : parâmetro da velocidade

$n_{0}$ : aproximação inicial para $n$

$a$ : parâmetro da velocidade

$a_{0}$ : aproximação inicial para $a$ 
b: parâmetro da velocidade

$b_{0}$ : aproximação inicial para $b$

$\Re$ : conjunto dos números reais

$\phi$ : diferença de potencial

$\phi_{m e d}$ : diferença de potencial experimental ou simulada sob condições experimentais

para determinados parâmetros de referência da velocidade.

$\phi_{\text {aprox }}$ : diferença de potencial aproximada

$\mu$ : permeabilidade magnética do meio

$\beta$ : permissividade

$\epsilon_{1}$ : medida da não uniformidade de $W$

$\sigma$ : condutividade elétrica

$\rho$ : resistividade

$\rho_{0}$ : aproximação inicial da resistividade

$\delta$ : volume do medidor de vazão

$\partial \Omega$ : descreve a fronteira do domínio

$(\xi, \gamma)$ : coordenadas de fronteira

$\tau$ : parâmetro do algorítmo $G E O_{v a r}$

\section{Operadores}

$\nabla .:$ Divergente

$\nabla$ : Gradiente

$\nabla \times:$ rotacional 


\section{Resumo}

Figueroa, T. P. (2005). Estudo sobre a viabilidade da tomografia eletromagnética na medição do perfil de velocidades de escoamentos monofásicos em dutos. São Carlos, 2005, 127p. Tese (Doutorado) - Escola de Engenharia de São Carlos, Universidade de São Paulo.

Este trabalho apresenta um estudo prospectivo referente ao desenvolvimento de um medidor eletromagnético inteligente de vazão, cuja finalidade é determinar a vazão de escoamento a partir da reconstrução do perfil de velocidade utilizando técnicas tomográficas. Em conseqüência disso, o medidor de vazão será capaz de corrigir a vazão dada, através da integração do perfil de velocidade correto reconstruído por tomografia. A técnica de reconstrução tomográfica utilizada é baseada na construção de um funcional de erro, gerado a partir da diferença entre voltagens simuladas numericamente para uma condição experimental, conhecidos os parâmetros determinantes da velocidade no interior da tubulação, e voltagens "aproximadas"simuladas numericamente para aproximações destes parâmetros. Neste trabalho, o modelo físico do medidor eletromagnético de vazão é baseado em um número de eletrodos colocados sobre as paredes do tubo sob uma estratégia de excitação específica, sem injeção de corrente, considerando o campo magnético uniforme. A partir da expansão do funcional de erro, sobre um conjunto de funções conhecidas, uma superfície de erro é gerada. As características da patologia desta superfície requerem outros tipos de técnicas de otimização. Técnicas tradicionais de otimização não são viáveis, pois o processo de busca pára no primeiro mínimo local encontrado. Essa convergência para mínimos locais é justificada devido à presença de regiões planas e vales apresentando vários mínimos locais circundando o ponto de mínimo global (ou ponto referente aos parâmetros ótimos da velocidade). Em vista da ocorrência deste fato, técnicas baseadas em algoritmos evolucionários são testadas e apresentadas para uma série de casos demonstrando a praticidade de nossa pesquisa.

Palavras-chave: medidor eletromagnético de vazão, reconstrução tomográfica eletromagnética, métodos de otimização. 


\begin{abstract}
Figueroa, T. P. Study on viability of the electromagnetic tomography in the velocity profile measurements on monophase flow in pipe. São Carlos, 2004. 127p.

Ph.D. Thesis - Escola de Engenharia de São Carlos, Universidade de São Paulo.
\end{abstract}

This work presents a prospective study on the development of an intelligent electromagnetic flow meter intended to determine output based on the reconstruction of velocity profile using tomographic techniques. As a result, the flow meter will be able to correct the output measure through the integration of the right velocity profile produced by tomography The tomographic reconstruction technique utilized is based on the definition of an error functional generated from the difference between voltages simulated numerically for a experimental condition, being known the parameters which define the velocity within the pipe and approximate voltages simulated numerically for approaches of these parameters. In this work the physical model of the electromagnetic flow meter is based on a number of electrodes flush mounted on pipe walls and under a specific strategy of excitement, without electrical current input and considering the magnetic field uniform. From the expansion of the error functional over a set of known functions an error surface is generated. The characteristics of the pathology of this surface require other types of optimization techniques. Traditional optimization techniques are not viable since the search stops at the first local minimum. This convergence to local minimums is justified due to the presence of flat regions and valleys presenting several local minimums around the global minimum point (or point relative to the optimum parameters of velocity). Due to this fact techniques based on evolutionary algorithms are tested and presented for a series of cases demonstrating the usefulness of our research.

Keywords: intelligent electromagnetic flow meter, electromagnetic tomography reconstruting, optimization methods. 


\section{Capítulo 1}

\section{Introdução}

Há um grande interesse da indústria no monitoramento e controle de processos envolvendo escoamentos. Isso ocorre em razão da crescente demanda ligada a normas ambientais mais rígidas, normas de qualidade mais estritas, otimização de custos, melhoria das condições de segurança, etc. Por isso, nos últimos anos, o desenvolvimento de técnicas de visualização de escoamentos tem se revelado uma alternativa extremamente interessante para a otimização de processos e equipamentos. Além de ser importante em aplicações envolvendo escoamentos multifásicos, em vista da problemática tecnológica fundamentalmente ligada a existência de regimes ou padrões característicos de escoamentos. Estes regimes, por sua vez, são determinantes no comportamento de parâmetros macroscópicos, tais como, perdas de pressão, trocas térmicas, etc, podendo variar de maneira brutal de uma configuração de escoamento para outra. Do ponto de vista das aplicações industriais, a segurança e longevidade de equipamentos e instalações somente podem ser asseguradas quando estes operam segundo os regimes de escoamento para os quais foram dimensionados. Isto implica não apenas na capacidade de antecipá-los durante a fase do projeto, mas também, durante a fase de operação, de diagnosticar em tempo real sob qual configuração o fluido está escoando assim como as possíveis transições entre elas. Devido a esses fatores, um dos focos de interesse da indústria é o desenvolvimento de metodologias de controle de parâmetros como campo de velocidade e vazão mássica total.

Este trabalho insere-se neste contexto, e utiliza a combinação de técnicas 
de visualização e medidores de vazão indutivos convencionais, em específico, medidores eletromagnéticos de vazão. Medidores eletromagnéticos de vazão são amplamente utilizados em vários setores da área industrial, como por exemplo:químico/petroquímico, saneamento, siderúrgico, indústria alimentícia, farmacêutica, entre outras. Seu princípio de funcionamento baseia-se na Lei de Indução de Faraday e sua característica fundamental é o alto grau de sensibilidade a perturbações no perfil de velocidade, ocasionados por alguns elementos de tubulação, tais como: curvas, redução, etc.

A fim de contornar este problema, e visando uma aplicação industrial otimizada, com o mínimo custo efetivo, além de medidas de vazão confiáveis, este trabalho propõe um estudo com o objetivo de obter um medidor eletromagnético inteligente de vazão, ou seja, um medidor capaz de corrigir possíveis erros referentes à experimentação e instalação. Para atingir este objetivo é necessário o conhecimento de dois modelos físicos e seus respectivos princípios de funcionamento: o medidor eletromagnético de vazão e a técnica tomográfica eletromagnética (EMT). A aplicação da EMT é de fundamental importância neste estudo e neste caso em específico baseia-se na minimização de um funcional de erro. Este funcional de erro é construido a partir da diferença entre o sinal de saida do medidor de vazão, simulado numericamente através das equações governantes para um determinado perfil de velocidade (perfil de referência), e o sinal de saida obtido da mesma simulação numérica, considerando perturbações nos parâmetros da velocidade. Com base na construção deste funcional de erro técnicas de otimização podem ser aplicadas, a fim de determinar os parâmetros ótimos da velocidade que minimizem o funcional. E a partir daí, corrigir a vazão volumétrica através do cálculo de integração do correto perfil de velocidade reconstruido por EMT. 


\section{Capítulo 2}

\section{Revisão Bibliográfica}

\subsection{Medidores de Vazão}

A medida de vazão é uma necessidade fundamental em muitos processos industriais. Sem a mesma, tais processos dificilmente poderiam ser controlados ou operados de forma segura e eficiente.

Na história, grandes nomes marcaram suas contribuições. Leonardo da Vinci (1452-1519) descreve através de esquemas e escritos muitos fenômenos envolvendo escoamentos. Mas o desenvolvimento de dispositivos práticos ocorreu na era industrial com o auxílio do trabalho de pesquisadores como Bernoulli, Pitot e outros (TOKATY, 1971).

A medição de vazão volumétrica, em escoamento confinado, consiste na determinação do volume de líquidos, gases e sólidos que passam por uma seção da tubulação na unidade de tempo. Matematicamente, vazão pode ser expressa pela equação 2.1 . 


$$
Q\left(m^{3} / s\right)=A\left(m^{2}\right) \cdot v(m / s)
$$

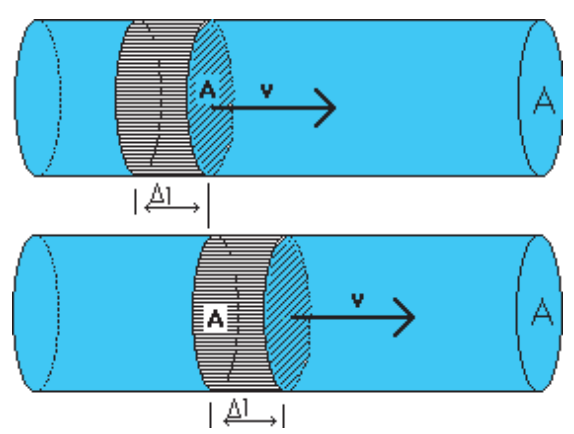

FIGURA 2.1: Seção Transversal do Tubo: $A$ é a área da seção transversal do tubo e $v$ velocidade do fluido

Generalizando, vazão também é definida como uma descarga volumétrica em um elemento de superfície qualquer (Figura 2.2, equação 2.2).

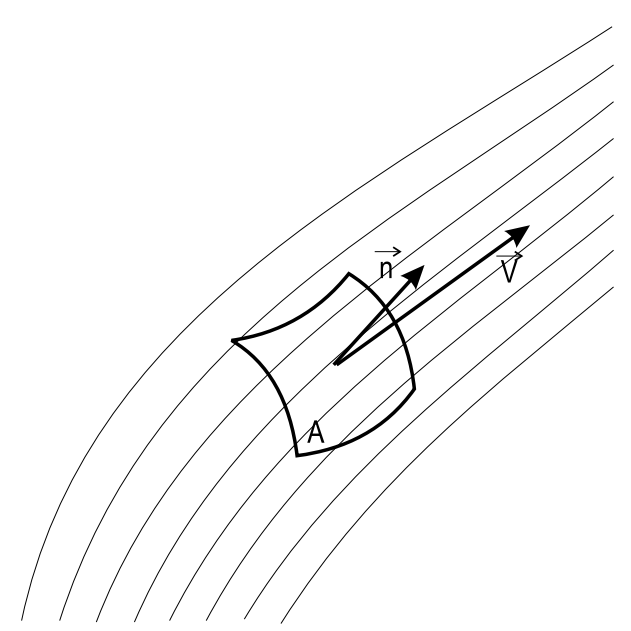

FIGURA 2.2: Elemento de Superfície Generalizado em um Campo de Escoamento para Cálculo de Vazão

$$
Q=\int_{A} \vec{v} \cdot \vec{n} d A
$$

Ou ainda, descarga mássica dada pela equação 2.3 . 


$$
Q=\int_{A} \rho \vec{v} \cdot \vec{n} d A
$$

Existe uma variedade de tipos de medidores de vazão para as mais diversas aplicações. A escolha do tipo de equipamento depende das condições de operação tais como:

- tipo de fluido (sólido, líquido, gás);

- característica do fluido (corrosivo, superviscoso, ...);

- característica do escoamento (alta pressão, pulsante, ...);

- número de fases (monofásico, multifásico, ...);

- valor econômico do fluido transportando.

Também deve-se levar em consideração outros fatores importantes, tais como:

- custo;

- precisão de leitura;

- a necessidade de calibração;

- a facilidade tanto da instalação como da manutenção.

A medição de vazão de fluidos representa um dos grandes desafios tecnológicos devido a forte influência do regime de escoamento. De fato, tanto os medidores comerciais quanto de laboratório para misturas gás-sólido ou envolvendo líquidos e gases, apresentam acuracidades insatisfatórias para a grande maioria das aplicações industriais. 


\subsubsection{Alguns Tipos de Medidores de Vazão}

Um modo eficiente de medir a vazão volumétrica em tubos é instalar algum tipo de restrição no tubo (Figura 2.3) e medir a diferença entre as pressões na região de baixa velocidade e alta pressão (1) e a de alta velocidade e baixa pressão (2). A Figura 2.3 mostra três tipos comuns de dispositivos dedicados a medição de vazão instantânea por pressão diferencial: Placa de Orifício, Bocal e o Tubo Venturi. A operação de cada um é baseada no mesmo princípio: um aumento de velocidade provoca uma diminuição na pressão.
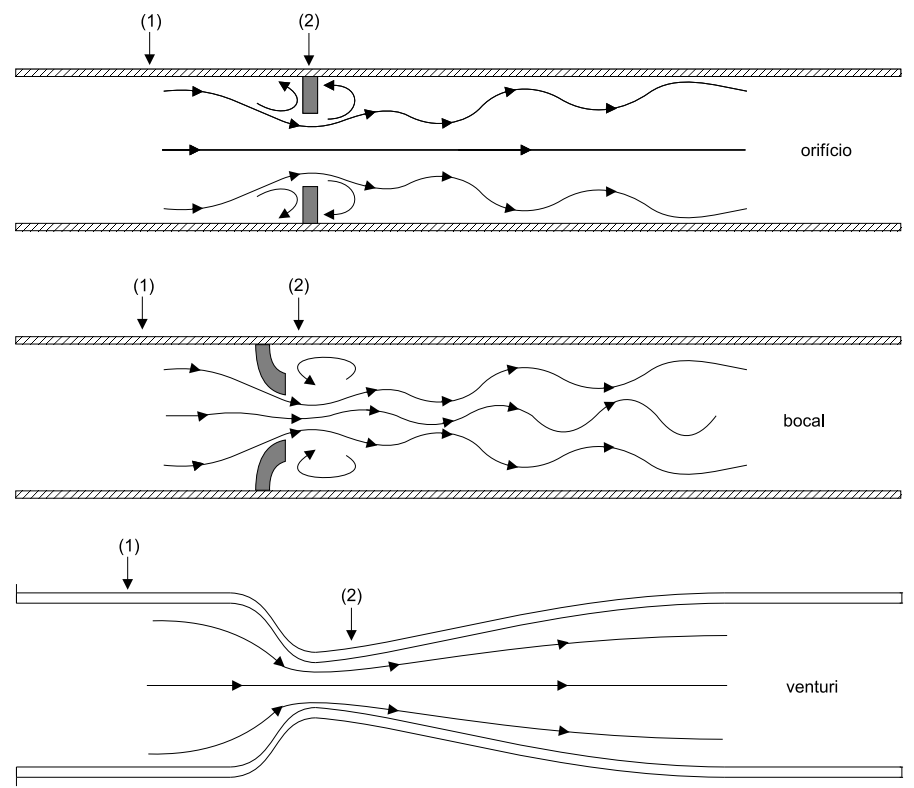

FIGURA 2.3: Dispositivos Típicos para medir vazão em tubos

Placa de Orifício : Dos muitos dispositivos inseridos numa tubulação para se criar uma pressão diferencial, o mais simples e mais comum empregado é o da placa de orifício. Consiste de uma placa precisamente perfurada, a qual é instalada perpendicularmente ao eixo da tubulação. Um arranjo comum é apresentado na Figura 2.4. A placa provoca uma redução da seção do fluxo e é montada entre dois anéis que contêm furos para tomadas de pressão em cada lado. O conjunto é fixado entre flanges, o que torna fácil sua instalação e manutenção. 


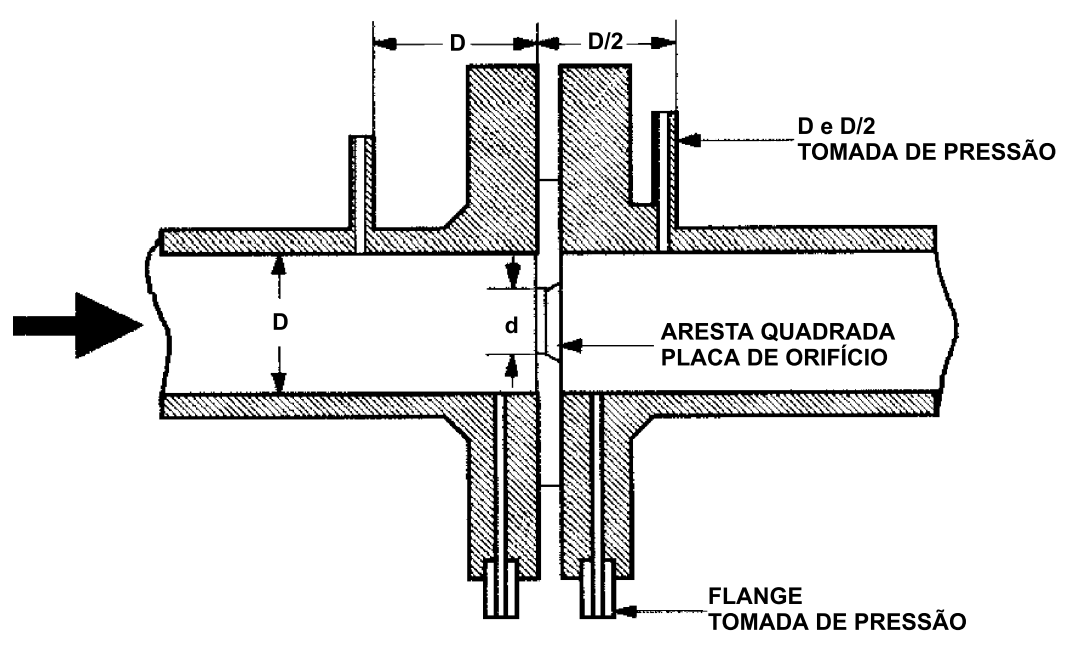

FIGURA 2.4: Placa de Orifício

Este dispositivo apresenta as seguintes vantagens:

- instalação fácil;

- econômica;

- construção simples;

- manutenção e troca simples.

E as desvantagens são:

- alta perda de carga;

- baixa rangeabilidade.

Medidores de gás por placa de orifício são potencialmente muito precisos, mas como é de conhecimento dos especificadores de medidores de vazão, essa precisão é possível somente se uma série de importantes critérios de instalação forem atendidos. Entre os mais importantes para precisão de vazão estão os requesitos de trecho reto à montante e à jusante. Para os medidores por placa de orifício e muitos outros tipos, o trecho reto requerido pode ultrapassar 30 diâmetros da linha. Exceto por linhas de transmissão que, por natureza, possuem longas distâncias ininterruptas de trecho reto. Esta exigência requer um difícil balanceamento entre atender a precisão 
especificada, e reduzir o custo instalado do medidor de vazão, através da minimização das modificações na linha (LEMKE, 2004).

Bocal : Bocais podem ser empregados como elementos medidores tanto em câmaras pressurizadas quanto em dutos. Detalhes do projeto, e localizações recomendadas para as tomadas de presão são apresentados em Bean (1971). O arranjo apresentado na Figura 2.5 é um exemplo de Bocal. Pode ser considerado uma placa de orifício com entrada suavizada.

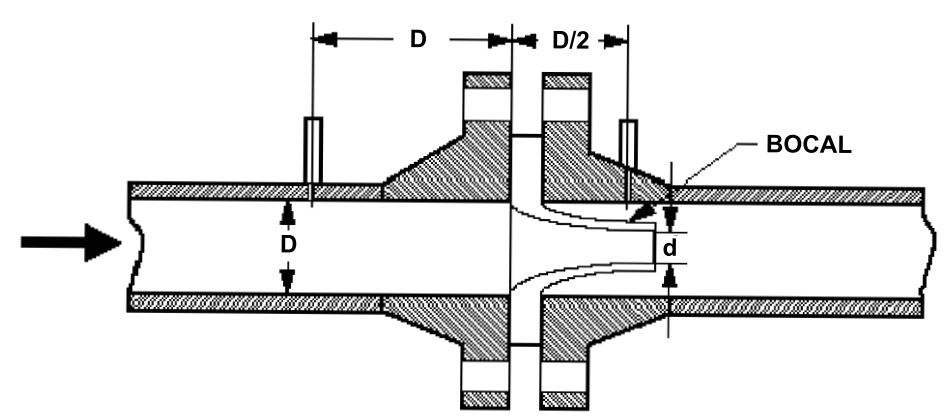

FIGURA 2.5: Bocal

O perfil dos bocais de vazão permitem sua aplicação em serviços onde o fluido é abrasivo e corrosivo. Seu principal uso é em medição de vapor com alta velocidade. Apresenta queda de pressão dentro de uma faixa entre o Venturi e a Placa de Orifício.

Tubo Venturi : O Venturi é o mais preciso e o mais caro desses três medidores de vazão. Apesar de apresentar o mesmo princípio de operação do Bocal e da Placa de Orifício, o Venturi é projetado de modo a reduzir as perdas de carga ao mínimo (o formato da contração é tal que "acompanha" as linhas de corrente, e minimiza a separação do escoamento na garganta, além disso, o formato da expansão é muito gradual para minimizar a separação no trecho de desaceleração do escoamento). A maior perda de carga que ocorre num Venturi, bem projetado, é devido as perdas por atrito nas paredes, ao invés das perdas associadas a separação do escoamento. 


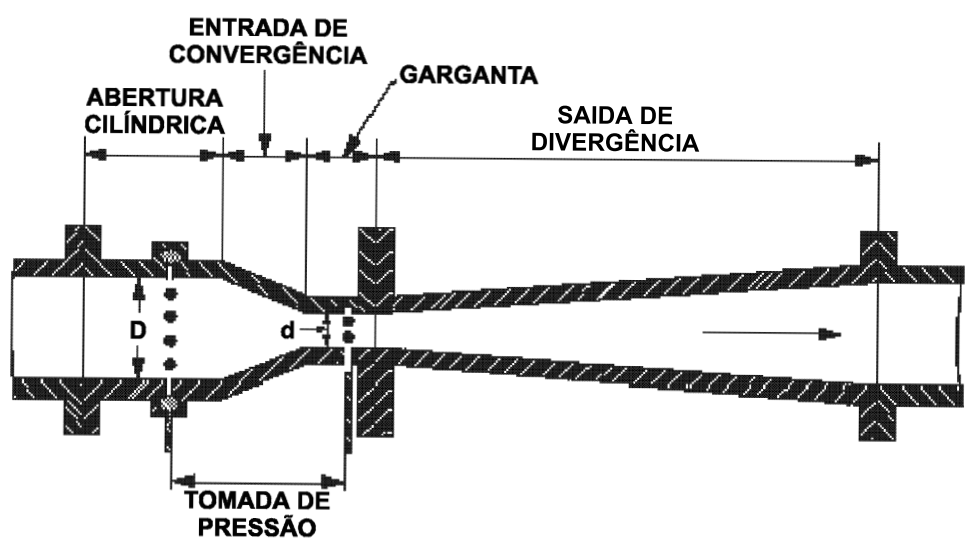

FIGURA 2.6: Venturi

Informações sobre o projeto, utilização e instalação podem ser encontrados em Bean (1971), Goldstein (1983), Benedict (1977) e Sptizer (1991)

Existem outros tipos de medidores de vazão que operam de modo diferente dos analisados, como por exemplo, o Rotâmetro ou Medidor de Área Variável (Figura 2.7) e o tipo Turbina (Figura 2.8), etc.

Rotâmetro : É constituído por um tubo transparente com escala, onde um flutuador (bóia) se move livremente. O flutuador é mais pesado do que o fluido que o desloca. O equilíbrio é atingido quando a diferença de pressão e o empuxo compensam a força gravitacional. A posição do flutuador indica a taxa de fluxo.

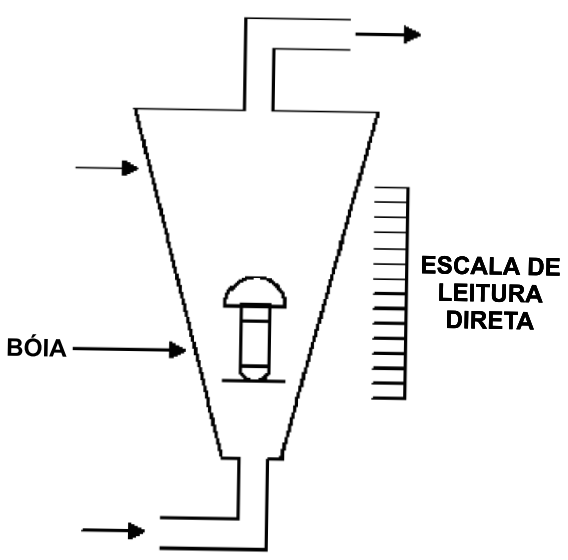

FIGURA 2.7: Rotâmetro 
Vantagens:

- Escala uniforme de fluxo;

- Através da troca do flutuador é possível mudar a capacidade de fluxo;

- Boa aceitação de fluidos corrosivos;

- Verificação visual da condição do fluxo.

Desvantagens:

- Só pode ser instalado na posição vertical;

- Em caso de fluido opaco, o flutuador não se torna visível;

- Não podem ser usados em líquidos que carregam grandes percentuais de sólidos em suspensão;

- Custo é alto para fluidos com altas temperaturas.

Turbina : Dentro do medidor há um elemento rotativo, ou pequena turbina, a qual gira livremente com uma velocidade angular que é aproximadamente proporcional a velocidade média do fluido no tubo. Essa velocidade angular é medida magneticamente, e é calibrada para fornecer uma medida precisa da vazão no medidor. 


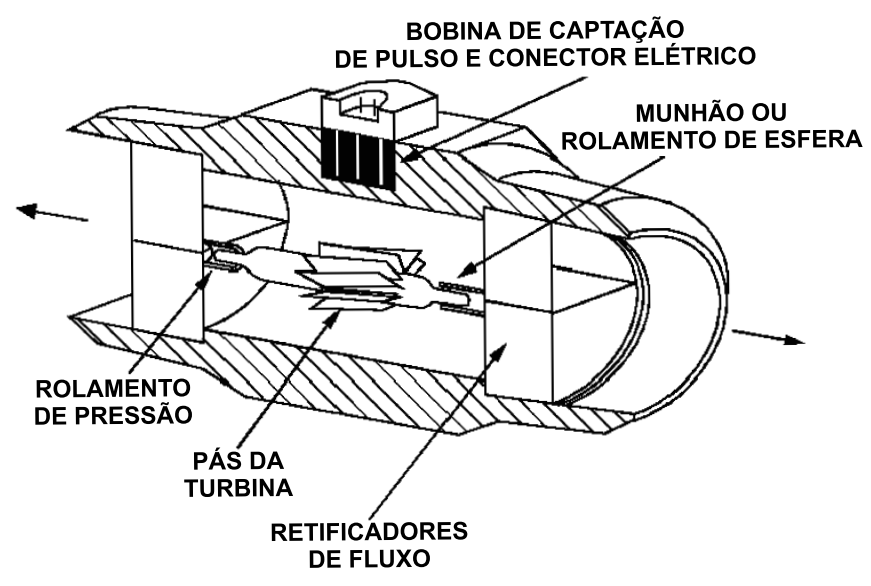

FIGURA 2.8: Turbina

Medidor Eletromagnético de Vazão : A essência do medidor eletromagnético de vazão consiste em medir a diferença de potencial entre dois ou mais eletrodos, dispostos nas paredes de um tubo contendo um fluido condutor de eletricidade, a uma determinada velocidade, sob um campo magnético imposto.

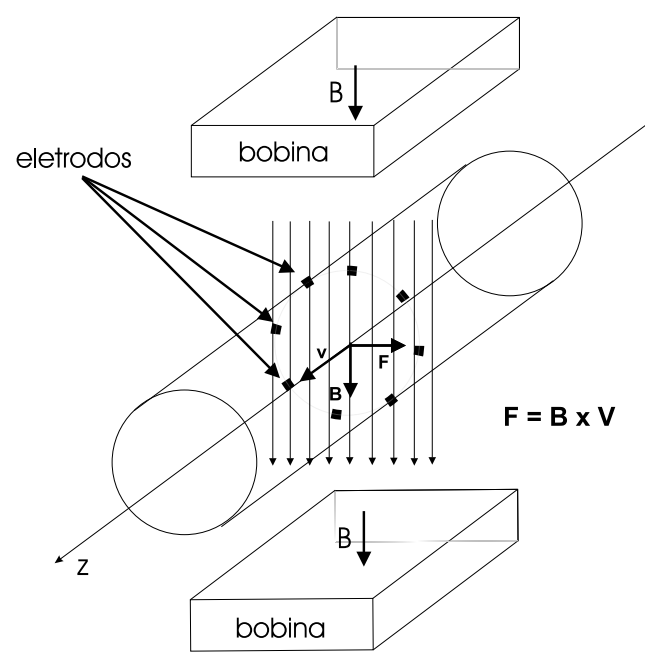

FIGURA 2.9: Representação Física do Medidor Eletromagnético de Vazão

Funcionamento: Uma bobina produz um campo de indução magnética $\vec{B}$, cujas linhas de força são perpenduculares à velocidade $\vec{v}$ do fluido condutor de eletricidade. A força magnética gerada provoca o deslocamento de 
cargas $q$ presentes no fluido e, um campo elétrico é obtido no interior do tubo. Logo, pela Lei de Indução de Faraday, surge uma força eletromotriz, estabelecendo-se uma diferença de potencial entre os eletrodos.

Os medidores eletromagnéticos de vazão podem ser divididos em dois tipos: o sensível a voltagem e a corrente. Muitos dos medidores comerciais de vazão são sensíveis a voltagem, porque a voltagem não depende da impedância entre os eletrodos (AHN, DO OH e KIM, 2003). Sua perda de carga é equivalente a de um trecho de tubulação, já que não possui qualquer obstrução. É virtualmente insensível à densidade e à viscosidade do fluido de medição. Medidores magnéticos são, portanto, ideais para medição de produtos químicos altamente corrosivos, fluidos com sólidos em suspensão, lama, água, polpa de papel. Sua aplicação estende-se desde saneamento até indústrias químicas, papel e celulose, mineração e indústrias alimentícias. A única restrição, em princípio, é que o fluido tem que ser eletricamente condutivo. Tem ainda como limitação o fato de fluidos com propriedades magnéticas adicionarem um certo erro de medição (GALLI e ONOFRE).

A Tabela ${ }^{1} 2.1$ apresenta informações comparativas da utilização em líquidos de alguns dos medidores mencionados. Não deve ser considerado uma referência absoluta, são apenas informações auxiliares obtidas de fabricantes.

\footnotetext{
${ }^{1}$ www.dee.ufma.br/ liea/arquivos/Procad/Felicio/transdutores\%20de\%20fluxo\%20sanguineo.ppt
} 
TABELA 2.1: Tabela Comparativa

\begin{tabular}{|c|c|c|c|c|c|c|c|}
\hline Tipo & Utilização & Faixa & $\begin{array}{l}\text { Perda } \\
\text { de } \\
\text { pressão }\end{array}$ & $\begin{array}{l}\text { Precisão } \\
\text { aprox \% }\end{array}$ & $\begin{array}{c}\text { Comprim } \\
\text { prévio } \\
\text { diam }\end{array}$ & $\begin{array}{l}\text { Sensib } \\
\text { à } \\
\text { viscosid }\end{array}$ & $\begin{array}{l}\text { Custo } \\
\text { relativo }\end{array}$ \\
\hline Bocal & Líquidos comuns. & $4: 1$ & Média & $\begin{array}{c} \pm 1 / \pm 2 \mathrm{da} \\
\text { escala }\end{array}$ & 10 a 30 & Alta & Médio \\
\hline Eletromagnético & $\begin{array}{l}\text { Líquidos condutivos com } \\
\text { suspensões }\end{array}$ & $40: 1$ & Não há & $\begin{array}{c} \pm 0,5 \text { da } \\
\text { proporção }\end{array}$ & 5 & Não há & Alto \\
\hline Placa de orifício & $\begin{array}{l}\text { Líquidos comuns. } \\
\text { Alguma suspensão. }\end{array}$ & $4: 1$ & Média & $\begin{array}{c} \pm 2 / \pm 4 \text { da } \\
\text { escala }\end{array}$ & 10 a 30 & Alta & Baixo \\
\hline Rotâmetro & Líquidos comuns. & $10: 1$ & Média & $\begin{array}{c} \pm 1 / \pm 10 \\
\text { da escala }\end{array}$ & Nenhum & Média & Baixo \\
\hline Tubo de Venturi & $\begin{array}{l}\text { Líquidos comuns. } \\
\text { Alguma suspensão. }\end{array}$ & $4: 1$ & Baixa & $\begin{array}{l} \pm 1 \text { da } \\
\text { escala }\end{array}$ & 5 a 20 & Alta & Médio \\
\hline Turbina & $\begin{array}{l}\text { Líquidos comuns. Pouca } \\
\text { suspensão. }\end{array}$ & $20: 1$ & Alta & $\begin{array}{l} \pm 0,25 \text { da } \\
\text { proporção }\end{array}$ & 5 a 10 & Alta & Alto \\
\hline
\end{tabular}

Na Tabela 2.1 observa-se que a maioria dos medidores apresentam perda de pressão, o que leva a um custo adicional devido a energia total requerida. Por exemplo, considere um medidor tipo Venturi $17^{\circ}$ (água). Para

- uma vazão mássica: $\dot{m}=1 \mathrm{~kg} / \mathrm{s}$

- $\beta=0.8$

- perda de pressão máxima: $\Delta P_{\max }=10 \mathrm{KPa}$

A perda de pressão permanente:

$$
\Delta P_{\text {perm }}=\left(0.218-0.42 \beta+0.380 \beta^{2}\right) \Delta P_{\max }=1.252 \mathrm{kPa}
$$

Com uma potência de bombeamento

$$
W=\frac{\Delta P \dot{m}}{\rho \eta}=1.565 W
$$


Em um ano de utilização contínua a energia (E) total requerida é de aproximadamente,

$$
E=24 \frac{\text { horas }}{\text { dias }} \quad \cdot 365 \text { dias } 1.565 \quad \frac{k W}{1000}=13.7 \mathrm{kWh}
$$

Outro fator importante e que exerce grande influência no bom funcionamento do medidor de vazão é operá-lo segundo os padrões para o qual foi calibrado. Todo fabricante de medidor de vazão comercial deve entregar o equipamento calibrado segundo normas, como por exemplo, a ISO 9104:BS 7526, a qual descreve as condições sob as quais a calibração deverá ser realizada, recomendando que o projeto primário seja posicionado no mínimo 10 diâmetros a jusante e 5 diâmetros a montante de algum distúrbio do escoamento. Na Tabela 2.1 ( $6^{a}$ coluna) pode-se observar este tipo de exigência para cada tipo de medidor. Bates e Franklim (2004) confirmam a importância do cuidado com relação a calibração, ao projetarem um medidor eletromagnético multi-eletrodo, o qual é composto de nove medidores eletromagnéticos convencionais alojados em um único corpo. Este tem sido utilizado em condições adversas do fluxo, imediatamente a jusante de um tubo de comunicação do tanque. Os resultados mostram que cuidados iniciais com a calibração, de acordo com as condições recomendadas para tubulações em padrões internacionais, proporcionam erros abaixo de $1 \%$.

É importante deixar claro que as exigências estabelecidas segundo a Tabela 2.1 ( $6^{a}$ coluna) e a ISO 9104:BS 7526 são necessárias afim de garantir o desenvolvimento do escoamento que atenue o efeito de distorções, quando este está sujeito a perturbações decorrente de alguma condição de instalação (Figura 2.11). A Figura 2.10 mostra as condições sob as quais o medidor de vazão é calibrado, ou seja, o medidor de vazão é calibrado para operar em um trecho reto de tubulação. Enquanto que a Figura 2.11 é um exemplo do que acontece com o perfil de velocidade quando o medidor é instalado próximo de elementos de tubulação, tais como curvas. 


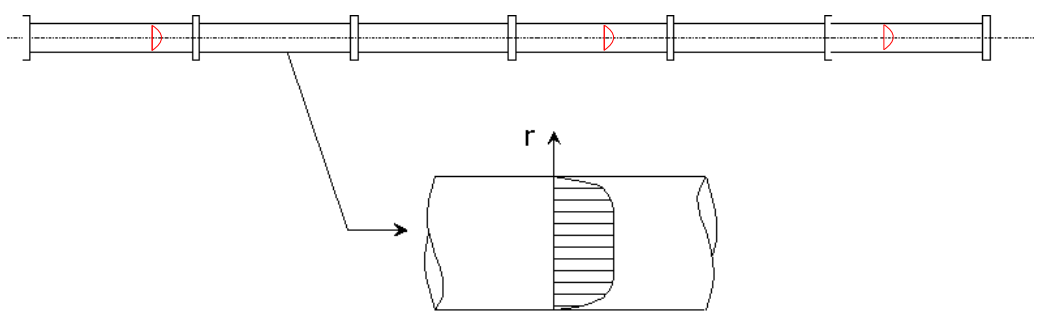

FIGURA 2.10: Perfil de velocidades desenvolvido

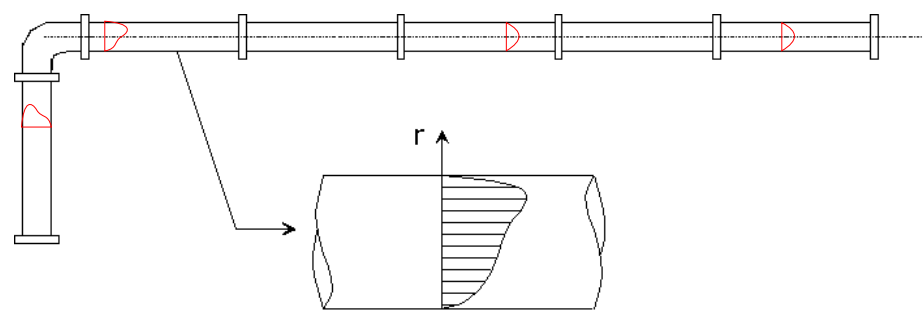

FIGURA 2.11: Perfil de velocidades perturbado devido a curva

Um outro fator importante é a componente de custo. Com base nas observações realizadas nota-se que, independente do tipo de medidor de vazão, a componente custo está associada a alguns fatores, tais como:

- custo inicial do equipamento;

- custo relativo a perda de carga;

- manutenção;

- aferição periódica;

- certificação.

\subsubsection{Medição e Controle de Vazão em Processos Indus- triais}

No contexto das aplicações que envolvem medição e controle de vazão em processos industriais, algumas técnicas híbridas foram desenvolvidas. No campo da indústria petroquímica, pode ser citado o trabalho de Boyer e Lemonier 
(1996) no qual é apresentado um processo de medição de escoamento gás-águaóleo combinando sondas capacitivas e ultrasonoras para a medição de concentrações volumétricas, além de um Venturi para a determinação da velocidade. É interessante notar que, neste trabalho, são reportados erros inferiores a $3 \%$ na determinação das vazões individuais quando empregado um misturador estático Optmix ${ }^{\circledR}$ a montante da seção de medidas para assegurar um escoamento a bolhas altamente disperso. Outro trabalho bastante interessante é o de Hervieu (1995) que concebeu um medidor adaptado a medição de vazões bifásicas de propano constituido de um densitômetro capacitivo (determinação da fração de vazio) e de uma turbina (vazão volumétrica total).

Tendo em vista o mercado potencial para medidores de vazão multifásicos envolvendo gases e líquidos (inicialmente a indústria termonuclear e atualmente a indústria do petróleo), é seguro dizer que essa última encontra-se num estágio de desenvolvimento tecnológico bastante avançado em relação à medição de misturas envolvendo sólidos particulados. Basta lembrar que existem diversos fabricantes comer-ciais de medidores bifásicos para escoamentos gás-líquido, com especial destaque para escoamentos petrolíferos. Por exemplo, Christian Michelsen Research e Fluenta (www.fluenta.com) desenvolveram em conjunto um medidor baseado na utilização combinada de um densitômetro gama e sondas capacitivas para a medição de frações volumétricas e de medidas intercorrelativas de velocidade. Este aparelho vem sendo testado pela Petrobrás em suas plataformas marítimas. Existe também medidores fabricado pela Konsberg Offshore S.A., Framo Engineering S.A., e Multi-Fluid ASA cujos princípios de funcionamento combinam dispositivos de homogeneização, densitômetros gama, sondas capacitivas e Venturis obtendo medidas com precisão da ordem de $10 \%$.

Ao contrário da medição de escoamentos englobando gases e líquidos, a medição em escoamento de sólidos particulados tem recebido atenção relativamente menor, embora o mercado potencial seja igualmente bastante promissor. Uma das razões para isso são certamente as dificuldades intrínsecas ao sensoriamento que, não raro, deve ser feito num ambiente quimicamente inóspito, altamente abrasivo e a altas temperaturas. Apesar do desafio, alguns trabalhos 
podem ser encontrados na lite-ratura tecno-científica. Especificamente sobre medição de vazão pode-se citar Xie et al (1989) e Yan (1996), ambos empregando sondas capacitivas para o sensoriamento.

\subsection{Revisão histórica sobre Medidores Eletro- magnéticos de Vazão}

O trabalho de Williams*(1930 apud SHERCLIFF, 1962, p.2), aparentemente fora do interese acadêmico, resultou no primeiro artigo a ser publicado sobre o desenvolvimento de um medidor eletromagnético de vazão, ilustrado na Figura 2.12. Seus experimentos foram realizados com uma solução de sulfato de cobre, a qual foi distribuida ao longo de um tubo circular não condutor, sob um campo magnético uniforme transversal. Uma tensão contínua foi medida entre os dois eletrodos EE, e verificou-se que era proporcional a vazão do escoamento.

*WILLIAMS, E. J.(1930). The induction of e.m.f.s in a moving fluid by a magnetic field and its application to an investigation of the flow of liquids. Proc. Phys. Soc.,Lond.,42, 466 apud Shercliff, J. A. (1962). The Theory of Electromagnetic Flow-Measurement,Cambridge University Press, p.2 


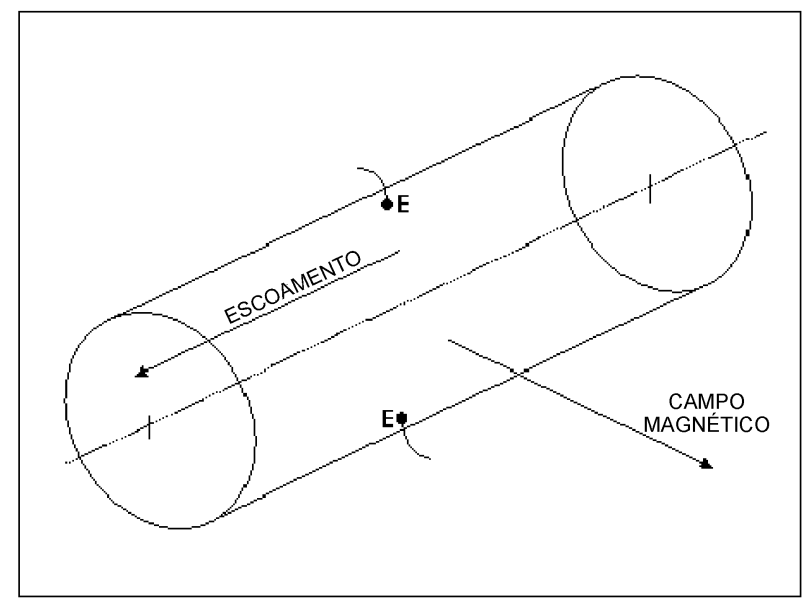

FIGURA 2.12: Medidor de Vazão de Campo Transversal

A partir deste trabalho, o medidor eletromagnético de vazão tornou-se uma atrativa solução para o registro de fluxo instantâneo de sangue em artérias. A grande vantagem é a resposta suficientemente rápida para indicar detalhes das pulsações de fluxo de sangue, além da possibilidade do sangue ser guardado inteiramente fechado e livre de contaminações. Outra vantagem é devido a pouca oposição ao fluxo, baseada na suposição da linearidade do medidor (isto é, a tensão induzida é proporcional a vazão), resultando em um sinal cuja média pode ser diretamente interpretada como pulsação média de sangue. A partir daí, muitas aplicações fisiológicas de medidores eletromagnéticos de vazão têm sido apresentadas na literatura. Um outro tipo de aplicação está relacionado ao advento da energia produzida em um reator nuclear após a segunda guerra mundial. Medidores eletromagnéticos de vazão são considerados a aplicação ideal em reatores de energia, por apresentar as qualidades necessárias às condições de operação, tais como: resistência a corrosão por metais radioativos liquefeitos em altas temperaturas, isenção de manutenção, além de apresentar uma calibração estável e fácil. Dessa forma, o medidor eletromagnético de vazão tem se tornado um protótipo ajustável em circuitos de metal líquido, tais como aqueles no reator Dounreay na Escócia (SHERCLIFF, 1962).

Em consequência da grande aceitação na época, muitas pesquisas passaram a ser realizadas, no sentido de compreender melhor toda a teoria envolvida 
em um projeto deste tipo. Shercliff (1954) foi o primeiro a estudar a teoria relacionada ao medidor eletromagnético de vazão para escoamento monofásico. Ele introduz uma função peso $(W)$, a qual representa o grau de contribuição da velocidade $(v)$ do fluido no sinal do medidor, em uma seção transversal de um duto. Através desta função peso $(W)$, a análise da sensibilidade $(\mathrm{S})$ do medidor eletromagnético de vazão, quantidade adimensional referente ao desempenho ou calibração do medidor, é descrita pela equação 2.4 .

$$
S=\frac{\phi_{E E}}{2 \mu H a v_{m}}=\frac{\iint v(x, y) W(x, y) d x d y}{\iint v(x, y) d x d y}
$$

onde $\phi_{E E}$ é a diferença de potencial induzida entre dois eletrodos $E$ e $E$ (Figura 2.12), $v_{m}$ é a velocidade média do escoamento, $a$ é o raio interno do tubo, $\mu$, a permeabilidade magnética, $H$ é o vetor excitação magnética e $W$ uma função peso.

Shercliff (1954) observou que, quando o perfil de velocidade é distorcido da simetria axial por forças magnetohidrodinâmicas, $S$ tende a 0.926 . Distúrbios onde o escoamento se concentra perto de ambos os lados da parede $S$ se aproxima de 0.5 , mas se o escoamento se concentra perto de um dos eletrodos, $S$ pode ser muito maior que a unidade.

Em consequência de estudos referentes a sensibilidade, muitas pesquisas vêm sendo realizadas visando obter um medidor eletromagnético de vazão ideal, cujo sinal de saida é proporcional a vazão de escoamento, independente da distribuição de velocidade.

Bevir (1970) analisou o desempenho do medidor eletromagnético de vazão em termos de um vetor peso $\vec{W}=\vec{B} \times \vec{j}$, o qual é uma extensão da função peso (SHERCLIFF, 1954) para três dimensões. Nesta análise, utiliza o conceito de corrente virtual $\vec{j}$, que é a densidade de corrente que seria estabelecida no líquido, pela passagem de corrente unitária entre os eletrodos, com $v=0$. É denominada virtual para distinguir das correntes resultantes do escoamento quando o medidor está em operação. Segundo Bevir (1970), a tensão induzida entre os eletrodos, 
em um medidor eletromagnético de vazão, é dada pela equação 2.5

$$
U=\int \vec{v} \cdot \vec{W} d \delta
$$

onde $\vec{v}$ é o vetor velocidade do fluido, $\vec{W}$ o vetor peso e $\delta$ é o volume do medidor de vazão.

Em seu trabalho, estabelece que é necessário obter uma configuração entre o campo magnético e os eletrodos, de tal modo que esta dependência sobre a velocidade desapareça, e o sinal de saida do medidor seja proporcional a vazão do escoamento, sem levar em consideração a distribuição da velocidade. A configuração estabelecida tem como hipóteses a incompressibilidade do fluido $(\nabla \cdot \vec{v}=0)$ e o confinamento de eletrodos e campo magnético $(\vec{W} \rightarrow 0$ a montante e a jusante). Com base nestas hipóteses, a condição necessária e suficiente para o sinal depender somente vazão de escoamento é que $\nabla \times \vec{W}=0$. Bevir (1970) apresenta uma pequena demonstração em seu artigo.

Este vetor peso $\vec{W}=\vec{B} \times \vec{j}$ representa a interação de correntes indutivas e o campo magnético. Esta interação é mais intensa no caso de metais líquidos, pois são altamente condutivos, ocorrendo como consequência problemas magnetohidrodinâmicos como:

- distorções do campo magnético por correntes induzidas;

- alterações na dinâmica do fluido, através de perturbações do perfil de velocidade e, adicão de uma queda de pressão na seção transversal do medidor, devido a forças de corpo produzidas sob a influência do campo.

Com fluidos condutivos não metálicos, que é o caso deste trabalho, estes efeitos são ignorados. Em todo caso, muitos trabalhos de pesquisadores usaram a influência desta interação, a fim de prever ou reduzir a sensibilidade com relação ao fluxo, próximo aos eletrodos, e a possíveis distúrbios nos perfis de velocidade.

Hemp (1975) retoma as pesquisas de Bevir (1970) para medidores de vazão com eletrodos pontuais. Acredita que este tipo de medidor pode ser ideal ou 
suficientemente próximo do ideal, a partir de uma escolha apropriada de campo magnético, pois a problemática existente com eletrodos pontuais é devido a sensibilidade deste tipo de projeto referente ao fluxo próximos dos eletrodos. Medidas alternativas a fim de reduzir estes efeitos têm sido pesquisadas, como por exemplo, a proposta de redução da intensidade do campo magnético, próximo aos eletrodos, através da fixação de uma tira de permalloy. O permalloy é um metal, liga de níquel contendo de $20 \%$ a $60 \%$ de ferro, e apresenta a propriedade de ser altamente permeável magneticamente. Dando prosseguimento as pesquisas, Hemp (1975) apresenta um método teórico, cujo objetivo é encontrar um campo magnético ideal para a utilização de eletrodos pontuais. Neste método considera o fluxo em um tubo cilíndrico com paredes isoladas eletricamente, onde o tubo e o líquido não apresentam propriedade magnética, e a velocidade do fluido é tomada em toda a parte como paralela ao eixo do tubo (perfil retilíneo), mas não necessariamente simétrica em relação ao eixo. Propõe um projeto do magneto, possibilitando a obtenção de uma expressão para a eficiência do medidor. Determina uma função peso $W$ para um arbitrário campo magnético, e define uma quantidade $\epsilon_{1}$, a qual é uma medida da não uniformidade de $W$ sobre a seção transversal do tubo. Os resultados mostraram que os efeitos dos perfis de velocidade podem ser reduzidos. Em situações onde o escoamento não é simétrico, o erro máximo esperado na leitura de um medidor de vazão, com uma melhor escolha do campo magnético, é de aproximadamente 10\%, comparado com aproximadamente 50\%, para um medidor eletromagnético convencional de eletrodos pontuais. Hemp (1975) conclui que o método pode ser usado para encontrar campos magnéticos que atenuem possíveis distúrbios dos perfis de velocidade, através do fornecimento de detalhes do projeto de um eletromagneto. Além disso, mostra que um medidor de vazão projetado para responder uniformemente ao escoamento retilíneo, pode ser completamente impreciso, quando certos tipos de circulações de fluxo são presentes.

O’Sullivan e Wyatt (1983) derivou funções pesos retilíneas (W) para vários números, tamanhos e formas de eletrodos a partir de um escoamento retilíneo, considerando as paredes do tubo isoladas, de variáveis espessuras, e 
adotando algum campo magnético. As deduções matemáticas são descritas e um programa computacional é esboçado. Diagramas são apresentados de ambas as funções pesos, retilíneas e simétricas em relação ao eixo do tubo, as quais têm sido determinadas para dife-rentes medidores de vazão, tais como: medidor de vazão de uso médico, medidor de vazão de uso médico com dois eletrodos, medidor de vazão de uso médico com seis eletrodos. Neste trabalho, o objetivo não é obter uma configuração ótima de eletrodos e campo magnético, a atenção é focada no sentido de reduzir a intensidade do campo central com magnetos curtos. Em todo caso, o método descrito possibilita predizer a existência da sensibilidade do medidor para alguma distribuição de velocidade retilínea.

É fato que a exatidão do medidor eletromagnético de vazão é fortemente influenciado pela forma do perfil de velocidade. Sendo que na prática, o medidor deve ser localizado suficientemente distante de distorções nas instalações. Em muitas faixas de aplicações isto é indesejável, difícil ou até mesmo impossível. Entretanto os métodos descritos até aqui apresentam seus problemas ou limitações.

Horner e Mesch (1995), propuseram uma abordagem baseada em métodos tomográficos, o qual implica na medida de muitos dados. Entretanto estas adicionais informações não são utilizadas para a reconstrução do perfil de velocidades, mas para obter uma estimativa da vazão média volumétrica. Neste caso, através de deduções matemáticas do modelo do medidor eletromagnético de vazão, é descrita uma função transdutor. Esta função transdutor, deve ser de tal forma que minimize a sensibilidade aos perfis de velocidades, para um dado número de eletrodos. Neste trabalho, os resultados teóricos foram constatados a partir da realização de experimentos, usando uma instalação consistindo de um campo magnético rotativo, em um plano perpendicular a direção do escoamento, e de múltiplos pares de eletrodos. Os resultados mostraram que erros devido a assimetria dos perfis tornam-se pequenos com o aumento do número de eletrodos. Em consequência, observou-se uma significativa melhora na exatidão, comparado a um sistema convencional de dois eletrodos com campo alternado. Esta proposta opera com medidas de erros inferiores a $1 \%$ e em condições de escoamento 
que causam erros acima de 6\%, com medidores convencionais de dois eletrodos. Dando prosseguimento a este trabalho, Horner, Mesch e Trachtler (1996) apresentaram relativas vantagens de adicionais pares de eletrodos e componentes de campo magnético. Os resultados foram comparados com o trabalho de Horner e Mesch (1995) e os dados teóricos foram avaliados experimentalmente. Visando encontrar o valor médio da vazão utilizou-se métodos tomográficos, afim de extinguir alguns erros causados pela distribuição não uniforme do perfil de velocidades. Seus resultados apresentaram um ganho de exatidão com mais do que quatro eletrodos, já que fortes distorcões de fluxo podem causar grandes erros nas medidas, até mesmo com medidores de vazão de quatro eletrodos. Além disso, estes erros podem ser reduzidos usando dois campos magnéticos perpendiculares e mais do que dois eletrodos. Pois medidores convencionais de dois eletrodos apresentam exatidão nas medidas para fluxo simétrico axialmente, mas se ocorrem distorções do fluxo, na maioria dos casos, os erros são inaceitáveis. Entretanto, concluiram que em sistemas de seis ou oito eletrodos, os erros são bastante reduzidos.

A tentativa de usar medidores eletromagnéticos de vazão para aplicação em escoamentos multifásicos está resultando em intensivas pesquisas referentes aos efeitos da distribuição da fase sobre o desempenho do medidor.

Zhang (1997) analisa o desempenho de um medidor eletromagnético de vazão em escoamentos multifásicos através de simulaçõs numéricas. Por conveniência em análise, as fases são idealmente classificadas em isoladoras e condutoras. As interfaces são distintas e homogêneas. Por simplicidade, o problema é tratado como bidimensional em um domínio anular. Uma aplicação direta deste problema é em escoamento bifásico anular. Zhang (1997) investigou o caso de uma única bolha de gás na água. O objetivo principal refere-se ao estudo da função peso do medidor e não são consi-derados efeitos da distribuição de velocidade. Para a solução analítica da função peso considerou-se o campo magnético uniforme e diversos pares de eletrodos pontuais, em um domínio anular excêntrico. Essa solução é obtida por expansão em séries, utilizando o recurso do mapeamento para projetar um domínio anular excêntrico em um concêntrico. Situações de 
várias posições e diâmetros da bolha foram calculados para estimar a não uniformidade da função peso sob a seção transversal do tubo. Resultados numéricos mostraram que a não uniformidade da função peso no caso de dois pares de eletrodos é menor do que no caso de um par de eletrodos, para pequenas razões $b / R$, onde b é o raio da fase isoladora e $\mathrm{R}$ é o raio do tubo, enquanto que para maiores razões $b / R$, o contrário se aplica.

Em aplicações práticas, o comprimento de uma bolha de gás é geralmente mais curto do que o comprimento axial do medidor. Neste caso, a suposição de bolhas longas no trabalho de Zhang (1997) não é verdadeira. A existência de tais bolhas afetam a corrente virtual de maneira que ela não se torna mais simétrica com respeito ao plano dos eletrodos (ZHANG, 1998).

Zhang (1998) procura entender o efeito de uma única bolha de gás, ao longo do eixo do tubo, sobre a corrente virtual do medidor eletromagnético de vazão. Este estudo é obtido por um método alternativo. Este método divide o domínio de interesse em dois simples sub-domínios. Em cada sub-domínio , o potencial da current virtual é expressado em séries com coeficientes não conhecidos. Através deste método esses coeficientes são encontrados por um processo de iteração. Vários tamanhos de bolhas e posições ao longo do eixo do tubo são considerados nos cálculos. Por simplicidade nas expressões matemáticas e na economia do tempo computacional, o trabalho foi proposto para um modelo bidimensional, porém a diferença entre um modelo 2D e 3D é considerado e discutido.

Zhang (1999) dá proseguimento a estes estudos para o caso bidimensional considerando um número maior de bolhas, três bolhas, através de um método semi-analítico. A idéia básica do método é simples: ele divide a solução de um problema real de valor de fronteira em duas ou mais partes, cada uma das quais tem uma forma simples (usualmente em séries) e satisfaz uma parte das condições de fronteira, mas com alguns erros referentes a outras partes. Os erros são eliminados por um processo numérico de convergência. As bolhas podem ser de raios e posições variáveis no domínio, contanto que são circulares e não sobrepõem-se. Neste trabalho, também é discutido a extensão deste método para o caso tridimensional. 
Em uma análise geral, pode-se dizer que a natureza transiente e complexas geometrias de escoamento gás-líquido causam dificuldades na medição da velocidade do escoamento a partir de um medidor eletromagnético de vazão. Recentemente, um medidor sensitivo a corrente foi introduzido para obter medidas com alta resolução temporal. Neste estudo, Kim et al.(2004) aplicam a teoria do medidor sensitivo a corrente para medir a velocidade transiente em escoamento bifásico intermitente. Para fazer isto, utilizou-se do método de volume do fluido para obtenção do campo de velocidade e formas das bolhas de Taylor, considerando bolhas longas e curtas, em um tubo vertical, com o objetivo de simular a resposta de convencionais medidores sensitivos a voltagem e a corrente em um escoamento intermitente. Estes resultados foram comparados com dados experimentais e analíticos existentes e, houve uma concordância nos resultados. Além disso, computou-se a distribuição de potencial virtual para os eletrodos de tamanho finito, usando o método do volume finito para escoamento intermitente. Estabeleceu-se o sinal de saida predito para escoamento intermitente, através do campo de velocidade e do potencial virtual (ou função peso). Calibrou-se o medidor numericamente, afim de obter a velocidade média na seção transversal do líquido, em um plano de eletrodos, através do sinal de saida predito. Dois parâmetros de calibração foram requeridos para este procedimento: um coeficiente de escoamento padrão e um parâmetro de localização. Definiu-se o coeficiente de escoamento padrão pela razão da resistência do líquido entre os eletrodos para escoamento bifásico, com respeito a uma fase do escoamento, e o parâmetro de localização tem como função evitar erros na leitura do medidor causada por aceleração do líquido ou desaceleração nas vizinhanças dos eletrodos. Estes parâmetros foram calculados a partir do campo de velocidade computada e do potencial virtual. Os resultados podem ser usados para obter a velocidade média do líquido através do sinal medido para escoamento intermitente por um medidor sensitivo a corrente. Caso o sinal de saida do medidor de vazão seja obtido experimentalmente, estes parâmetros de calibração serão úteis para o cálculo com exatidão da velocidade média para escoamento intermitente.

Kim et al.(2005) realizam um estudo a partir do desenvolvimento de um 
medidor eletromagnético "avançado " com o objetivo de medir a velocidade média do líquido com altos transientes. Em adição, dois medidores condutores tipo anéis são fabricados para medir a fração de vazio e sua velocidade de propagação em escoamento intermitente. O sinal do medidor condutor com dois anéis depende da temperatura do líquido. Porém utilizou-se um medidor condutor com três anéis projetado por Coney (1973), o qual é independente da temperatura do líquido, comprovado experimentalmente. A fabricação dos medidores condutores concordaram com a solução analítica dada por Coney (1973). Através dos dados da velocidade média do líquido, a fração de vazio e a velocidade de propagação da fração de vazio, calculou-se a vazão de fluxo em cada fase.Definiu-se e avaliou-se parâmetros de calibração para medidores eletromagnéticos de vazão.

Baseado nessas pesquisas pode-se dizer que medidores de vazão insensíveis aos perfis de escoamentos tem se tornado um grande atrativo para pesquisadores e engenheiros de diversas áreas.

Xu et al (2001), obtiveram uma expressão para a velocidade média através das equações de Maxwell-Minkowski, obtidas a partir da integração da tensão induzida ao longo das paredes do tubo. Com o auxílio da expansão em série de Fourier do campo de velocidade, Horner et al (1996) deduziram uma expansão afim de estimar a velocidade média para um sensor de N-eletrodos. Segundo essa expansão, observararam que a aplicação de um segundo campo magnético homogêneo ao primeiro, reduziria o termo referente ao erro, pois este termo exerce influência sob um componente que determina o perfil de escoamento e o número de eletrodos. Exceto erros sistemáticos, o medidor de vazão indutivo multi-eletrodos apresenta desvantagem em relação aos erros randômicos, devido a existência de imprevisíveis fontes de ruido. Vários métodos têm sido empregados afim de eliminar os ruidos das medidas. Porém a hipótese de utilização de vários sensores, traz a possibilidade de uma tecnologia de fusão multi-sensor (KARISSON, 1998) que fornece uma estimativa segura e robusta. Neste artigo, dois campos magnéticos ortogonais foram utilizados para gerar um campo magnético rotativo (PEYTON et al, 1996). O campo rotativo pode ser influenciado pelo fluxo através de diversos ângulos e, muitas medidas podem ser obtidas, tornando assim aplicável a técnica 
tomográfica. Dessa forma, estimou-se a velocidade média através da fusão destes dados medidos pelo sensor em vários ângulos.

Com base nestas informações, pode-se dizer que muitas pesquisas devem ser realizadas no sentido de obter um modelo de medidor eletromagnético de vazão com uma precisão confiável, proveniente de um projeto barato e de fácil instalação. Nos últimos anos, tem havido um interesse político e ambiental relativo ao custo de fornecimento de água para consumo, o qual é subsequentemente gasto através de vazamentos de tubos. Este interesse tem inevitavelmente conduzido as companias de água a admitirem que precisam ter conhecimento do destino deste fornecimento; eles necessitam medir exatamente o escoamento de água em diferentes partes de sua rede de distribuição.

O projeto de medidores mecânicos convencionais de água tem sido pouco alterado nos ultimos 50 anos; eles têm partes que estão sujeitas ao desgaste e ao rompimento, além de ter um limite de vida. Medidores magnéticos, ultrassônicos e vortex são hoje relativamente mais baratos e comuns. Bates e Turner (2004) propõem estudos sobre o fluxo de escoamento associados com um novo medidor eletromagnético de vazão, conhecido comercialmente como AquaMaster, o qual tem sido recentemente introduzido pela ABB Automação especificamente para medidas de fluxo de água no Reino Unido. O presente estudo proporcionou um aumento na eficiência do AquaMaster. Isso ocorreu a partir do desenvolvimento de um programa, o qual inclue estudos da dinâmica dos fluidos computacional e experimental, a jusante e montante do medidor, bem como no interior de seu corpo. Este artigo fornece detalhes destes estudos, os quais tem sido baseados sob o uso de instrumentação a laser para fornecer a visualização do escoamento e, quando apropriado, perfis detalhados de ambos perfis da velocidade média e rms.

\subsection{Tomografia de Processos Industriais}

A utilização da técnica tomográfica iniciou-se primeiramente no diagnóstico de desordens no pulmão, na década de 30. Desde então a técnica médica tem 
avançado para obter uma melhor resolução da imagem. Nesta área, o sensoriamento tomográfico é baseado no uso de radiações eletromagnéticas de alta energia como raios X e $\Gamma$. O uso de tais métodos de radiação em aplicações industriais é indesejável devido ao problema de segurança e alto custo (DICKIN et al, 1992).

Nos últimos anos, o desenvolvimento de técnicas de visualização de escoamentos multifásicos tem se revelado uma alternativa extremamente interessante para a otimização de processos e equipamentos. A razão pode ser atribuida a diversos fatores, dentre eles a necessidade de satisfazer normas de qualidade mais estritas, otimização de custos, condições de segurança, etc.

Para a indústria, as técnicas tomográficas representam uma alternativa interessante no sentido de permitir um monitoramento mais detalhado do processo e, portanto um controle mais eficaz dos equipamentos.

Na metade da década de 80, trabalhos baseados em sistemas de processos tomográficos começaram a ser difundidos.

O Instituto de Ciência e tecnologia, da Universidade de Manchester, na Inglaterra, foi o primeiro a desenvolver e a testar um projeto sobre tomografia capacitiva elétrica, para imagens de escoamento multifásico, em vasos de óleo e transporte pneumático. Ao mesmo tempo, um grupo do Centro de Tecnologia e Energia em Morgantown (USA), projetava um sistema de tomografia capacitiva para medir a distribuição da porosidade em leito fluidizado gasoso. Com estas iniciativas, ambos os grupos demonstraram por volta dos anos 90, não somente a viabilidade da técnica tomográfica, mas também seu grande potencial em processos industriais (BECK e WILLIAMS, 1996).

As técnicas tomográficas elétricas, em particular, fornecem um sistema de imagem barato, não intrusivo, apresentando uma baixa resolução, mas o suficiente para a análise da distribuição interna dos processos. Essas técnicas podem ser sub-divididas em:

- Tomografia de Capacitância Elétrica (ECT): envolve medidas de perfis de capacitância e produz imagens da distribuição de permissividade;

- Tomografia de Impedância Elétrica (EIT): é baseada sobre medidas padrão 
de resistência e reatância e, podem produzir imagens de condutividade $(\sigma)$ e, permissividade $(\beta)$;

- Tomografia de Indutância Eletromagnética (EMT): completa o conjunto destas técnicas e, atualmente é a menos desenvolvida. EMT emprega medidas de indutância para extrair dados tomográficos relacionados a distribuição de permeabilidade $(\mu)$ e condutividade $(\sigma)$.

Algumas características destas técnicas são apresentadas na tabela 2.2.

TABELA 2.2: Comparação de técnicas tomográficas elétricas

\begin{tabular}{|c|c|c|c|c|}
\hline MÉtodos & TFO DE DISPOSI, 200 & VALORES MEDIDOS & $\begin{array}{l}\text { PRAPRIEDADES } \\
\text { TIFICAS DO MATERIALL } \\
\end{array}$ & TIFO DE MATERIAL \\
\hline ECT & & CAFACITANCIÁC & $\begin{array}{c}\sigma \\
<10^{-1} \mathrm{~s} / \mathrm{m} \\
(\mid \mathrm{w})\end{array}$ & 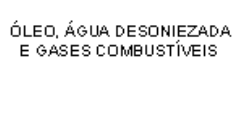 \\
\hline ERT(EIT) & & RESISTENCIAAR R & 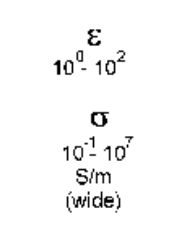 & 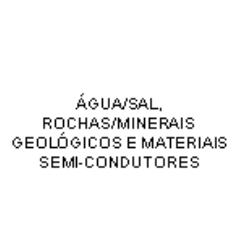 \\
\hline EMT & & INDUTAANACIA & 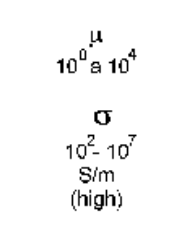 & $\begin{array}{l}\text { METAIS, ALGUNS MINERAIS } \\
\text { EAGUAIONIZADA }\end{array}$ \\
\hline
\end{tabular}




\section{Capítulo 3}

\section{Modelagem do Medidor Eletromagnético de Vazão}

Considerou-se o fluido não magnético, obedecendo a Lei de Ohm, tal que a corrente é proporcional e paralela ao campo elétrico. Adotou-se a permeabilidade do vácuo e, condutividade isotrópica, não afetada pelo campo magnético ou movimento do fluido. E alguns aspectos foram ignorados, tais como: efeito de correntes indutivas sobre a distribuição do campo, efeito de forças eletromagnéticas sobre o escoamento, variações de condutividade e efeitos termoelétricos e, desprezou-se correntes devido a convecção de cargas pelo movimento do fluido.

Com base nestas suposições, formulou-se o modelo físico referente ao medidor eletromagnético de vazão, a partir da Lei de Ohm para o fluxo de corrente no fluido (SHERCLIFF, 1962; BEVIR, 1970), descrita pela equação 3.1:

$$
\vec{J}=\sigma[\vec{E}+(\vec{v} \times \vec{B})]
$$

onde $\vec{J}$ é o vetor densidade de corrente, $\sigma$ a condutividade do fluido, $(\vec{E}+\vec{v} \times \vec{B})$ é o campo elétrico devido ao movimento do fluido, $\vec{E}$ é o campo elétrico em um sistema de coordenadas estacionária, $\vec{v}$ é a velocidade do fluido e $\vec{B}$ é o vetor de indução magnética. O termo $\vec{v} \times \vec{B}$ representa a força eletromotriz induzida pelo movimento do fluido, enquanto $\vec{E}$ se refere ao campo elétrico devido a distribuição 
de cargas no fluido.

Excluindo os termos de auto indução $\frac{\partial \vec{B}}{\partial t}$ e o deslocamento de corrente, as equações de Maxwell resultam em:

$$
\begin{gathered}
\nabla \times \vec{E}=0 \\
\nabla \times \vec{B}=\mu \vec{J}
\end{gathered}
$$

Da equação 3.2, vemos que o potencial elétrico $\phi$ pode ser definido de maneira usual tal que $\vec{E}=-\nabla \phi$.

A equação 3.3 descreve como o campo magnético imposto induz a corrente elétrica no fluido devido ao seu movimento. Em consequência, a equação de conservação de cargas resulta em:

$$
\nabla \cdot \vec{J}=0
$$

Aplicando-se a equação 3.4 na equação 3.1:

$$
\begin{gathered}
\nabla \cdot J=\nabla \cdot(-\sigma \nabla \phi)+\nabla \cdot[\sigma(\vec{v} \times \vec{B})]=0 \\
\nabla \cdot J=-\nabla \sigma \cdot \nabla \phi-\sigma \nabla^{2} \phi+\nabla \sigma \cdot(\vec{v} \times \vec{B})+\sigma \nabla \cdot(\vec{v} \times \vec{B})=0
\end{gathered}
$$

Desenvolvendo a equação 3.6 para a condutividade do fluido $(\sigma)$ constante, e fazendo as simplificações necessárias, obtém-se:

$$
\nabla^{2} \phi=\nabla \cdot(\vec{v} \times \vec{B})
$$

Calculando o lado direito da equação 3.7, ou seja: 


$$
\nabla \cdot(\vec{v} \times \vec{B})=\vec{B} \cdot(\nabla \times \vec{v})-\vec{v} \cdot(\nabla \times \vec{B})
$$

para $\nabla \times \vec{B}=0$, a equação 3.7 torna:

$$
\nabla^{2} \phi=\vec{B} \cdot(\nabla \times \vec{v})
$$

Supondo a velocidade do fluido com apenas a componente $\overrightarrow{v_{z}}$ na direção $z:$

$$
\vec{v}=\left(0,0, v_{z}\right)=0 \vec{i}+0 \vec{j}+v_{z} \vec{k}
$$

e o campo magnético uniforme:

$$
\vec{B}=\left(0, B_{0}, 0\right)=0 \vec{i}+B_{0} \vec{j}+0 \vec{k}
$$

Determinou-se $\nabla \times \vec{v}$ :

$$
\nabla \times v=\left[\begin{array}{ccc}
\vec{i} & \vec{j} & \vec{k} \\
\frac{\partial}{\partial x} & \frac{\partial}{\partial y} & \frac{\partial}{\partial z} \\
0 & 0 & v_{z}
\end{array}\right]=\frac{\partial}{\partial y} v_{z} \vec{i}-\frac{\partial}{\partial x} v_{z} \vec{j}+0 \vec{k}
$$

e o produto escalar $\vec{B} \cdot(\nabla \times \vec{v})$, lado direito da equação 3.8 :

$$
\vec{B} \cdot(\nabla \times \vec{v})=\left(0 \vec{i}+B_{0} \vec{j}+0 \vec{k}\right)\left(\frac{\partial}{\partial y} v_{z} \vec{i}-\frac{\partial}{\partial x} v_{z} \vec{j}+0 \vec{k}\right)=-B_{0} \frac{\partial}{\partial x} v_{z}
$$

Substituindo este resultado na equação 3.8, obtem-se a forma bidimen- 
sional simplificada da equação 3.7, como segue:

$$
\nabla^{2} \phi=-B_{0} \frac{\partial v_{z}}{\partial x}
$$

Esta é a equação do medidor de vazão a qual, juntamente com condições de fronteiras apropriadas, determina a distribuição de potencial $\phi$ dada a distribuição de velocidade $\vec{v}$ e o vetor de indução magnética $\vec{B}$. 


\section{Capítulo 4}

\section{Tomografia de Indutância Eletromagnética - EMT}

EMT é uma técnica de tomografia elétrica baseada no uso de medidas de indutância. Essa técnica pode gerar imagens a partir da distribuição de material condutivo eletricamente e permeável magneticamente no interior do domínio. Suas aplicações potenciais referem-se a identificação da distribuição de materiais que são caracterizados por alta condutividade ou comportamento ferro/ferro magnético. Como por exemplo, em separação de processos, localização e detecção de corpos estranhos, inspeção alimentícia e inspeção de componentes de metal com defeitos. Os princípios de operação de EMT podem ser divididos em quatro operações genéricas:

- excitação da região de interesse a partir de um campo magnético;

- distorções do campo magnético, resultante do material no interior do domínio;

- medidas de fronteira resultantes de valores de campo periférico;

- reconstrução da imagem, o que frequentemente diz respeito a um problema inverso, o qual envolve a conversão das medidas anteriores em uma imagem da distribuição original do material.

O sistema experimental consiste de três principais divisões: o sensor primário, o sensor eletrônico e o computador para a reconstrução da imagem. 


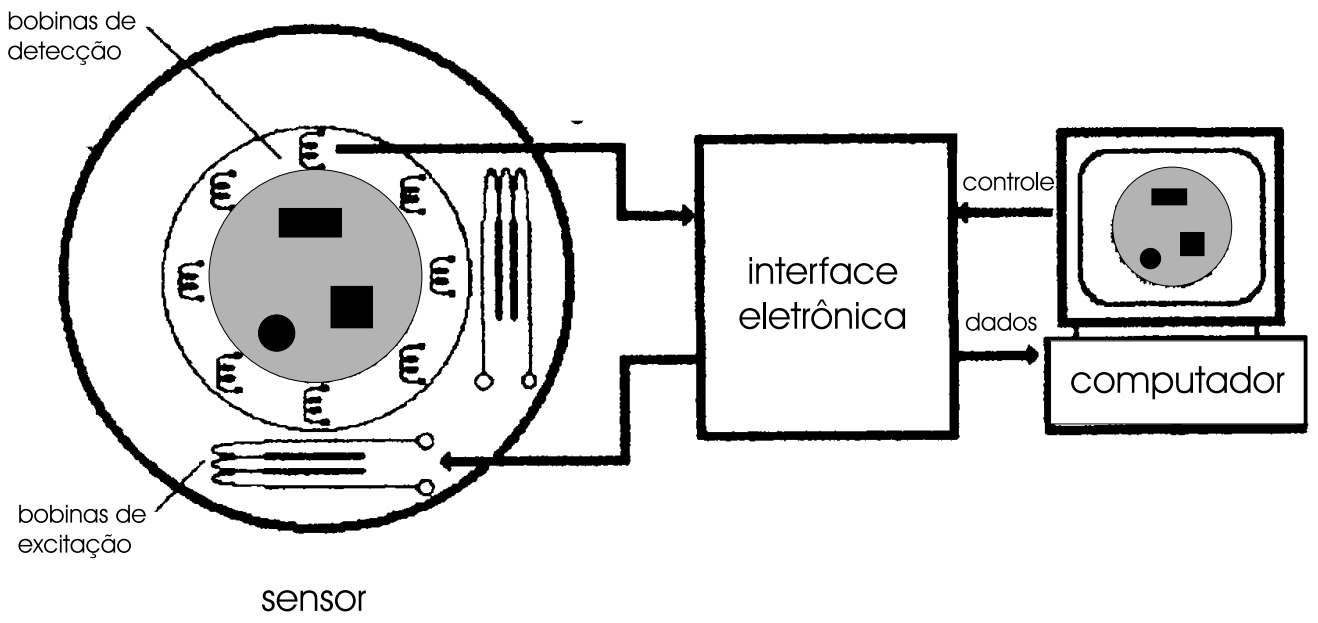

FIGURA 4.1: Diagrama de um típico Sistema de Tomografia Eletromagnética

O sensor opera de maneira usual associado a sistemas tomográficos. O domínio é energizado por um campo magnético criado por uma ou mais bobinas de excitação. As medições são realizadas através de uma bobina detectora, obtendo-se sinais da região periférica, que correspondem a um conjunto de projeções do escoamento em análise. Os sinais são subsequentemente digitalizados e transferidos a um computador, o qual opera um algoritmo de reconstrução da imagem, para criar uma imagem ou extrair alguns outros dados tomográficos, por exemplo, uma fração de componente.

Em sistemas tomográficos elétricos, como EMT, o problema de reconstrução é complicado devido ao efeito soft-field, ou seja, as linhas do campo de excitação são distorcidas; gerando um campo não uniforme com uma dependência não linear em relação à distribuição da condutividade ou da permissividade. Em outras palavras, na utilização de sensores elétricos há uma interação entre o campo e o meio sensoriado, que faz com que as linhas equipotenciais se deformem em todas as direções. 
A seguir serão apresentados alguns exemplos dessa iteração entre efeitos eletromagnéticos aliado ao efeito soft-field para diferentes materiais.

Na Figura 4.2, o objeto de diâmetro $40 \mathrm{~mm}$ is localizado em um sensor eletromagnético de 8-pólos (espaço de localização do objeto: 200mm).

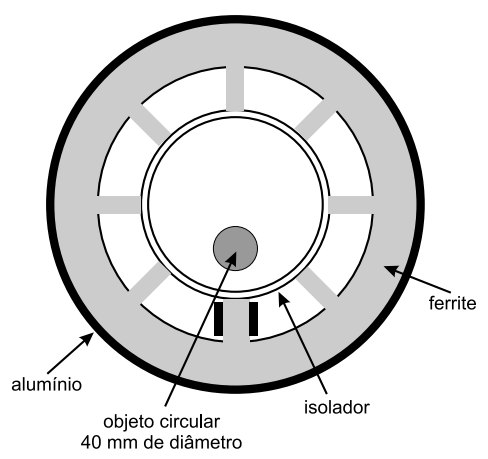

FIGURA 4.2: Modelo

Se o objeto circular é magnético e não condutor então o fluxo magnético escoa preferencialmente sobre o objeto. E a interação entre as bobinas aumenta, resultando em um aumento nas medidas (Figura 4.3).

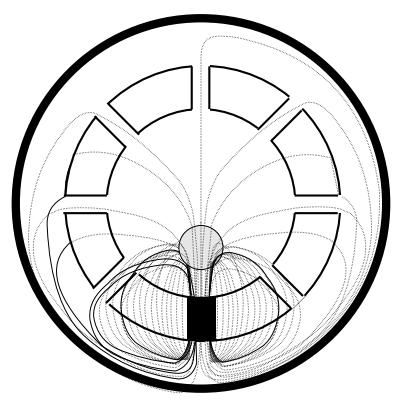

FIGURA 4.3: Objeto circular de ferrite

Alternativamente se o objeto é não magnético e condutor, o fluxo no objeto é reduzido devido as correntes em rodamoinhos, e as medidas são reduzidas. Essas correntes elétricas aparecem em massas metálicas como consequência da variação de fluxo que as atravessam. Esta situação é apresentada na Figura 4.4 para um objeto circular de alumínio com uma frequência de excitação de $100 k \mathrm{~Hz}$. Neste caso, o efeito skin prevê virtualmente alguma penetração do campo aplicado no 
objeto.

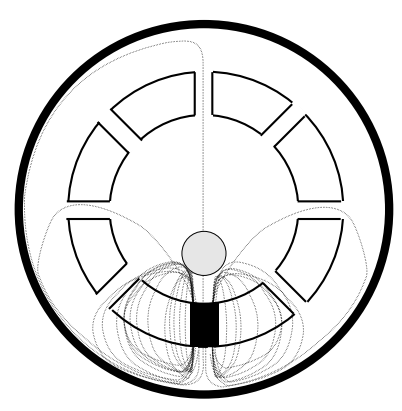

FIGURA 4.4: Objeto circular de alumínio

Finalmente o objeto cujo material que é magnético e condutivo apresenta ambos os efeitos e a camada de revestimento do objeto age como um preferencial caminho ao fluxo do escoamento.

O efeito soft-field explica a discrepância entre a imagem real e a gerada através de sensores elétricos e um método tradicional de reconstrução. Portanto, o emprego direto de técnicas de reconstrução desenvolvidas para sensores de campo não deformável, em dispositivos de sensoriamento elétrico, produzem resultados comparativamente mais pobres. Por isso, métodos específicos são desenvolvidos para tomografia de campos deformáveis. Neste trabalho, utilizou-se uma técnica baseada na minimização de um funcional de erro (seção 4.2), visando um bom desempenho do método a partir da escolha apropriada da estrutura do funcional de erro e algoritmo de solução.

\subsection{Tomografia Eletromagnética \& Medidor Eletro- magnético de Vazão}

A combinação de técnicas tomográficas com medidores convencionais de vazão é descrita por Horner e Mesch (1995). Esta combinação é um avanço recente sobre o estabelecido efeito de Faraday, usado para medidas de escoamento em líquidos condutivos. Seu mecanismo de execução consiste na obtenção de um sensor tomográfico a partir da combinação de múltiplos eletrodos com um campo 
de excitação magnético rotativo. Apesar da quantidade de dados ou informações obtidos pelo sensor tomográfico, estes não são usados para a reconstrução do perfil de velocidade. E sim para a obtenção de uma estimativa no desempenho do parâmetro desejado, ou seja, a velocidade média. Esta combinação é utilizada neste trabalho a partir do acoplamento entre a equação modelo do convencional medidor eletromagnético de vazão e uma abordagem funcional da técnica de reconstrução tomográfica eletromagnética, considerando o campo magnético uniforme. A idéia dessa abordagem funcional tem como fator decisivo a sensibilidade do medidor de vazão. Como descrito no capítulo 2 , as medidas de vazão são fortemente influenciadas por distúrbios do perfil de velocidade. Vários métodos foram propostos com o objetivo de contornar o efeito dessa sensibilidade afim de ao menos obter uma porcentagem de erro menor nas medidas. Contudo, até hoje pesquisadores vêm tentando obter medidas com um nível de exatidão confiável a partir de um projeto barato e de fácil implementação.

Com base na combinação destes princípios físicos, medidor eletromagnético de vazão e tomografia eletromagnética, a proposta deste trabalho visa o desenvolvimento de um medidor eletromagnético inteligente de vazão que seja capaz de corrigir as medidas obtidas por um convencional medidor de vazão. Essa correção depende da reconstrução do correto perfil de velocidade do fluido em uma tubulação.

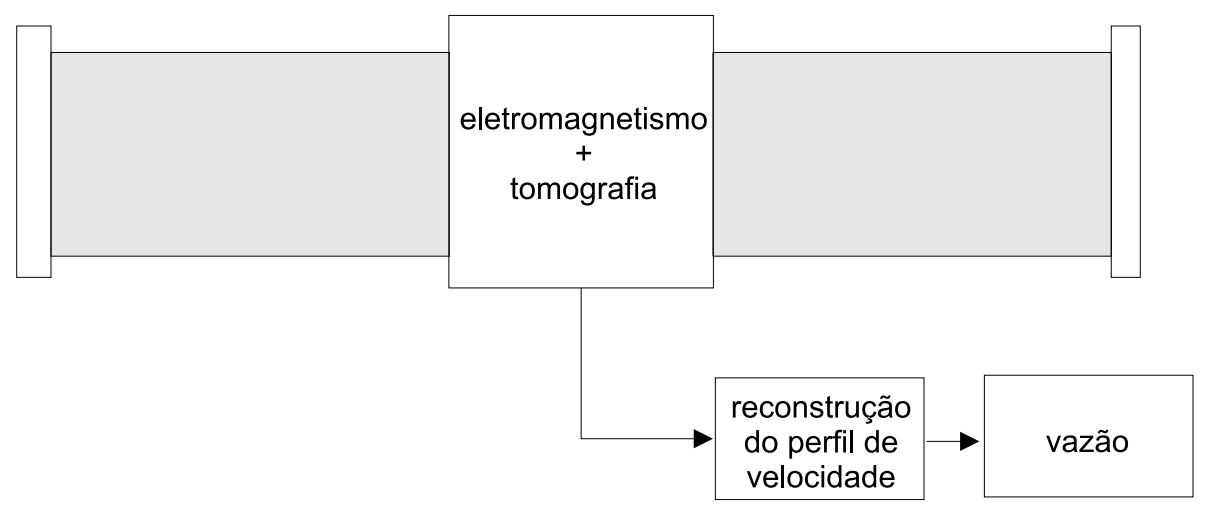

FIGURA 4.5: Esquema do processo de reconstrução tomográfica 


\subsection{Técnica Numérica de Reconstrução Tomo- gráfica Eletromagnética}

O processo de reconstrução do perfil de velocidade é realizado através de uma técnica numérica de reconstrução. Esta técnica é baseada na construção de um funcional de erro. Este funcional de erro deve ser construido de tal forma que quantifique a diferença entre a distribuição de contraste medida e a aproximada através de comparações entre valores medidos na fronteira com os correspondentes valores obtidos pelo modelo físico. A idéia é confrontar medidas obtidas através de um modelo experimental e de um modelo matemático. Neste trabalho, o funcional de erro (e) é dado pelo erro relativo entre uma resposta " experimental" $\left(\phi_{\text {med }}\right)$ e uma resposta aproximada $\left(\phi_{\text {aprox }}\right)$, ambas simuladas a partir do mesmo modelo físico. Sendo que para a simulação da resposta experimental supõe-se conhecido a distribuição de velocidade no interior da tubulação e, para a simulação da resposta aproximada utiliza-se uma aproximação desta distribuição de velocidade.

$$
e_{1}=\frac{\left\|\phi_{\text {med }}-\phi_{\text {aprox }}^{1}\right\|_{\infty}}{\left\|\phi_{\text {med }}\right\|_{\infty}}
$$

Generalizando para um certo número de medidas aproximadas $\left(\phi_{\text {aprox }}\right)$, temos:

$$
e_{i}=\frac{\left\|\phi_{m e d}-\phi_{\text {aprox }}^{i}\right\|_{\infty}}{\left\|\phi_{\text {med }}\right\|_{\infty}}
$$

com $i=1,2, \ldots, k$, onde $k$ corresponde ao número de medidas aproximadas.

Essas respostas, ou sinais de saida do medidor eletromagnético de vazão $\left(\phi_{\text {med }}\right.$ e $\left.\phi_{\text {aprox }}\right)$, são obtidas da resolução do problema direto, onde o estímulo e o mecanismo de transformação são conhecidos (Figura 4.6). 


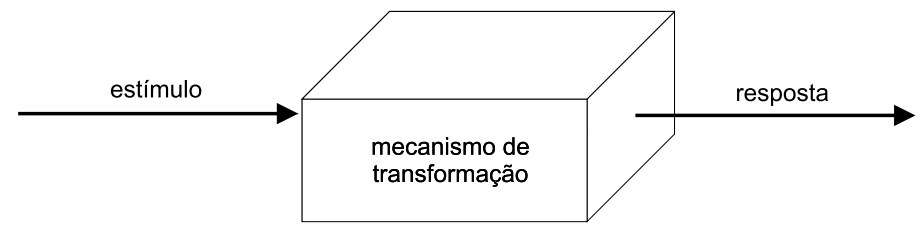

FIGURA 4.6: Esquema geral de um problema de determinação de parâmetros

Porém, o problema de Tomografia eletromagnética é formulado como um problema inverso tomográfico, onde o estímulo e a resposta são conhecidos e a incógnita é o mecanismo de transformação.

Neste trabalho, o problema inverso consiste na resolução de um problema de otimização, ou seja, a solução é obtida a partir da minimização do funcional de erro. 


\section{Capítulo 5}

\section{Resolução do Problema Direto}

As medidas dos potenciais experimentais $\left(\phi_{m e d}\right)$ foram calculadas através da resolução do problema direto, utilizando-se a equação modelo do medidor eletromagnético de vazão, equação 3.9:

$$
\nabla^{2} \phi=-B_{0} \frac{\partial v_{z}}{\partial x} \quad \text { em } \Omega
$$

$\Omega$ indica o domínio do problema e $(x, y)$ representa um ponto no interior do domínio $(\Omega)$. A interação entre $\Omega$ e o ambiente externo se dá através de seu contorno $\partial \Omega$ e é definida por relações representando as variáveis de excitação. Matematicamente, as equações que reproduzem os perfis de excitação são:

$$
\left\{\begin{array}{l}
\frac{\partial \phi(\xi, \gamma)}{\partial n}=0 \quad(\xi, \gamma) \quad \in \quad \partial \Omega-\{(1,0)\} \\
\phi(\xi, \gamma)=0 \quad(\xi, \gamma)=(1,0)
\end{array}\right.
$$

A equação 5.1 representa um exemplo de condição de fronteira mista (sem injeção de corrente), onde $(\xi, \gamma)$ indica um ponto sobre a fronteira $\partial \Omega$ de $\Omega$. 


\subsection{Adimensionalização}

Primeiramente adimensionalizou-se a equação 3.9, adotando-se:

$$
\phi^{*}=\frac{\phi}{\phi_{0}} \quad x^{*}=\frac{x}{L} \quad v^{*}=\frac{v}{v_{0}}
$$

Dessa forma podemos escrever o operador $\nabla=\left(\frac{\partial}{\partial x}, \frac{\partial}{\partial y}, \frac{\partial}{\partial z}\right)$, como sendo:

$$
\begin{gathered}
\nabla=\left(\frac{\partial}{\partial x}, \frac{\partial}{\partial y}, \frac{\partial}{\partial z}\right)=\left(\frac{\partial}{\partial x^{*} L}, \frac{\partial}{\partial y^{*} L}, \frac{\partial}{\partial z^{*} L}\right)=\frac{1}{L}\left(\frac{\partial}{\partial x^{*}}, \frac{\partial}{\partial y^{*}}, \frac{\partial}{\partial z^{*}}\right) \\
\Rightarrow \nabla=\frac{1}{L} \nabla^{*}
\end{gathered}
$$

Substituindo na equação 3.9 temos:

$$
\begin{gathered}
\frac{1}{L^{2}} \nabla^{* 2} \phi^{*} \phi_{0}=-B_{0} \frac{\partial}{\partial x^{*} L} v^{*} v_{0} \\
\nabla^{* 2} \phi^{*}=\frac{-B_{0} v_{0}}{L} \frac{\partial v^{*}}{\partial x^{*}} \frac{L^{2}}{\phi_{0}} \\
\nabla^{* 2} \phi^{*}=\frac{-B_{0} v_{0} L}{\phi_{0}} \frac{\partial v^{*}}{\partial x^{*}}
\end{gathered}
$$

Definindo $M=\frac{\phi_{0}}{B_{0} v_{0} L}$,

$$
\Rightarrow \nabla^{* 2} \phi^{*}=-\frac{1}{M} \frac{\partial v^{*}}{\partial x^{*}}
$$


Logo a equação 3.9 resulta em:

$$
\nabla^{2} \phi=-\frac{1}{M} \frac{\partial v}{\partial x}
$$

Uma formulação bidimensional foi utilizada, visto que a análise foi realizada em uma seção transversal do tubo, utilizando-se a equação em coordenadas polares

$$
\frac{\partial^{2} \phi}{\partial r^{2}}+\frac{1}{r} \frac{\partial \phi}{\partial r}+\frac{1}{r^{2}} \frac{\partial^{2} \phi}{\partial \theta^{2}}=-\frac{1}{M}\left(\cos (\theta) \frac{\partial v}{\partial r}-\frac{1}{r} \operatorname{sen}(\theta) \frac{\partial v}{\partial \theta}\right)
$$

Onde:

- $(r, \theta)$ é um ponto no interior do domínio $\Omega$;

- $M=\frac{\phi_{0}}{B_{0} v_{0} L}$ é um número adimensional (considerou-se $\mathrm{M}=1$ );

- $v$ é a velocidade do fluido;

- $\phi$ é a diferença de potencial no interior do domínio $\Omega$.

\subsection{Discretização da Equação Diferencial Par- cial}

Para a discretização das derivadas da equação 5.3, utilizou-se o método de diferenças finitas. As derivadas parciais de primeira ordem foram aproximadas por diferenças centradas e as derivadas de segunda ordem por diferenças centradas de segunda ordem, obtendo-se

$$
\frac{\phi_{i+1, j}-2 \phi_{i, j}+\phi_{i-1, j}}{d r^{2}}+\frac{1}{r_{i}}\left(\frac{\phi_{i+1, j}-\phi_{i-1, j}}{2 d r}\right)+\frac{1}{r_{i}^{2}}\left(\frac{\phi_{i, j+1}-2 \phi_{i, j}+\phi_{i, j-1}}{d \theta^{2}}\right)=g_{i, j}
$$


onde i,j indicam as coordenadas na malha respectivamente nas direções $r$ e $\theta$. Sendo

$$
\begin{array}{cl}
r_{i}=(i-1) d r & i=1, \ldots, P r \\
\theta_{j}=(j-1) d \theta & j=1, \ldots, P t
\end{array}
$$

$P_{r}, P_{t}$ são, respectivamente, o número de pontos nos intervalos $[0, R]$ e $[0,2 \pi]$ e $g_{i, j}$ corresponde ao lado direito da equação 5.3 , onde:

$$
d r=\frac{R}{P_{r}-1} \quad \text { e } \quad d \theta=\frac{2 \pi}{P_{t}-1}
$$

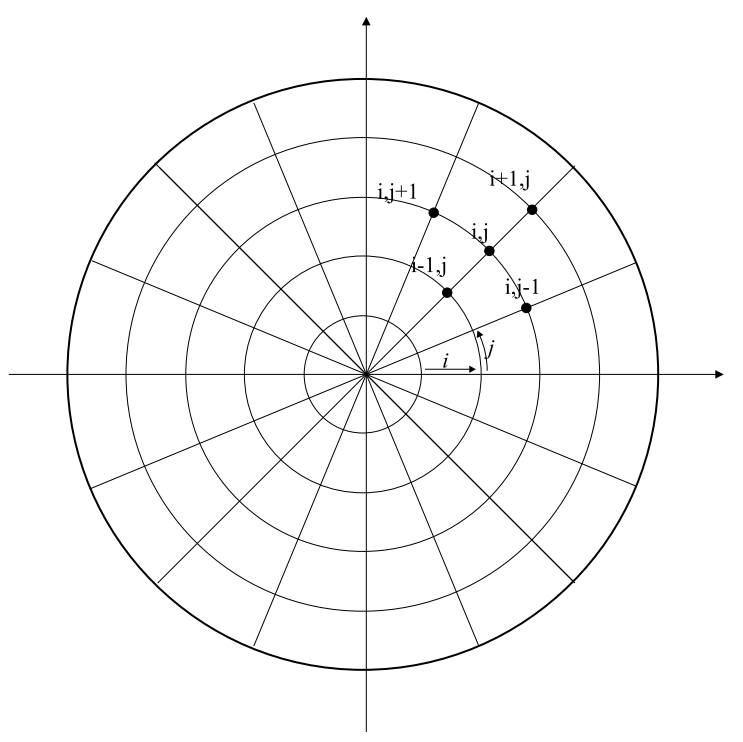

FIGURA 5.1: Malha em coordenadas polares

A equação 5.4 apresenta um problema: ela não é definida para $r=0$. Essa situação é contornada utilizando uma idéia apresentada por Davis(1979), que tem por base a discretização da equação 5.2 nos pontos centrais, utilizando coordenadas cartesianas. Para uma melhor compreensão dessa abordagem, acompanhe o detalhamento a seguir. 
A equação 5.2 em coordenadas cartesianas é dada por

$$
\frac{\partial^{2} \phi}{\partial x^{2}}+\frac{\partial^{2} \phi}{\partial y^{2}}=-\frac{1}{M}\left(\frac{\partial v}{\partial x}\right)
$$

Discretizando a equação 5.5, utilizando diferença centrada de segunda ordem para as derivadas de segunda ordem, temos:

$$
\frac{\phi_{i+1, j}-2 \phi_{i, j}+\phi_{i-1, j}}{d x^{2}}+\frac{\phi_{i, j+1}-2 \phi_{i, j}+\phi_{i, j-1}}{d y^{2}}=\tilde{g}_{i, j}
$$

Simplificando a equação 5.6 temos:

$$
a_{1} \phi_{i+1, j}-4 a_{1} \phi_{i, j}+a_{1} \phi_{i-1, j}+a_{1} \phi_{i, j+1}+a_{1} \phi_{i, j-1}=\tilde{g}_{i, j}
$$

onde:

$$
a_{1}=\frac{1}{d x^{2}}=\frac{1}{d y^{2}}
$$

Aplicando a equação 5.7 no ponto central da malha, ou seja, no ponto $(1, \mathrm{j})$ temos:

$$
a_{1} \phi_{2,1}-4 a_{1} \phi_{1, j}+a_{1} \phi_{2, a p 2}+a_{1} \phi_{2, a p 1}+a_{1} \phi_{2, a p 3}=\tilde{g}_{1, j}
$$

onde:

$$
a p 1=\frac{P t-1}{4}+1 \quad \text { ap } 2=\frac{P t-1}{2}+1 \quad \text { ap3 }=\frac{3}{4}(P t-1)+1
$$

A equação 5.8 é aplicada nos pontos da malha onde $i=1$ e 
$j=1, \ldots, P t-1$. Nos demais pontos da malha é utilizada a equação 5.4. Simplificando a equação 5.4 temos:

$$
R(i) \phi_{i, j}+S(i) \phi_{i+1, j}+Q(i) \phi_{i-1, j}+c(i) \phi_{i, j+1}+c(i) \phi_{i, j-1}=g_{i, j}
$$

onde:

$$
\left\{\begin{array}{l}
R(i)=-2\left[a_{2}+c(i)\right] \\
S(i)=a_{2}+b_{1}(i) \\
Q(i)=a_{2}-b_{1}(i) \\
a_{2}=\frac{1}{d r^{2}} \\
b_{1}(i)=\frac{1}{2 i d r^{2}} \\
c(i)=\frac{1}{i^{2} d r^{2} d \theta^{2}}
\end{array}\right.
$$

Com a aplicação das equações 5.8 e 5.10 em cada um dos pontos da malha, obtem-se um sistema linear.

No que tange a aplicação dessa estratégia, é necessário um cuidado especial com relação ao particionamento do intervalo $[0,2 \pi]$. O número de pontos nesse intervalo deve ser definido de tal modo que haja dois segmentos contidos nos eixos cartesianos. Observe na figura abaixo que a malha definida no domínio circular possui dois segmentos $\overline{A B}$ e $\overline{C D}$ ortogonais e cada um contido em um eixo cartesiano. No caso, $\overline{A B}$ contido no eixo x e $\overline{C D}$ no eixo y. 


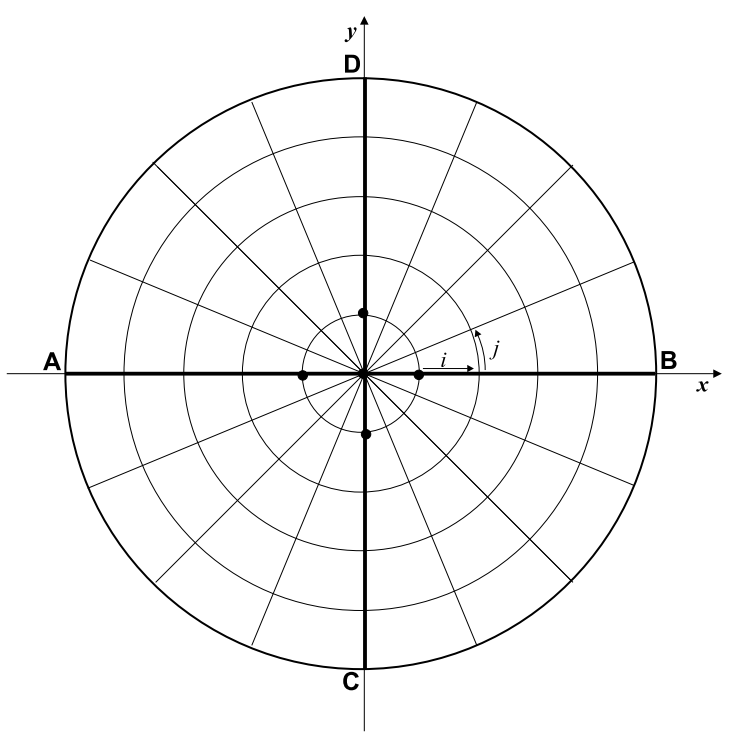

FIGURA 5.2: Malha em coordenadas polares

O sistema linear $A x=v_{b}$ gerado, considerando uma enumeração dos nós fixando primeiro $i$ e depois variando $j$, tem a matriz dos coeficientes $A$ a seguinte apresentação por blocos

$$
A=\left[\begin{array}{ccccccc}
M & N & & & & & \\
E_{1} & F_{1} & G_{1} & & & & \\
& E_{2} & F_{2} & G_{2} & & & \\
& & E_{3} & F_{3} & G_{3} & & \\
& & & \ddots & \ddots & \ddots & \\
& & & & E_{P_{t}-2} & F_{P_{t}-2} & G_{P_{t}-2} \\
& & & & & Q & H
\end{array}\right]
$$

onde

$$
M=\left[\begin{array}{ccccc}
-4 a_{1} & & & & \\
& -4 a_{1} & & & \\
& & \ddots & & \\
& & -4 a_{1} & \\
& & & -4 a_{1}
\end{array}\right]
$$




$$
N=\left[\begin{array}{ccccccccc}
a_{1} & \ldots & a_{1} & \ldots & a_{1} & \ldots & a_{1} & \ldots & 0 \\
a_{1} & \ldots & a_{1} & \ldots & a_{1} & \ldots & a_{1} & \ldots & 0 \\
\vdots & & \vdots & & \vdots & & \vdots & & \vdots \\
a_{1} & \ldots & a_{1} & \ldots & a_{1} & \ldots & a_{1} & \ldots & 0 \\
a_{1} & \ldots & a_{1} & \ldots & a_{1} & \ldots & a_{1} & \ldots & 0
\end{array}\right]
$$

$$
E_{i}=\left[\begin{array}{lllll}
Q(i) & & & & \\
& Q(i) & & & \\
& & \ddots & & \\
& & Q(i) & \\
& & & Q(i)
\end{array}\right]
$$

$$
F_{i}=\left[\begin{array}{ccccc}
R(i) & c(i) & & & c(i) \\
c(i) & R(i) & c(i) & & \\
& \ddots & \ddots & \ddots & \\
& & c(i) & R(i) & c(i) \\
c(i) & & & c(i) & R(i)
\end{array}\right]
$$

$$
G_{i}=\left[\begin{array}{ccccc}
S(i) & & & & \\
& S(i) & & & \\
& & \ddots & & \\
& & S(i) & \\
& & & S(i)
\end{array}\right]
$$




$$
H=\left[\begin{array}{ccccc}
R\left(P_{r}\right) & c\left(P_{r}\right) & & & \\
c\left(P_{r}\right) & R\left(P_{r}\right) & c\left(P_{r}\right) & & \\
& \ddots & \ddots & \ddots & \\
& & c\left(P_{r}\right) & R\left(P_{r}\right) & c\left(P_{r}\right) \\
& & & c\left(P_{r}\right) & R\left(P_{r}\right)
\end{array}\right] \text { e } \quad \text { (5.17) }
$$

O vetor $v_{b}$ é formado por $g_{i, j}$ e $\tilde{g}_{i, j}$, sendo este, dependendo de $i$ e $j$, subtraído por termos do primeiro membro do sistema de equações onde o valor da função incógnita $\phi_{i, j}$ é conhecido.

\subsection{Armazenamento}

A matriz $A$ é uma matriz esparsa, ou seja, somente um pequeno número de elementos da matriz são diferentes de zero. Resolver por um método direto o sistema linear com uma matriz esparsa pode envolver a resolução da ordem de $O\left(N^{3}\right)$ operações aritméticas. Além disso, problemas extensos sobrecarregam o espaço de memória e é inviável reservar armazenamento para elementos nulos. Há dois objetivos que devem ser apresentados em métodos de resolução de matriz esparsa: economia de tempo e economia de espaço.

Press et al. (1992), no livro Numerical Recipes, apresenta um armazenamento indexado por linhas em que somente os elementos não nulos da matriz 
são estocados. Para isso são utilizados dois vetores: um de elementos reais (com precisão simples ou dupla), responsável por armazenar os valores não nulos da matriz, e outro vetor de elementos inteiros, responsável pelo armazenamento dos índices dos valores não nulos. Neste trabalho, utilizou-se apenas a idéia deste método de armazenamento, visto que essa subrotina baseia-se na varredura de todos os elementos da matriz original para identificar aqueles diferente de zero, demandando portanto um tempo excessivamente longo. A subrotina apresentada no Numerical Recipes tem como entrada a matriz inteira e não é necessário ter conhecimento da estrutura da mesma. Já na subrotina desenvolvida nesse trabalho foi utilizada a idéia de armazenamento do Numerical Recipes e também o já prévio conhecimento da estrutura da matriz dos coeficientes, ou seja, na implementação do método foram analisadas algumas características da matriz $A$, assim os dois vetores de armazenamento foram montados diretamente, baseado na generalização dos elementos não nulos da matriz $A$. Esta forma de armazenamento reduziu consideravelmente o tempo de execução dos cálculos.

\subsection{Resolução do Sistema Linear}

O sistema foi resolvido pelo método dos gradientes bi-conjugados précondicionado, o qual é uma generalização do método dos gradientes conjugados, ou seja, é válido para qualquer tipo de matriz. Na implementação foi utilizada a rotina PBCG (Preconditioned biconjugate gradient method), do pacote computacional Numerical Recipes in Fortran (PRESS et al, 1992). Vários são os motivos pelos quais utilizou-se este método para resolver o sistema linear do problema em questão. Uma está no fato da matriz dos coeficientes ser esparsa, e portanto métodos iterativos são mais adequados por economia de memória. Outra reside no fato da matriz dos coeficientes não ser simétrica definida positiva, situação que pode ser observada na estrutura da matriz apresentada na seção 5.2. Basta ver que não é simétrica e devido a isso o método dos gradientes conjugados não pode ser utilizado. Assim sendo, o método mais adequado é o método dos gradientes biconjugados com pré-condicionamento, pois sua aplicação independe do tipo de 
matriz. A velocidade é uma característica de grande relevância nesse método.

\subsubsection{Método Gradiente Bi-Conjugado Pré-Condicionado}

Para a aplicação deste método é necessário ter uma matriz precondicionada $\widetilde{A}$ de maneira que $\widetilde{A}^{T} . A \approx I$. A idéia é resolver facilmente o sistema linear para algum $\widetilde{A}$ perto de A, permitindo o algoritmo convergir em poucos passos.

Algoritmo

1. Constrói-se 4 sequência de vetores $r_{k}, \widetilde{r}_{k}, p_{k} \quad$ e $\widetilde{p}_{k} \quad, k=1,2, \ldots$

2. $x_{1}$ : aproximação inicial para a solução, $r_{1}=b-A \cdot x_{1} \quad, \widetilde{r}_{1}=r_{1} \quad, p_{1}=r_{1}$ e $\quad \widetilde{p}_{1}=\widetilde{r}_{1}$

3. Aplicar a seguinte sequência de recorrência:

(a) Resolve os dois sistemas auxiliares

$$
\left\{\begin{array}{l}
\widetilde{A} z_{k}=r_{k} \\
\widetilde{A}^{T} \cdot z_{k}=\widetilde{r}_{k}
\end{array}\right.
$$

(b) Resolve a seqüência de equações a seguir

$$
\begin{aligned}
& \alpha_{k}=\frac{\bar{r}_{k} z_{k}}{\bar{p}_{k} A p_{k}} \\
& r_{k+1}=r_{k}-\alpha_{k} A p_{k} \\
& \bar{r}_{k+1}=\bar{r}_{k}-\alpha_{k} A^{T} \bar{p}_{k} \\
& \beta_{k}=\frac{\bar{r}_{k+1} z_{k+1}}{\bar{r}_{k} z_{k}} \\
& p_{k+1}=z_{k}+\beta_{k} p_{k} \\
& \bar{p}_{k+1}=\bar{z}_{k}+\beta_{k} \bar{p}_{k} \\
& x_{k+1}=x_{k}+\alpha_{k} p_{k}
\end{aligned}
$$

Essa sequência garante que $r_{k+1}$ seja de fato, o resíduo de $b-A . x_{k+1}$. Quando $r_{m+1}=0$ então $x_{m+1}$ é a solução procurada. 
O algoritmo PBCG satisfaz condições que garantem que a busca pela solução seja obtida através de direções conjugadas:

condição de biortogonalidade: $\bar{r}_{i} \cdot r_{j}=r_{i} \cdot \bar{r}_{j}=0, \quad j<i$

condição de biconjugação: $\quad \bar{p}_{i} \cdot A \cdot p_{j}=p_{i} \cdot A^{T} \cdot \bar{p}_{j}, \quad j<i$

condição de ortogonalidade mútua: $\quad \bar{r}_{i} \cdot p_{j}=r_{i} \cdot \bar{p}_{j}=0, \quad j<i$

Para a matriz precondicionada utilizou-se a parte diagonal da matriz A e, o vetor solução inicial, o vetor nulo. 


\section{Capítulo 6}

\section{Resolução do Problema Inverso}

Neste capítulo serão descritos os passos para a determinação da vazão em uma seção da tubulação, sem conhecer a velocidade do fluido, tendo apenas a diferença de potencial obtida experimentalmente por um sensor eletromagnético.

Podemos dizer que acaba de ser descrito um problema inverso tomográfico, onde conhecemos o estímulo (estratégia de excitação) e a resposta (medidas de potenciais experimentais), tendo como incógnita o mecanismo de transformação, ou causa.

Os problemas inversos são característicos de um grande número de problemas matematicamente mal condicionados das ciências físicas, médicas e outras. Esse mal condicionamento intrínseco pode, sob certas circunstâncias, afetar a qualidade das imagens. No concernente a visualização tomográfica de escoamentos, erros experimentais em associação a erros numéricos de truncamento e arredondamento, podem ser amplificados e corromper fortemente os resultados. Esta classe de problemas constituem uma abordagem para resoluções de problemas nos quais não é possível resolver de forma tradicional, devido possuirem mais incognitas do que equações ou por serem extremamente sensíveis à presença de ruidos nos dados.

Uma definição bastante abrangente sobre problemas inversos é apresentada no livro de Engl, Hanke e Neubauer (1996): "Resolver um problema inverso é determinar causas desconhecidas a partir de efeitos desejados ou observados". Diferentemente, problemas diretos requerem um conhecimento completo e preciso 
das causas para a determinação dos efeitos.

Neste trabalho, o problema inverso é abordado como um problema de otimização, em que os parâmetros da velocidade, são ajustados até que o funcional de erro (e), equação 4.1, atinja seu mínimo global.

Considere:

- $v_{\text {real }}$ : a velocidade no interior de uma tubulação;

- $\alpha$ e $n$ : parâmetros da velocidade;

- $v_{\text {aprox }}$ : a velocidade para um valor arbitrário do parâmetro $\alpha$ e $n$.

Durante o problema inverso, o problema direto é resolvido várias vezes. Ou seja, para cada valor arbitrário de $\alpha$ e $n$, calcula-se $\phi_{\text {aprox }}$ a partir do modelo numérico descrito pelo conjunto de equações 3.9 e 5.1, referente respectivamente ao modelo físico e condição de fronteira. As medidas experimentais foram simuladas pelo mesmo conjunto de equações, considerando valores de $\alpha$ e $n$, característicos de uma distribuição de velocidade padrão. Essas medidas $\phi_{\text {med }}$ e $\phi_{\text {aprox }}$ são confrontadas através do funcional de erro $e(\alpha, n)$, até que o erro seja mínimo (Figura 6.1).

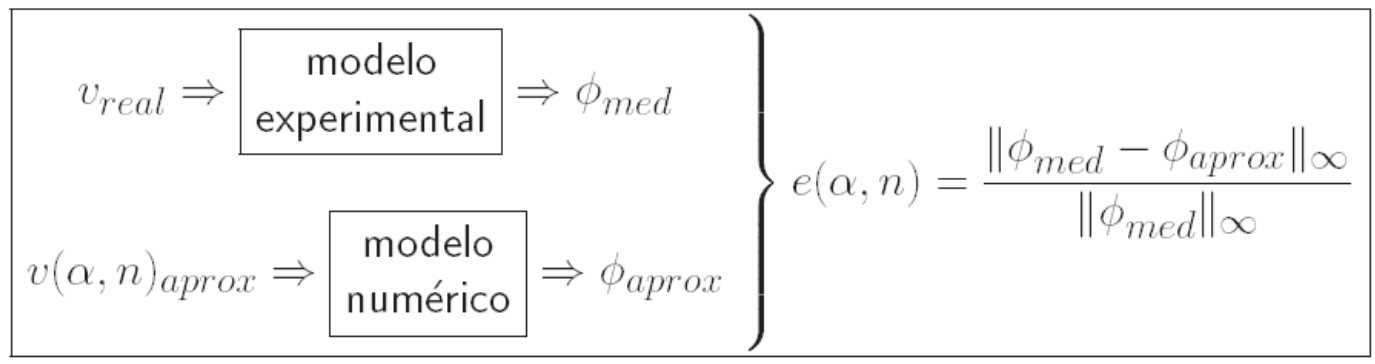

FIGURA 6.1: Esquema do problema inverso

Ou seja, $v(\alpha, n)_{\text {aprox }}$ é ajustado até que $e(\alpha, n) \rightarrow 0 \Rightarrow v(\alpha, n)_{\text {aprox }} \rightarrow v_{\text {real }}$. Sendo assim, é possível reconstruir o perfil de velocidade, simplesmente através de um processo de busca dos parâmetros ótimos. Parâmetros ótimos que minimizem o funcional de erro, resultando em uma boa aproximação entre $\phi_{\text {med }}$ e $\phi_{\text {aprox }}$. 
Esta formulação valida nossa proposta:

$$
Q=\int_{A} \vec{v}_{\text {aprox }} \cdot \eta d A
$$

\subsection{Problema de Otimização}

Seja $l_{1}, l_{2}, \ldots l_{n}$, parâmetros da velocidade, onde cada parâmetro $l_{i}, i=$ $1, \ldots, n$ pertence a um determinado intervalo real. O objetivo é resolver o seguinte problema de minimização:

$$
\begin{gathered}
\operatorname{Min}\left(e\left(l_{1}, l_{2}, \ldots l_{n}\right)\right) \\
l_{i(\min )}<l_{i}<l_{i(\max )}
\end{gathered}
$$

ou seja, determinar os parâmetros ótimos da velocidade que minimizem o funcional de erro (e).

Para a escolha de um método de otimização, vários fatores devem ser analisados, como por exemplo: dimensão do problema, natureza da função, restrições a serem consideradas, tipo de mínimo procurado (local ou global) e natureza das variáveis do problema.

\subsection{Restrições}

As restrições são associadas aos limites inferiores e superiores das variáveis relacionadas a parametrização dos perfis de velocidade, validando sua existência em um dado intervalo admissível. 


\subsection{Natureza das Variáveis}

As variáveis do problema podem ser classificadas como contínuas, uma vez que podem assumir quaisquer valores reais dentro do intervalo definido.

Esse tipo de problema de otimização, com variáveis contínuas, são definidos em um espaço N-dimensional contínuo e não são cabíveis de enumeração das possíveis configurações. A aplicação em domínios contínuos é bem mais complicada do que em espaços discretos, pois podem ocorrer configurações topológicas problemáticas como "vales longos e estreitos", que representam uma das maiores dificuldades na otimização global. Por outro lado, os espaços contínuos permitem ter a noção de "descida contínua em uma direção favorável" e, busca pelo mínimo em uma vizinhança, enquanto que os conceitos de "direção" e "vizinhança", podem não ter nenhum sentido no espaço discreto.

\subsection{Mínimo Global}

Consideramos como mínimo global o ponto onde a função assume o menor valor comparado com qualquer outro ponto.

Problemas inversos são caracterizados por encontrar um extremo local de uma função não-convexa (Figura 6.2). Um problema não-convexo geralmente apresenta muitos mínimos locais diferentes do global procurado.

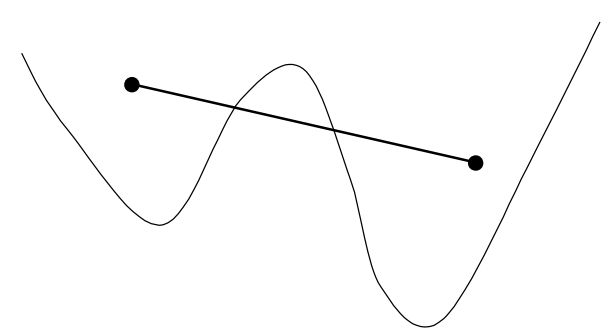

FIGURA 6.2: Exemplo de função não-convexa

Neste trabalho, aplicou-se alguns algoritmos baseados no gradiente local da função, o qual convergiu para o mínimo mais próximo e, não necessariamente 
para o mínimo global. Nestes casos é preciso dispor de algoritmos que fujam dos mínimos locais e, convirjam para o global. Normalmente, é feito uso de uma variável aleatória para permitir que a sequência de busca examine o domínio como um todo e, não apenas em uma região.

\subsection{Heurísticas de busca}

Uma boa parte das heurísticas são desenvolvidas para resolver especificamente uma classe de problemas. Uma resolução heurística consiste em encontrar um conjunto de regras que permitem determinar relações satisfatórias para um problema, num espaço de tempo razoável. No contexto da inteligência artificial, heurística é um algoritmo que fornece algumas garantias, geralmente empíricas, em termos de computação e qualidade de solução. Apesar de não garantir a obtenção da solução exata, existe argumento a favor do uso de heurísticas: o que está sendo otimizado é um modelo do problema real. Não existe garantia de que a melhor solução para o modelo seja também a melhor solução para o problema que fundamenta o real.

\subsection{G.A. - Algoritmo Genético}

Algoritmos Genéticos (G.A.) são uma família de modelos computacionais inspirados pela teoria da evolução biológica dos sistemas naturais de Charles Darwin (1809-1922). Esses algoritmos codificam uma solução potencial para um problema específico em uma estrutura de dados simples associada ao cromossomo e, aplicando operadores sobre essas estruturas, tal que a informação crítica seja preservada. Algoritmos Genéticos são vistos como otimizadores de funções e, tem sido aplicado com sucesso na área de engenharia industrial (GEN e CHENG, 1997).

A implementação de um G.A. começa com uma população de cromossomos. Avalia-se essas estruturas, ou seja, aplica-se a função objetivo, e alocam-se oportunidades reprodutivas de tal forma que os cromossomos representantes de 
uma melhor solução para o problema alvo terão mais chances de "reprodução" do que aqueles que são soluções pobres.

Esta descrição particular de um G.A. é intencionalmente abstrata, porque em um senso comum, o termo algoritmo genético tem dois significados. Em uma interpretação estrita, o G.A. refere-se ao modelo introduzido e investigado por Holland (1975) no livro Adaptation in Natural and Artificial Systems.

Em uma visão mais ampla, algoritmo genético é qualquer modelo baseado em população que usa os operadores seleção e recombinação para gerar novos pontos em um espaço de busca. Muitos modelos de algoritmos genéticos tem sido introduzidos por pesquisadores trabalhando sob perspectiva experimental. Muitos desses pesquisadores são orientados à aplicação e estão tipicamente interessados em algoritmos genéticos como ferramenta de otimização.

Além do trabalho original de Holland (1975), Goldberg (1989), Davis(1991) entre outros, consolidaram o uso desta técnica.

Em resumo, os Algoritmos Genéticos têm as seguintes características:

- usam técnica de aleatória;

- são robustos (abrangentes);

- trabalham unicamente com o valor da função objetivo e não suas derivadas;

- utilizam somente regras probabilísticas (não determinísticas) e

- são de uso geral (meta-heurísticas).

A tabela a seguir mostra a relação entre os termos usados na Genética e elementos de um problema de Otimização. 
TABELA 6.1: Correspondência entre os termos da Genética e do Algoritmo Genético

\begin{tabular}{|l|l|}
\hline Terminologia da Genética & Problema de Otimização \\
\hline $\begin{array}{l}\text { Cromossomo (seqüências do ADN que } \\
\text { contêm a codificação } \\
\text { que especifica um organismo) }\end{array}$ & $\begin{array}{l}\text { um ponto do espaço codificado } \\
\text { (vetor n-dimensional) }\end{array}$ \\
\hline Indivíduo & $\begin{array}{l}\text { um ponto no espaço das soluções (solução } \\
\text { candidata para um determinado problema) }\end{array}$ \\
\hline $\begin{array}{l}\text { População } \\
\text { (conjunto de indivíduos) }\end{array}$ & $\begin{array}{l}\text { conjunto de pontos que fazem parte da } \\
\text { busca no espaço de soluções }\end{array}$ \\
\hline $\begin{array}{l}\text { Geração } \\
\text { (diferentes populações no processo de evolução) }\end{array}$ & iteração \\
\hline $\begin{array}{l}\text { Gene } \\
\text { (cada uma das partes do cromossomo que } \\
\text { contém uma característica particular do } \\
\text { organismo) }\end{array}$ & $\begin{array}{l}\text { parte da solução } \\
\text { (cada elemento do ponto codificado) }\end{array}$ \\
\hline $\begin{array}{l}\text { Genótipo } \\
\text { (conjunto completo de cromossomos de um } \\
\text { organismo) }\end{array}$ & $\begin{array}{l}\text { representação codificada de um conjunto de } \\
\text { soluções }\end{array}$ \\
\hline $\begin{array}{l}\text { Fenótipo } \\
\text { (características resultantes de um organismo) }\end{array}$ & $\begin{array}{l}\text { representação decodificada de um conjunto } \\
\text { de soluções }\end{array}$ \\
\hline
\end{tabular}

Estrutura do G.A.:

$t \rightarrow 0$ (t:iteração ou geração)

Inicializa $P(t)(\mathrm{P}(\mathrm{t})$ :População de indivíduos na geração $\mathrm{t})$

Avalia $P(t)$

Enquanto (Critério não for satisfeito) faça

Recombine $P(t)$ (através de crossover (cruzamentos) e mutações) para obter $C(t)$

Avalie $C(t)(\mathrm{C}(\mathrm{t})$ :descendentes na geração $\mathrm{t})$

Selecione $P(t+1)$ a partir de $P(t)$ e $C(t)$

$$
t \rightarrow t+1
$$

Fim enquanto

Os Algoritmos Genéticos possuem diversos parâmetros a serem ajustados, como por exemplo: população inicial, tamanho da população, definição da função de fitness, tipo de seleção e operadores genéticos: crossover e mutação, taxa de cruzamento, taxa de mutação, etc. 


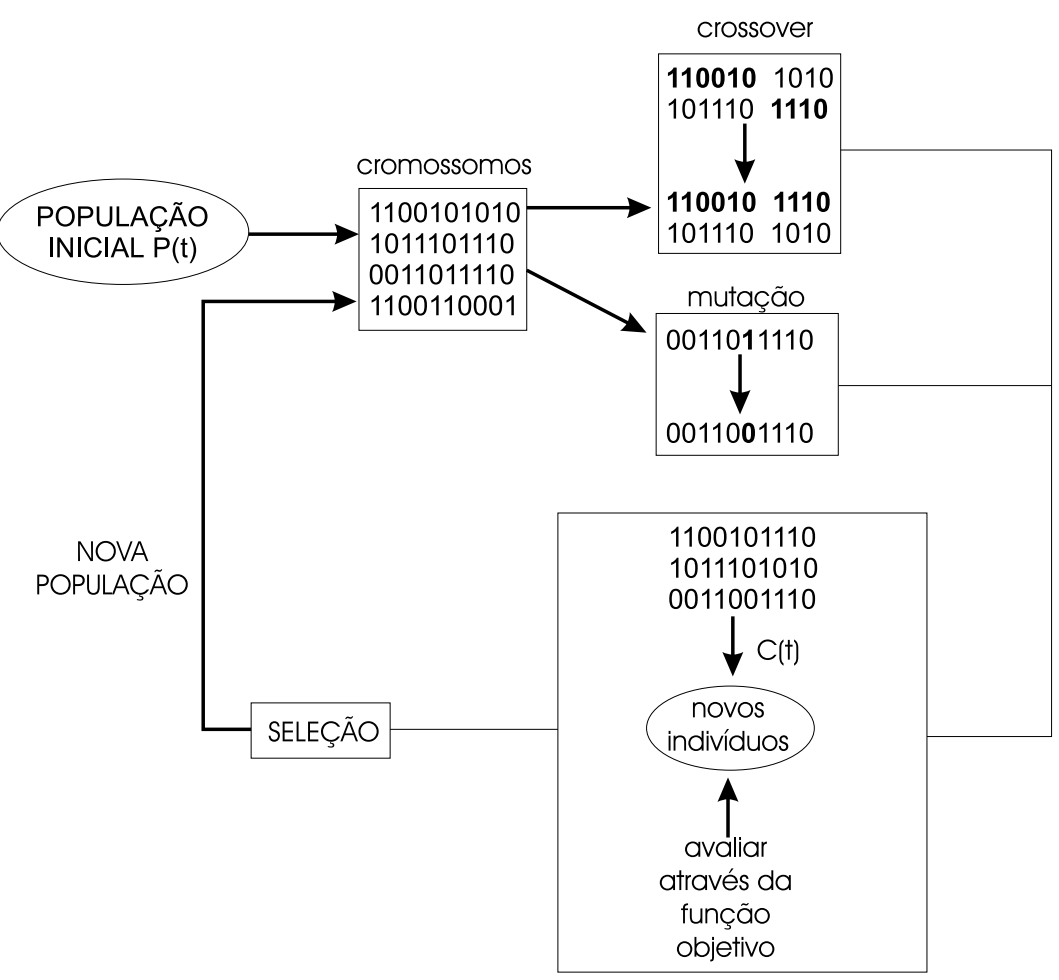

FIGURA 6.3: Estrutura Geral dos Algoritmos Genéticos

Goldberg (1989), descreve as principais diferenças entre os algoritmos genéticos e os algoritmos de otimização convencionais, as quais são:

- trabalham com um conjunto de soluções codificadas, não com as soluções propriamente ditas;

- realizam a busca a partir de uma população de soluções, não com um única solução;

- usam informações somente da função objetivo (fitness), não das suas derivadas ou outros conhecimentos extras;

- usam regras de transição probabilística, não regras determinísticas.

A seguir serão discutidos alguns itens necessários para a construção de um G.A.:

População: Geralmente os algoritmos clássicos de otimização realizam uma busca ponto a ponto, ou seja, a partir de um ponto inicial, faz uma perturbação 
e obtém um novo ponto. Esse tipo de busca é baseado no gradiente ou derivadas de alta ordem da função objetivo. Esta busca ponto a ponto leva ao perigo de cair em um de mínimo local. Algoritmos Genéticos executam uma pesquisa multi direcional por manter uma população de soluções potenciais. Esse tipo de busca população-a-população permite uma maior diversidade de soluções e, consequentemente a possibilidade de escapar de mínimos locais.

A população inicial, normalmente é gerada aleatoriamente no espaço codificado. Porém, dependendo do conhecimento a priori do problema tratado, ou se existir uma solução aproximada para o problema, a população inicial pode ser fornecida no espaço das soluções.

O tamanho da população se refere ao número de pontos manipulados a cada geração e afeta diretamente o desempenho e a eficiência dos algoritmos genéticos. Com uma po-pulação pequena o desempenho é baixo, pois a população fornece uma pequena cobertura representativa do domínio, além de prevenir convergências prematuras para as soluções locais, porém, compromete o tempo de execução do programa.

Codificação: A codificação de uma solução do problema é um dos pontos chaves dos Algoritmos Genéticos (GEN e CHENG, 1997). Porém, para muitas aplicações, especialmente para problemas reais da engenharia industrial, o G.A. tradicional é difícil de ser aplicado diretamente, pois a cadeia binária não é uma codificação natural. As principais dificuldades do G.A. tradicional (com representação binária) ocorrem quando são aplicados a pro-blemas multidimencionais, de alta precisão, domínios contínuos ou que possuam restrições não triviais. Como consequência, os G.A. podem gastar um tempo computacional muito alto para encontrar a solução ótima, ou não conseguem a precisão desejada para a solução, ou seja, possui uma falta de habilidade de busca local refinada. Várias técnicas de codificação tem sido criadas para problemas particulares, por exemplo, codificação em número real para problemas de otimização restrita e, codificação inteira para pro- 
blemas de otimização combinatorial.

Operadores Genéticos: A geração de novos indivíduos é feita através dos operadores genéticos de reprodução: crossover e mutação. O crossover é uma função que recebe como entrada um subconjunto da população e cria outro conjunto, geralmente são utilizados dois indivíduos (pais) para criação de um ou mais filhos. Uma mutação consiste de uma pequena perturbação aleatória que modifica um cromossomo, produzindo filhos com características diferentes dos pais. Tanto a reprodução como a mutação servem para diversificar a população e manter características de adaptação adquiridas pelas gerações anteriores.

\section{Crossover}

Para a representação binária, pares de pais são tomados e seus materiais genéticos são trocados. Aleatoriamente, determina-se um ponto onde os cromossomos dos pais serão cortados (ponto de crossover), produzindo dois segmentos anteriores e dois posteriores. Os segmentos posteriores são trocados produzindo dois novos cromossomos completos. Esse procedimento é conhecido como one-point crossover, conforme ilustrado na figura 6.4.

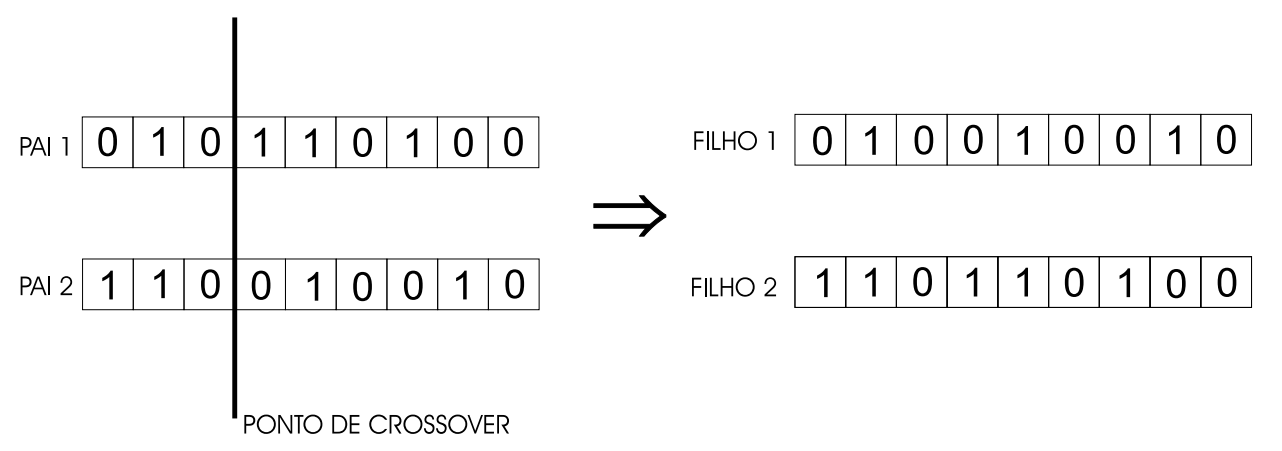

FIGURA 6.4: Desenho Cruzamento com apenas um corte (one-point crossover)

Outra possibilidade é cortar os cromossomos dos pais em dois pontos e gerar os filhos intercalando as partes cortadas dos dois pais (two-point crossover), como exemplificado na Figura 6.5.

Alguns operadores propostos para a representação em ponto flutuante: 


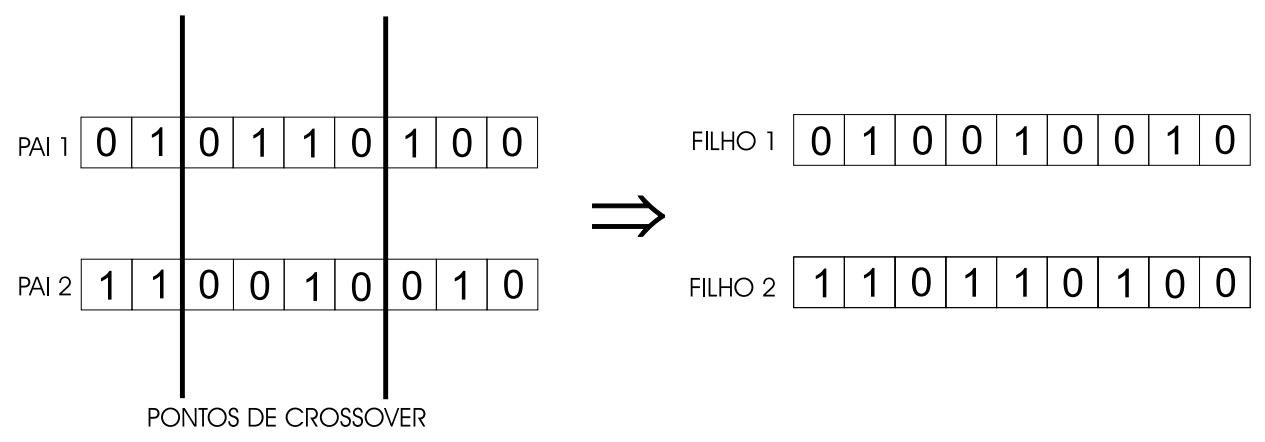

FIGURA 6.5: Desenho Cruzamento com dois cortes (two-point crossover)

Crossover simples: São selecionados dois indivíduos para serem os pais $x=\left(x_{1}, x_{2}, \ldots, x_{n}\right)$ e $y=\left(y_{1}, y_{2}, \ldots, y_{n}\right)$, os quais são cortados após a késima posição e seus descendentes recebem a parte anterior ao corte de um dos pais e a posterior do outro, da seguinte forma:

$$
\begin{aligned}
& x^{*}=\left(x_{1}, \ldots, x_{k}, y_{k+1}, \ldots, y_{n}\right) \\
& y^{*}=\left(y_{1}, \ldots, y_{k}, x_{k+1}, \ldots, x_{n}\right)
\end{aligned}
$$

onde n é o número de variáveis.

Crossover Aritmético: Definido pela média ponderada entre os vetores. Por exemplo, dois vetores $\mathrm{x}$ e $\mathrm{y}$ podem gerar dois descendentes da seguinte forma:

$$
\begin{aligned}
& x^{*}=w_{1} x+w_{2} y \\
& y^{*}=w_{1} y+w_{2} x
\end{aligned}
$$

Diferentes combinações entre $w_{1}$ e $w_{2}$ definem a região onde os descendentes são gerados. Por exemplo, as condições:

- $w_{1}, w_{2}>0$

- $w_{1}+w_{2}=1$ 
quando satisfeitas simultaneamente, geram um operador normalmente chamado de crossover convexo. Se somente a segunda condição for satisfeita tem-se um crossover afim. E se nenhuma exigência for requerida, isto é, os multiplicadores $w_{1}$ e $w_{2}$ variam no espaço real, tem-se um crossover linear.

\section{Mutação}

A mutação é utilizada para introduzir inovações à população e prevenir que a população se sature com cromossomos semelhantes e ocorra a convergência prematura, além de assegurar que nenhum ponto do espaço de busca tenha probabilidade nula de ser examinado. A mutação consiste de uma mudança aleatória em um gene do cromossomo com baixa probabilidade de ocorrência em cada geração. Exemplo:

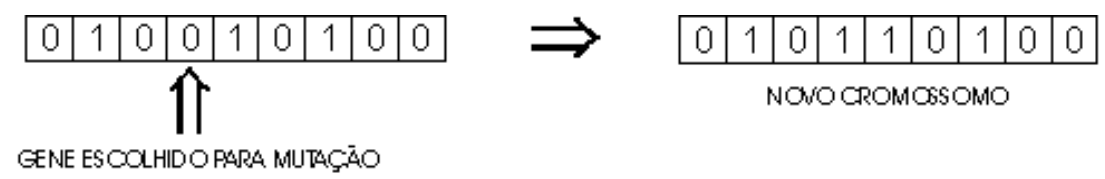

FIGURA 6.6: Exemplo de mutação para cromossomos binários

Operadores de mutação para representação em ponto flutuante:

Mutação uniforme: É a substituição de um gene (número real) por um número real selecionado aleatoriamente dentro de um intervalo específico. Seja $x=\left(x_{1}, x_{2}, \ldots, x_{n}\right)$ o cromossomo que sofrerá mutação e $\mathrm{k}$ um número inteiro aleatório $k=1,2, \ldots, n$, o descendente gerado é $x^{*}=\left(x_{1}, x_{2}, \ldots, x_{k}^{*}, \ldots, x_{n}\right)$, onde $x_{k}^{*}$ é um valor aleatório distribuido uniformemente no intervalo $\left[x_{k, \text { inf }}, x_{k, \text { sup }}\right]$. Os valores de $x_{k, \text { inf }}$ e $x_{k, \text { sup }}$ são respectivamente, os limitantes inferior e superior da variável $x_{k}$, que podem ser determinados pela restrição de domínio ou calculados dinamicamente por um conjunto de desigualdades (MICHALEWICZ,1996).

Outra possibilidade é substituir o gene $x_{k}$ por $x_{k, \text { inf }}$ ou $x_{k, \text { sup }}$, cada um deles com igual probabilidade. Este tipo de mutação é chamado boundary mutation. (MICHALEWICZ, LOGAN e SWAMINATHAN, 1994) 
Mutação Dinâmica: Também chamada de mutação não-uniforme, foi introduzida por Janilow e Michalewicz (1991) com objetivo de melhorar a capacidade de sintonia fina do operador com objetivo de obter alta precisão. Para um dado pai $x=\left(x_{1}, x_{2}, \ldots, x_{n}\right)$ cujo elemento $x_{k}$ foi selecionado para sofrer mutação, o descendente resultante é $x^{*}=\left(x_{1}, x_{2}, \ldots, x_{k}^{*}, \ldots, x_{n}\right)$, onde $x_{k}^{*}$ é selecionado aleatoriamente a partir de 2 escolhas possíveis:

$$
\begin{aligned}
& x_{k}^{*}=x_{k}+\Delta\left(t, x_{k, \text { sup }}-x_{k}\right), \text { se o dígito aleatório for zero } \\
& x_{k}^{*}=x_{k}-\Delta\left(t, x_{k}-x_{k, \text { sup }}\right), \text { se o dígito aleatório for um }
\end{aligned}
$$

A função $\Delta(t, y)$ retorna um valor no intervalo $[0, y]$, tal que o valor de $\Delta(t, y)$ se aproxima de 0 a medida que t cresce (t é o número de gerações).

$$
\Delta(t, y)=y \cdot r \cdot\left(1-\frac{t}{T}\right)^{b}
$$

onde r é um número aleatório no intervalo [0,1], T é o número máximo de gerações e, b é um parâmetro que determina o grau de não uniformidade.

Seleção: A seleção dos indivíduos mais aptos é baseada nos valores da função de fitness de cada indivíduo. Podemos classificar em: determinística, aleatória e estocástica.

\subsection{GEO - Algoritmo de Otimização Extrema Generalizado}

Este algoritmo é uma generalização do método EO (Otimização Extrema), proposto por Boettcher e Percus (2001). Portanto antes de comentar sobre o GEO, será descrita uma breve introdução ao método EO, para uma melhor compreensão dos critérios e estrutura do GEO e o porque de sua utilização.

Método EO: O EO é inspirado no modelo de evolução biológica de BAK e Sneppen (1993), baseado sob os princípios self-organized criticality (SOC)(BAK 
e SNEPPEN, 1993). O SOC é o estado para o qual grandes sistemas interativos evoluem naturalmente, atingindo uma situação crítica, onde uma única alteração em um dos seus elementos gera avalanches que podem alcançar algum número de elementos do sistema. A evolução neste modelo é gerada por um processo onde a pior parte da população é sempre forçada a mutar. Além disso, a parte mais próxima, portanto afetada por sua evolução, são também forçadas a mutar. Ao mesmo tempo essa aproximação preserva através do processo de busca, a possibilidade de verificação de diferentes regiões do espaço das variáveis (via avalanches, capacitando o algoritmo escapar de ótimos locais.

Algoritmo EO

1. Inicialize aleatoriamente configurações $\mathrm{C}$ de variáveis $x_{i}$ do modelo; impõe $C_{\text {best }}=C$,

2. Para a corrente configuração C:

(a) Avalia a fitness $F_{i}$ para cada variável $x_{i}$,

(b) Encontre $j$ satisfazendo $F_{j} \leq F_{i}$ para todo $i$,

(c) Escolhe $C^{*}$ na vizinhança $\mathrm{N}(\mathrm{C})$ de $\mathrm{C}$, tal que $x_{i}$ deve alterar,

(d) Assume $C=C^{*}$, incondicionalmente, e,

(e) Se $V(C)<V\left(C_{\text {best }}\right)$ então $C_{\text {best }}=C$

3. Repita o passo 2 até atingir o critério de parada,

4. Retorna $C_{\text {best }}$ e $V\left(C_{\text {best }}\right)$.

Testes mostraram que este algoritmo é bastante competitivo para problemas de otimização, porém quando aplicados em determinados tipos de problemas, podem levar a busca determinística (BOETTCHER e PERCUS, 2001). A fim de evitar isso e melhorar os resultados (BOETTCHER e PERCUS, 2001), introduziram um único parâmetro ao algoritmo $(\tau)$, denominando o método de $\tau-E O$, o qual apresentou um desempenho superior, até mesmo 
em casos onde o EO não levaria a mínimos locais.

Algoritmo $\tau-E O$

1. Inicialize aleatoriamente a população de $\mathrm{N}$ variáveis do modelo;

2. Para cada variável do modelo atribui um número de fitness, o qual representa o grau de "quanto melhor é" no processo de otimização;

3. Posiciona as variáveis do modelo de acordo com seu número de fitness;

4. Muta a variável de acordo com a distribuição de probabilidade $P_{k_{1}} \propto$ $k_{1}^{-\tau}$, onde $k_{1}$ se refere a posição das variáveis;

5. Repita o passo 2 até atingir o critério de parada;

6. Retorna a melhor solução encontrada durante o processo.

Eles observaram que para $\tau \rightarrow 0$ o algoritmo percorre um caminho aleatório, enquanto que para $\tau \rightarrow \infty$ temos um caminho de busca determinística. A introdução deste parâmetro permite ao algoritmo escolher alguma variável para mutar, mas previlegia aqueles com baixo fitness.

Note que, em EO (ou sua variação $\tau-E O$ ) a população de espécies ou indivíduos é formada por suas variáveis, e não uma coleção de soluções do modelo como em Algoritmos Evolucionários (EAs).

Uma desvantagem deste método é que uma definição geral do fitness para as variáveis individuais pode evidenciar em ambiguidade ou até mesmo resultar em soluções impossíveis. Isto significa que para cada novo problema de otimização avaliado, será necessário um novo modo de definir a fitness das variáveis do modelo. Em consequência disto, uma generalização do $\tau-E O$, o GEO foi desenvolvido afim de tornar o método aplicável a uma extensa classe de problemas de otimização, sem interessar como a fitness das variáveis do modelo seriam avaliadas e capazes de trabalhar com qualquer tipo de variáveis: inteira, discreta, contínua. Neste algoritmo, a avaliação da fitness não é feita diretamente às variáveis do modelo, mas a população 
das espécies que codifica as variáveis. Cada espécie recebe sua fitness, e eventualmente muta, seguindo regras gerais.

GEO: É baseado no modelo evolucionário de Bak e Sneppen (1993), mas aplicando a aproximação $\tau-E O$ para mutar as espécies.

\section{Algoritmo GEO}

1. Inicializa aleatoriamente uma string binária de tamanho L, a qual codifica $\mathrm{N}$ variáveis do modelo, cujo comprimento do bit é $l_{j}, j=1, \ldots, N$. Para a configuração inicial C de bits, calcula o valor da função objetivo $\mathrm{V}$ e seta $C_{\text {best }}=C$ e $V_{\text {best }}=V$,

2. Para cada bit i da string, em cada iteração:

(a) Muta o bit (de 0 para 1 ou 1 para 0 ) e calcula o valor da função objetivo $V_{i}$ da configuração de string $C_{i}$,

(b) Avalia o fitness do bit calculando $\Delta V_{i}=\left(V_{i}-V_{\text {best }}\right)$, o qual indica o relativo ganho (ou perda) que tem ao mutar o bit, comparado com o valor da melhor função objetivo encontrada,

(c) retorna o valor original ao bit.

3. Posiciona o bit de acordo com o seu valor de fitness, de $k_{1}=1$ para o menos adptado até $k_{1}=L$ para o melhor adaptado,

4. Escolhe com probabilidade uniforme um candidato bit i para mutar (muta de 0 para 1 ou de 1 para 0 ). Gera um número randomicamente RAN com distribuição uniforme na faixa $[0,1]$. Se $P_{i}\left(k_{1}\right)=k_{1}^{-\tau}$ é igual ou maior do que RAN, o bit é confirmado a mutar. Caso contrário escolhe um novo candidato bit, e repete o processo até um bit ser confirmado a mutar,

5. Seta $C=C_{i}$ e $V=V_{i}$ com o bit i confirmado para mutar no passo 4;

6. Se $V<V_{\text {best }}\left(V>V_{\text {best }}\right.$, para um problema de maximização), então seta $V_{\text {best }}=V$ e $C_{\text {best }}=C$,

7. Repete o passo 2-6 até um dado critério de parada ser alcançado, 


\section{Retorna $C_{\text {best }}$ e $V_{\text {best }}$}

Note que no passo 4 um bit é escolhido para mutar, mas a confirmação dessa mutação depende de sua posição no rank. O mais apto (com altos valores de rank) são menos inclinados a ter essa mutação confirmada e, somente o bit menos adaptado (rank=1) é sempre confirmado para mutar, se escolhido. 


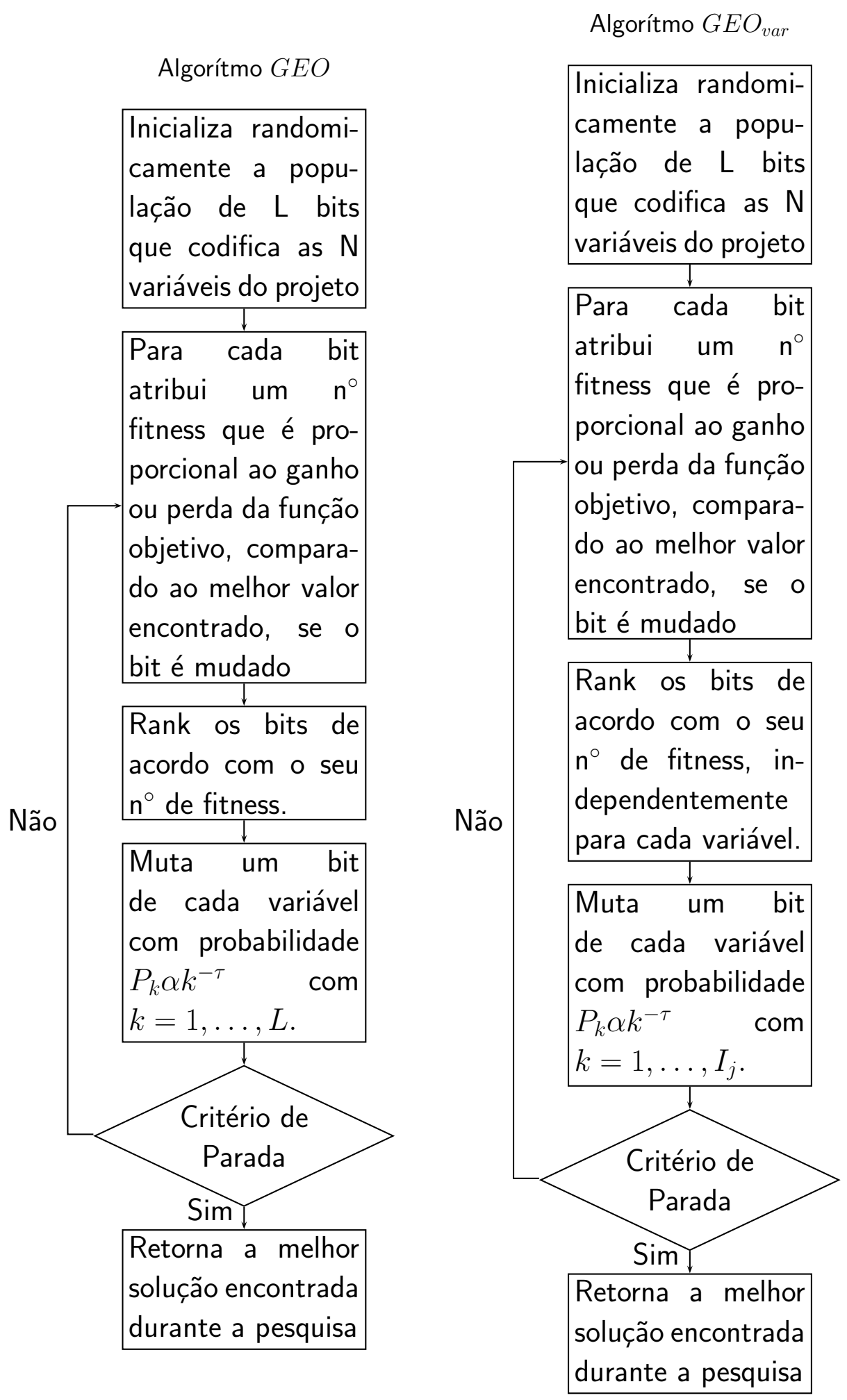

FIGURA 6.7: Algoritmos GEO 
No $G E O_{v a r}$ (SOUSA, et al 2003) a implementação segue os mesmos passos do algoritmo GEO, mas muta e ordena separadamente as subpopulações de bits que representam cada variável. A idéia do $G E O_{v a r}$ é tentar melhorar todas as variáveis simultaneamente, em cada iteração do algoritmo, a fim de acelerar o processo de pesquisa do mínimo global. Como em G.A., o GEO trabalha sobre uma população, embora em G.A., esta população é representada por um conjunto de soluções que coexistem e interagem através de um processo de busca, enquanto que em GEO há uma população de bits representando somente um modelo de solução em cada iteração. Em G.A., a população evolui através de seleção, crossover e mutação, visto que em GEO a evolução é conduzida pela mutação.

Codificação: As variáveis contínuas são representadas em GEO na forma binária, com precisão $p$ desejada. O número mínimo $(m)$ de bits necessários para alcançar uma certa precisão $p$ é dado por:

$$
2^{m} \geq\left[\frac{\left(x_{j}^{u}-x_{j}^{l}\right)}{p}+1\right]
$$

onde $x_{j}^{l}$ e $x_{j}^{u}$ são os limites inferior e superior, respectivamente das variáveis $j$, com $j=1, N$ e $p$ é a precisão desejada. O valor físico de cada variável é obtida através da equação:

$$
x_{j}=x_{j}^{l}+\left(x_{j}^{u}-x_{j}^{l}\right) .\left[\frac{I_{j}}{\left(2^{l_{j}}-1\right)}\right]
$$

onde $I_{j}$ é o número inteiro obtido na transformação da variável $j$ de sua forma binária para a representação decimal.

Variáveis inteiras tem precisão $p=1$ e, podem ser tratadas como apresentado por Lin e Hajela (1992), para um G.A. de codificação binária. Mais detalhes sobre a codificação para variáveis inteiras é discutido por Sousa et al, 2003. 
Restrição: No GEO as restrições referentes aos limites sob as variáveis do modelo são diretamente incorporadas através da codificação das variáveis na forma binária. Restrições de igualdade e desigualdade são facilmente incorporadas no algoritmo simplesmente setando um alto (para um problema de minimização) ou baixo (para um problema de maximização) valor de fitness ao bit, que quando mutado leva a configuração a regiões não praticáveis do espaço do modelo.

\subsection{MNRL - O Método de Newton Raphson Linearizado}

Este método é utilizado em problemas inversos de Tomografia de Impedância Elétrica (EIT), (KIM et al, 2001), onde a fronteira é mapeada a partir de experimentos reais ou artificiais com o objetivo de obter imagens de resistividade $(\rho)$.

Seja,

$$
\Phi(\rho)=\frac{1}{2}\left[\phi_{\text {med }}-\phi_{\text {aprox }}(\rho)\right]^{T}\left[\phi_{\text {med }}-\phi_{\text {aprox }}(\rho)\right]
$$

onde $\phi_{m e d}$ é o vetor referente a diferença de potencial medido na fronteira para um dado valor de $\rho$, ou seja, $\rho_{r}$ e $\phi_{\text {aprox }}(\rho)$ é o vetor diferença de potencial para um valor aproximado de $\rho$.

Minimizar $\Phi(\rho)$ em 6.1 significa determinar o valor de $\rho$ tal que

$$
\Phi^{\prime}(\rho)=\left[\phi_{\text {aprox }}^{\prime}(\rho)\right]^{T}\left[\phi_{\text {med }}-\phi_{\text {aprox }}(\rho)\right]=0
$$

onde $\left[\phi_{\text {aprox }}^{\prime}(\rho)\right]_{i, j}=\frac{\partial \phi_{\text {aprox }_{i}}}{\partial \rho_{j}}$ é a matriz Jacobiana.

A solução da equação 6.2 é determinada através da aplicação do chamado Método de Newton-Raphson Linearizado. Segue o processo de obtenção desse método. 
Expandindo $\Phi^{\prime}(\rho)$ em Série de Taylor, em torno de $\rho^{k}$, até o termo de primeira ordem, obtém-se 6.3:

$$
\Phi^{\prime}\left(\rho^{k+1}\right)=\Phi^{\prime}\left(\rho^{k}\right)+\Phi^{\prime \prime}\left(\rho^{k}\right)\left(\rho^{k+1}-\rho^{k}\right)
$$

Note que se $\Phi^{\prime}\left(\rho^{k+1}\right) \cong 0$ então

$$
\Phi^{\prime}\left(\rho^{k}\right)+\Phi^{\prime \prime}\left(\rho^{k}\right)\left(\rho^{k+1}-\rho^{k}\right) \cong 0
$$

Igualando a expressão (equação 6.5) a zero e isolando $\rho^{k+1}$, tem-se:

$$
\rho^{k+1}=\rho^{k}-\left[\Phi^{\prime \prime}\left(\rho^{k}\right)\right]^{-1} \Phi^{\prime}\left(\rho^{k}\right) .
$$

Esse é o chamado Método de Newton-Raphson. O termo $\Phi^{\prime \prime}$ é chamado de matriz Hessiana (equação 6.6).

$$
\Phi^{\prime \prime}\left(\rho^{k}\right)=\left[\phi_{\text {aprox }}^{\prime}\left(\rho^{k}\right)\right]^{T} \phi_{\text {aprox }}^{\prime}\left(\rho^{k}\right)-\left[\phi_{\text {aprox }}^{\prime \prime}\left(\rho^{k}\right)\right]^{T}\left\{I \otimes\left[\phi_{\text {med }}-\phi_{\text {aprox }}\left(\rho^{k}\right)\right]\right\}
$$

onde $\otimes$ representa o produto matricial de Kronecker entre a matriz identidade $I$ e o vetor $\phi_{\text {med }}-\phi_{\text {aprox }}\left(\rho^{k}\right)$. Como $\phi_{\text {aprox }}^{\prime \prime}(\rho)$ é difícil de calcular e seus termos são relativamente pequenos, o segundo termo da equação 6.6 é desprezado. Portanto a matriz Hessiana é modificada e assume a seguinte apresentação:

$$
\Phi^{\prime \prime}(\rho)=\left[\phi_{\text {aprox }}^{\prime}\left(\rho^{k}\right)\right]^{T} \phi_{\text {aprox }}^{\prime}\left(\rho^{k}\right)=J^{T} J
$$

onde $J$ é a matriz Jacobiana. Esta modificação no Método de Newton Raphson gera o chamado Método de Newton-Raphson Linearizado

$$
\rho^{k+1}=\rho^{k}-\Delta \rho^{k}
$$

onde : 


$$
\Delta \rho^{k}=\left[J^{T} J\right]^{-1}\left[J^{T}\left\{\phi_{\text {med }}-\phi_{\text {aprox }}\left(\rho^{k}\right)\right\}\right]
$$

Para assegurar a convergência do método é importante que seja tomada uma boa aproximação inicial. A melhor aproximação inicial $\rho_{0}$ que deve ser tomada é aquela que minimiza o funcional

$$
\left\|\phi_{\text {med }}-\frac{\rho_{0}}{\rho_{r}} \phi_{\text {aprox }}\left(\rho_{r}\right)\right\|
$$

no sentido dos mínimos quadrados. Na expressão acima $\rho_{r}$ é a resistividade adotada como referência, para a qual $\phi_{m e d}$ é obtido.

Como critério de parada, o método é executado até $\epsilon$ ou erro global (equação 6.9)

$$
\epsilon=\sqrt{\frac{\left(\phi_{\text {aprox }}(\rho)-\phi_{\text {med }}\right)^{T}\left(\phi_{\text {aprox }}(\rho)-\phi_{\text {med }}\right)}{\phi_{\text {med }}^{T} \phi_{\text {med }}}}
$$

atingir um valor mínimo predeterminado para uma precisão desejada. E este valor mínimo é atingido quando a convergência dos parâmetros para seus valores ótimos for alcançada. 


\section{Capítulo 7}

\section{Resultados}

Neste capítulo são apresentados alguns testes realizados com o objetivo de encontrar os parâmetros ótimos da velocidade, os quais determinarão a distribuição de velocidade no interior da tubulação. Visando a possibilidade de uma aplicação prática, buscou-se eficiência e praticidade no desenvolvimento deste projeto. A aplicação prática consiste na determinação da vazão de escoamento em uma tubulação. Os testes foram realizados considerando uma tubulação de seção circular, contendo fluido de condutividade elétrica constante e conhecendo-se a distribuição de tensões elétricas no contorno do escoamento. As tensões elétricas são respostas da interação do campo magnético com o meio (fluido condutor). Neste caso em específico, adotou-se o campo magnético uniforme de intensidade e direção conhecida .

\subsection{Descrição do Problema Direto I}

A resolução deste problema gera uma aproximação da diferença de potencial experimental $\phi_{m e d}$. A análise é realizada em uma seção circular de um tubo de raio $\mathrm{R}=1$, considerando o domínio particionado conforme Figura 7.1. Para as direções $r$ e $\theta$ são fixados um número de pontos $P r=17$ e $P t=81$ respectivamente, seguindo as restrições referentes ao particionamento no intervalo $[0,2 \pi]$, comentadas no capítulo 4. No problema direto, a distribuição de velocidade é 
conhecida no interior do tubo, ou seja, a função velocidade é definida para cada ponto da malha. Neste caso em específico, a função é dada pela equação 7.1, que explicita o modelo de distribuição de velocidade no interior da tubulação.

$$
v(r, \theta)=\alpha\left(1-r^{n}\right), \quad D_{v}=[0,1] \times[0,2 \pi], \quad \alpha, n \in \Re, \quad \alpha \in(0,2] \quad e \quad n \in[1,3]
$$

Para o cálculo de $\phi_{m e d}$, utilizou-se essa parametrização do perfil de velocidade para valores de referência: $\alpha_{r e f}=1.0$ e $n_{r e f}=2.0$, definindo um perfil de velocidade parabólico, característico de escoamento laminar. Para estes valores de referência denominou-se perfil de referência.

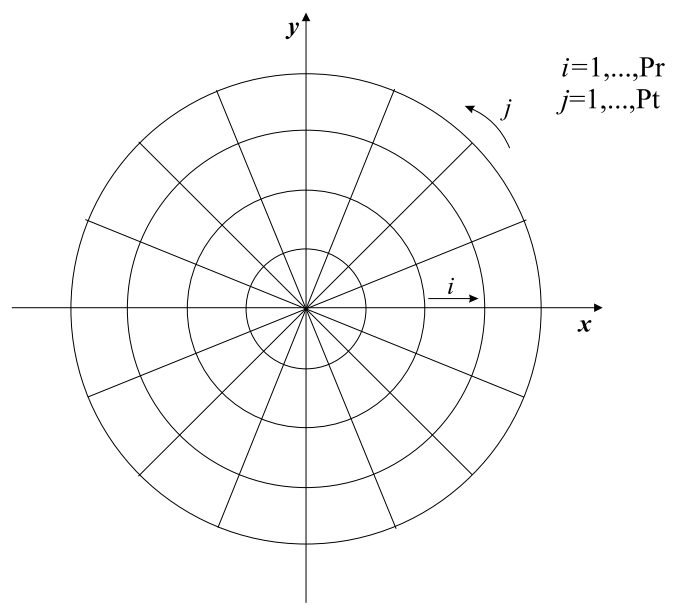

FIGURA 7.1: Malha em Coordenadas Polares

Uma análise importante é com relação a utilização de malhas muito refinadas. Após testes realizados concluiu-se que a aplicação deste tipo de malha demandaria muito tempo. Primeiramente, esses testes foram realizados em uma malha $17 \times 81$, pois essas dimensões são suficientes para visualização dos resultados. Estes resultados foram comparados com resultados de testes com malhas bem mais refinadas, verificando o mesmo resultado que tinha sido observado com uma malha $17 \times 81$. 


\subsection{Superfície de erro}

Obtido $\phi_{m e d}$, este será utilizado na construção do funcional de erro $(e)$, equação 4.1. A diferença de potencial aproximada $\phi_{a p r o x}$ é determinada através da resolução do problema direto para uma determinada aproximação dos parâmetros da velocidade $(\alpha$ e $n)$.

\section{Influência dos parâmetros $\alpha$ e $n$}

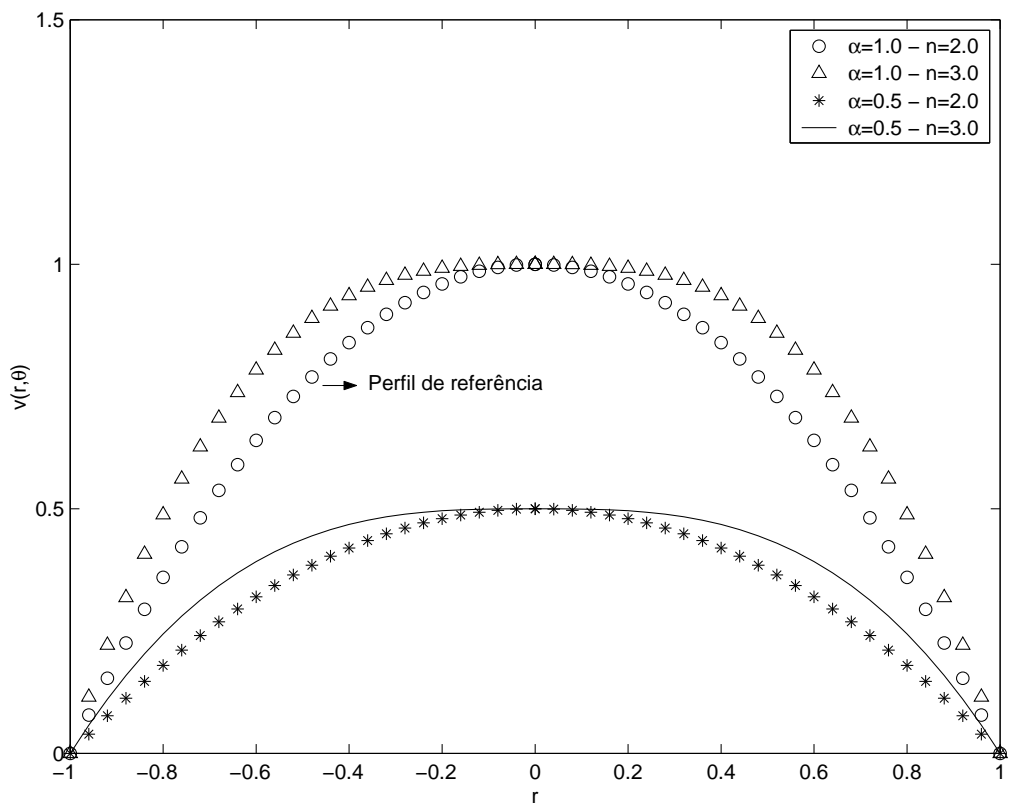

FIGURA 7.2: Função $v(r, \theta)$ para $\theta=0$

A partir da construção do funcional de erro determinou-se a superfície de erro, apresentada na Figura 7.3. 


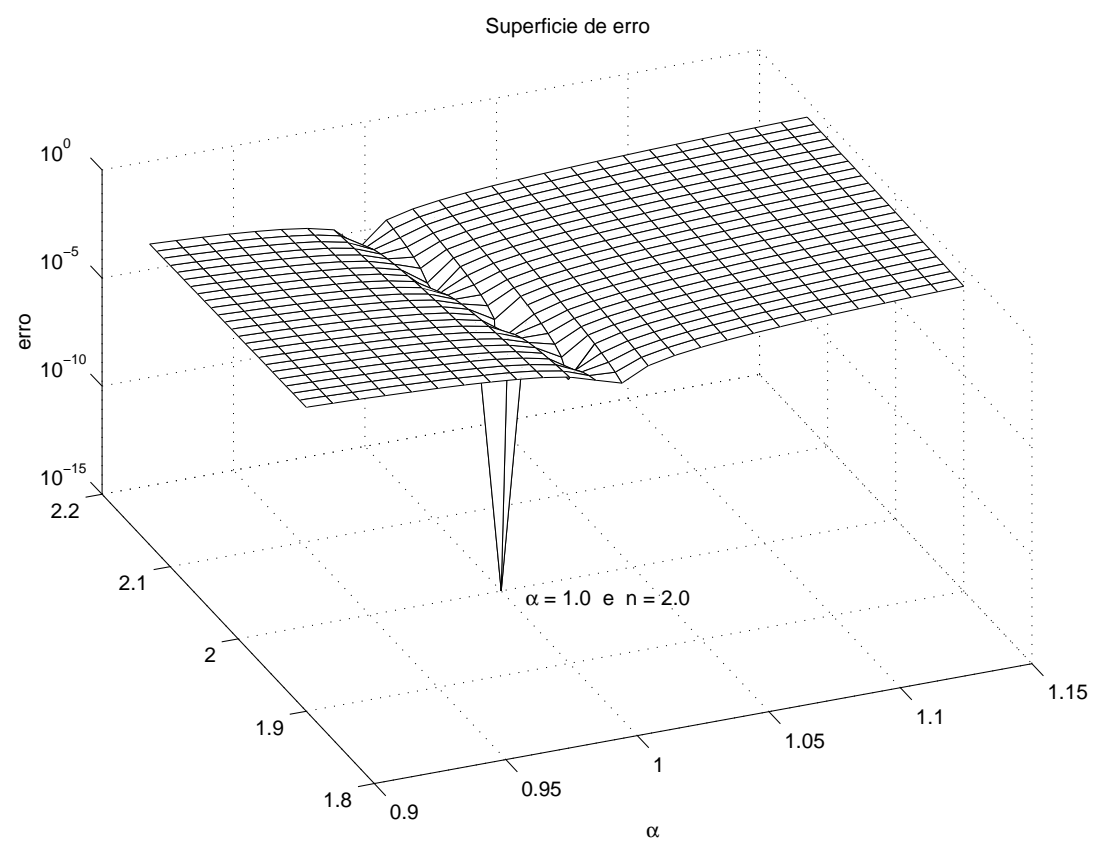

FIGURA 7.3: Superfície de Erro

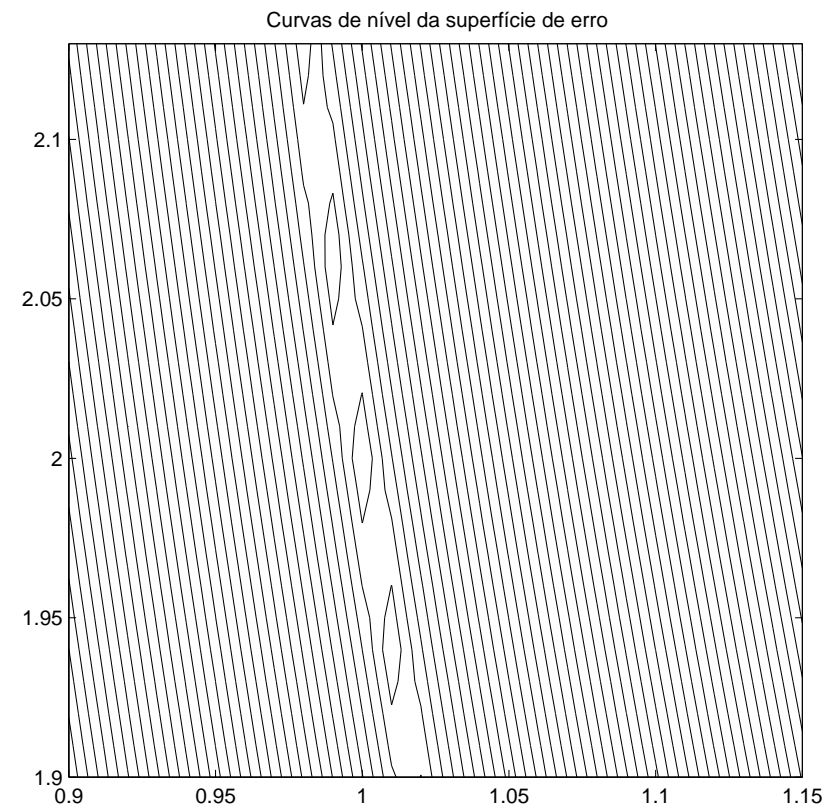

FIGURA 7.4: Curvas de Nível da Superfície de Erro 
No gráfico 7.3, a superfície de erro exibe um mínimo pronunciado na posição em que $(\alpha, n)_{\text {aprox }} \equiv(\alpha, n)_{\text {ref }}$. Além disso, esta superfície apresenta alguns problemas característicos de sua topologia, como a existência de vários pontos de mínimos locais e regiões planas, os quais podem comprometer seriamente a convergência dos métodos de otimização.

\subsection{Problema de Otimização I}

A partir da análise da topologia da superfície de erro e prevendo as possíveis implicações em um processo de otimização tradicional, optou-se por utilizar os algoritmos genéticos como um método de otimização a ser testado. O algoritmo genético foi implementado para o seguinte problema:

$$
\begin{aligned}
& \operatorname{Min}(e(\alpha, n)) \\
& 0.0<\alpha \leq 2.0 \\
& 1.0 \leq n \leq 3.0
\end{aligned}
$$

O objetivo é encontrar $\alpha$ e $n$, parâmetros ótimos da velocidade $v(r, \theta)=$ $\alpha\left(1-r^{n}\right)$, através dos quais $e(\alpha, n) \rightarrow 0$.

\subsubsection{Resultados da aplicação do G.A. - Algoritmo Genético}

Para a implementação do método utilizou-se os seguinte dados:

Representação das variáveis: em números reais, com uma população inicial de 20 vetores, dentro dos limites admissíveis.

Reprodução: crossover aritmético: média de dois pais escolhidos aleatoriamente entre os 5 primeiros indivíduos da população (ordenada).

Mutação: uniforme: substitui um gene escolhido aleatoriamente por um número real admissível dentro dos limites superior e inferior de cada variável. Foram realizados 4 mutações. Dentre essas 4 mutações, utilizou-se uma estratégia descrita a seguir: 
Sejam $f\left(x_{1}, x_{2}, x_{3}, \ldots, x_{n}\right)$ a função objetivo a ser minimizada e $t_{j}$ vetores com $n$ componentes que formam uma sub-população com m elementos resultantes do processo de mutação. A idéia do método, para o problema em questão, se resume na aplicação dos seguintes passos:

a. Para cada $x_{i}, \quad i=1,2, \ldots, n$, calcule $\frac{\partial f\left(t_{j}\right)}{\partial x_{i}}$, com $j=1,2, \ldots, m$, e tome $\bar{x}_{i}$ do vetor $t_{j}$, onde $\frac{\partial f\left(t_{j}\right)}{\partial x_{i}}$ assume o menor valor e, descarte o restante;

b. Com $\bar{x}_{i}, \quad i=1,2, \ldots, n$ forme um novo vetor $\bar{t}$ para mutação. Esse vetor será utilizado para gerar novos vetores;

c. Para cada $\bar{x}_{i}, \quad i=1,2, \ldots, n$, faça $y_{i}=\bar{x}_{i}-\beta \frac{\partial f(\bar{t})}{\partial x_{i}}, z_{i}=y_{i}-\beta \frac{\partial f(\bar{t})}{\partial x_{i}} \mathrm{e}$ $t e_{i}=z_{i}-\beta \frac{\partial f(\bar{t})}{\partial x_{i}}$. Cada um dos três elementos $\left(x_{i}, y_{i}\right.$ e $\left.t e_{i}\right)$ irão formar as i-ésimas componentes dos três novos vetores gerados a partir de $\bar{t}$.

Seleção: determinística: toma as 20 melhores soluções escolhidas a partir da geração anterior (20) mais os 7 descendentes (3 formados na reprodução e 4 na mutação). 
A tabela 7.1 refere-se aos resultados obtidos com a implementação do Algoritmo Genético (G.A.). Como o número de avaliações da função de fitness é muito grande para ser apresentado em uma tabela (1000 avaliações), a Tabela 7.1 registra apenas os valores obtidos a cada 50 avaliações da função de fitness (e).

TABELA 7.1: Tabela referente aos resultados obtidos com a aplicação do G.A.

\begin{tabular}{|c|c|c|c|c|}
\hline & \multicolumn{2}{|c|}{ Função de Fitness (e) } & \multicolumn{2}{|c|}{ Parâmetros } \\
\hline Número de Avaliações & Melhores soluções & Piores soluções & $\alpha$ & $n$ \\
\hline 1 & 4,756992E-03 & 2,863923E-01 & 0,991943000000 & 2,079212000000 \\
\hline 50 & $1,867128 \mathrm{E}-04$ & 4,810151E-04 & 1,004586000000 & 1,971873000000 \\
\hline 100 & $1,674582 \mathrm{E}-04$ & 1,676088E-04 & 1,004589000000 & 1,971967000000 \\
\hline 150 & 1,674532E-04 & 1,674532E-04 & 1,004589000000 & 1,971967000000 \\
\hline 200 & $2,240439 \mathrm{E}-05$ & 1,674532E-04 & 0,999980800000 & 1,999981000000 \\
\hline 250 & 1,269869E-05 & $7,222932 \mathrm{E}-05$ & 0,999988000000 & 1,999996000000 \\
\hline 300 & $6,116723 \mathrm{E}-07$ & 1,468829E-06 & 1,000007000000 & 1,999959000000 \\
\hline 350 & $2,679966 \mathrm{E}-07$ & 4,035614E-07 & 1,000007000000 & 1,999956000000 \\
\hline 400 & $2,659450 \mathrm{E}-07$ & $2,659450 \mathrm{E}-07$ & 1,000007000000 & 1,999956000000 \\
\hline 450 & $2,659450 \mathrm{E}-07$ & $2,659450 \mathrm{E}-07$ & 1,000007000000 & 1,999956000000 \\
\hline 500 & $2,659450 \mathrm{E}-07$ & $2,659450 \mathrm{E}-07$ & 1,000007000000 & 1,999956000000 \\
\hline 550 & $2,659450 \mathrm{E}-07$ & $2,659450 \mathrm{E}-07$ & 1,000007000000 & 1,999956000000 \\
\hline 600 & $2,659450 \mathrm{E}-07$ & $2,659450 \mathrm{E}-07$ & 1,000007000000 & 1,999956000000 \\
\hline 650 & $2,659450 \mathrm{E}-07$ & $2,659450 \mathrm{E}-07$ & 1,000007000000 & 1,999956000000 \\
\hline 700 & $2,659450 \mathrm{E}-07$ & $2,659450 \mathrm{E}-07$ & 1,000007000000 & 1,999956000000 \\
\hline 750 & $2,659450 \mathrm{E}-07$ & $2,659450 \mathrm{E}-07$ & 1,000007000000 & 1,999956000000 \\
\hline 800 & $2,659450 \mathrm{E}-07$ & $2,659450 \mathrm{E}-07$ & 1,000007000000 & 1,999956000000 \\
\hline 850 & $2,659450 \mathrm{E}-07$ & $2,659450 \mathrm{E}-07$ & 1,000007000000 & 1,999956000000 \\
\hline 900 & $2,659450 \mathrm{E}-07$ & $2,659450 \mathrm{E}-07$ & 1,000007000000 & 1,999956000000 \\
\hline 950 & $2,659450 \mathrm{E}-07$ & $2,659450 \mathrm{E}-07$ & 1,000007000000 & 1,999956000000 \\
\hline 1000 & $2,659450 \mathrm{E}-07$ & $2,659450 \mathrm{E}-07$ & 1,000007000000 & 1,999956000000 \\
\hline
\end{tabular}

A seguir são apresentados os gráficos, Figura 7.5 referente aos dados da Tabela 7.1. O gráfico, Figura 7.5 apresenta duas curvas, representando respectivamente as piores e as melhores soluções de cada geração. 

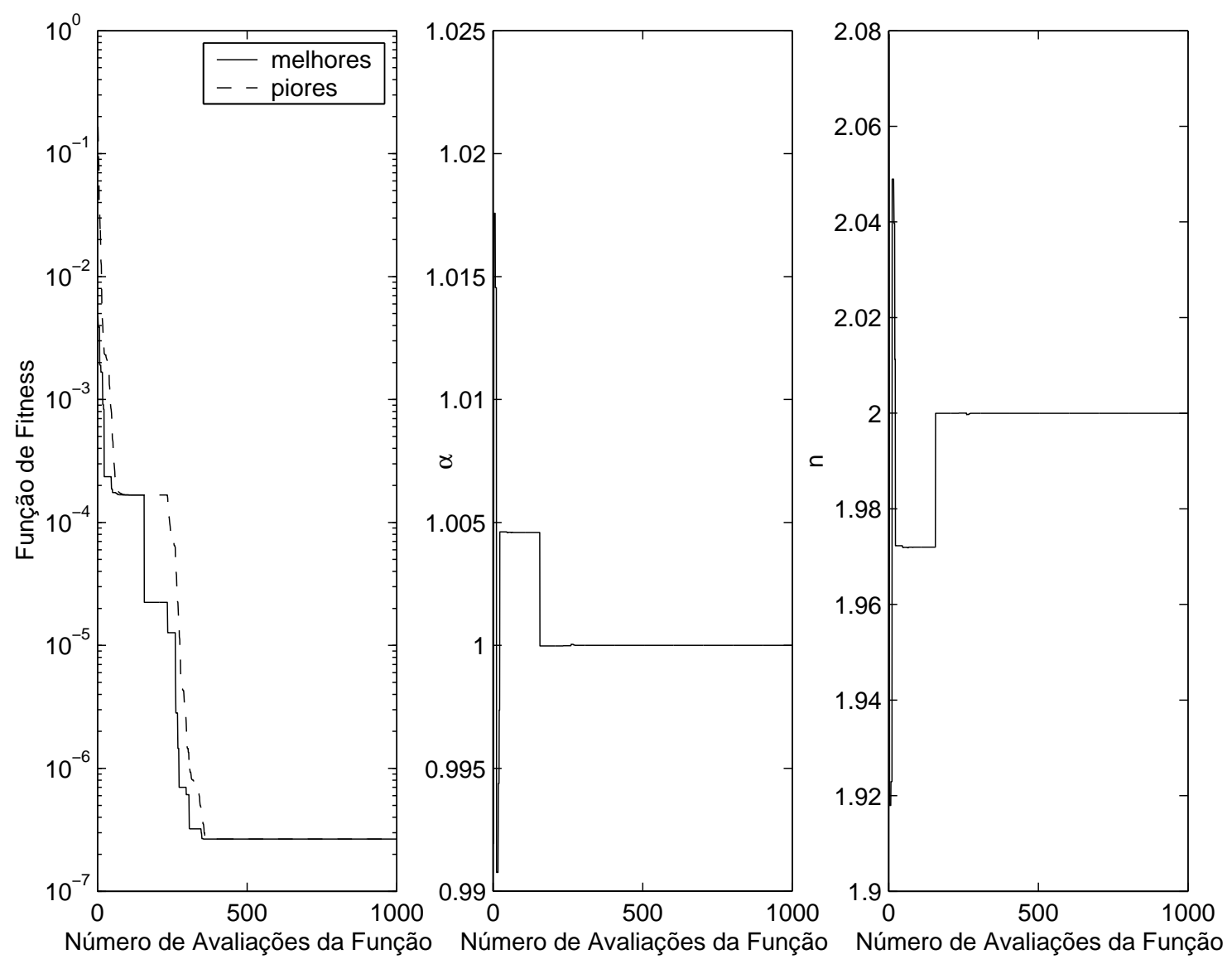

FIGURA 7.5: Resultados ótimos para a função de fitness e, variáveis $\alpha$ e $\mathbf{n}$

Analisando os gráficos observou-se (Figura 7.5) que o Algoritmo Genético (G.A.) converge para o ponto ótimo com uma ordem de precisão aceitável, mas que não é a ideal para o problema. Uma outra observação é que em um determinado número de gerações as curvas (piores e melhores) se sobrepõem, indicando que os piores e melhores indivíduos daquelas gerações são idênticos, neste caso, a população se tornou homogênea. Podemos dizer que ocorreu uma parada inadequada, e isso tem sérias implicações, pois a reprodução passa a não ter mais efeito, e somente é possível melhorar a solução se um "mutante" mais adaptado for eventualmente criado. Esse "mutante"pode aparecer de acordo com o procedimento que adotamos para o processo de mutação. Porém, pelo visto, seriam necessários um número maior de iterações a fim de obter um erro da ordem de $10^{-10}$, por exemplo. 


\subsubsection{Resultados da aplicação do GEO $_{v a r}$ - Algoritmo de Otimização Extrema Generalizado para $\tau=2.5$}

Para a implementação do $G E O_{v a r}$ referente ao mesmo problema (seção 7.3) utilizou-se $\tau=2.5$ e $p=10^{-10}$. Os resultados obtidos são apresentados na Tabela 7.2.

TABELA 7.2: Resultados obtidos com $G E O_{v a r}, \tau=2.5$

\begin{tabular}{|c|c|c|c|}
\hline Número de Avaliações & Função de Fitness $(\mathrm{e})$ & $\alpha$ & $\mathrm{n}$ \\
\hline 1 & $4,207713 \mathrm{E}-01$ & 0,487303200000 & 2,919508000000 \\
\hline 2 & $1,837757 \mathrm{E}-01$ & 0,987303300000 & 2,982008000000 \\
\hline 3 & $1,416126 \mathrm{E}-01$ & 0,862303300000 & 1,982008000000 \\
\hline 8 & $1,328427 \mathrm{E}-02$ & 0,987303300000 & 1,997633000000 \\
\hline 9 & $8,893535 \mathrm{E}-03$ & 0,991209500000 & 1,999586000000 \\
\hline 10 & $1,020550 \mathrm{E}-03$ & 0,999022000000 & 1,999830000000 \\
\hline 11 & $4,019408 \mathrm{E}-05$ & 0,999998600000 & 1,999846000000 \\
\hline 12 & $3,157136 \mathrm{E}-05$ & 0,999999500000 & 1,999876000000 \\
\hline 13 & $3,109454 \mathrm{E}-05$ & 1,000000000000 & 1,999876000000 \\
\hline 14 & $3,091449 \mathrm{E}-05$ & 0,999999900000 & 1,999877000000 \\
\hline 15 & $1,797318 \mathrm{E}-07$ & 1,000000000000 & 1,999999000000 \\
\hline 16 & $1,195152 \mathrm{E}-07$ & 0,999999900000 & 2,000000000000 \\
\hline 17 & $4,435134 \mathrm{E}-16$ & 1,000000000000 & 2,000000000000 \\
\hline
\end{tabular}

Os resultados apresentados na Tabela 7.2 mostram a rapidez e a ordem de convergência do método para a solução ótima, quando comparado aos resultados obtidos com a aplicação dos Algoritmos Genéticos (Tabela 7.1). Analisando os gráficos, Figura 7.5 e Figura 7.6 é possível comparar os resultados obtidos em ambos os métodos. 

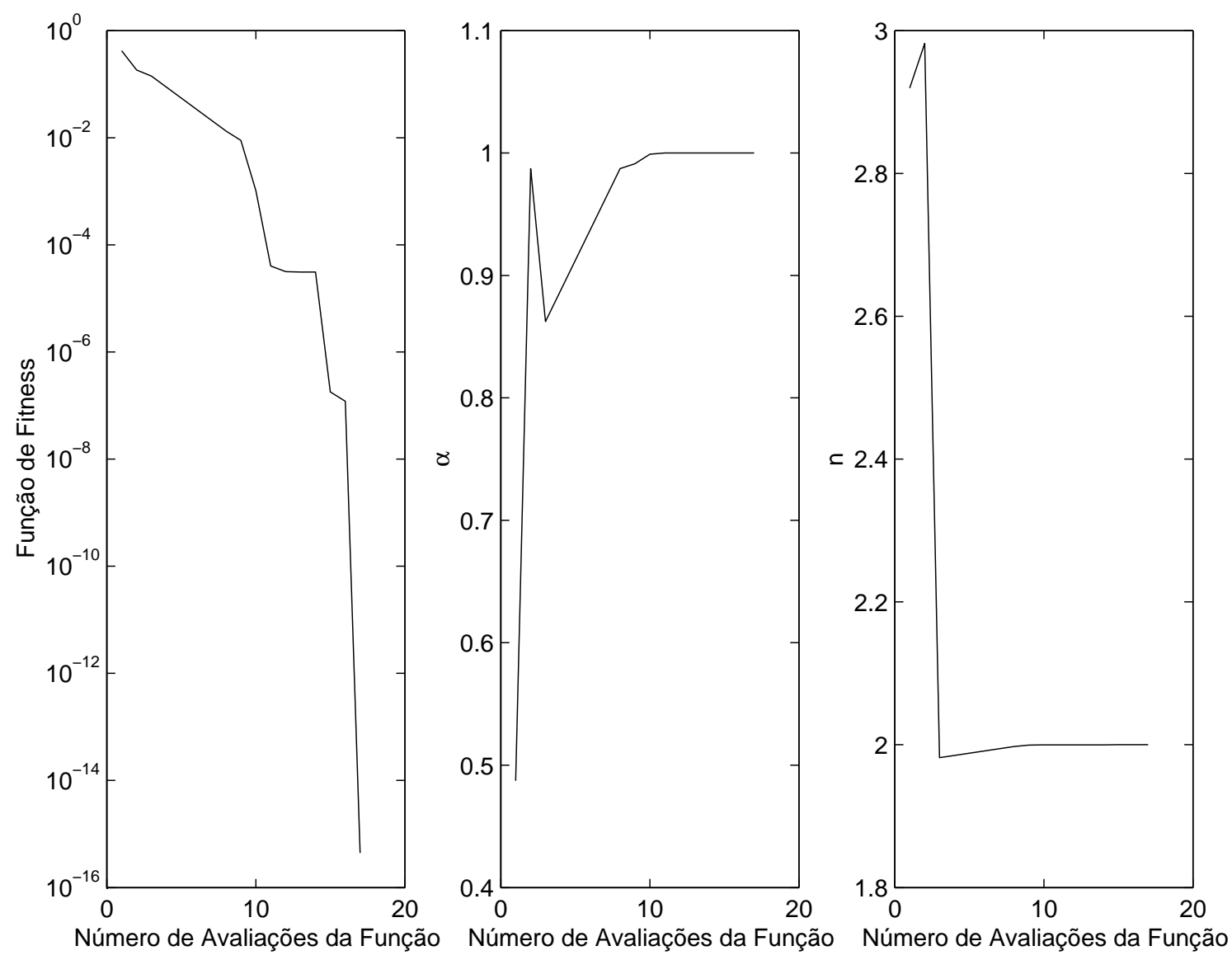

FIGURA 7.6: Resultados ótimos para a função de fitness e, variáveis $\alpha$ e $\mathbf{n}$

Com a aplicação do $G E O_{v a r}$, o funcional de erro convergiu para o ponto ótimo em um pequeno número de avaliações da função objetivo. A utilização deste algoritmo apresentou muitas vantagens em relação ao G.A., como por exemplo, redução do tempo computacional, presença de apenas um parâmetro para ajustar, além de ser um algoritmo de fácil implementação. Devido a estas características

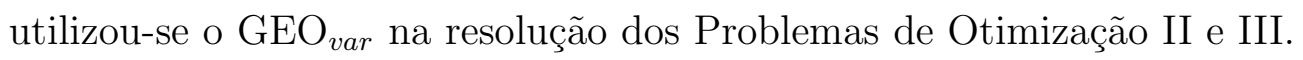

\subsection{Problema Direto II}

Neste caso utilizou-se a mesma formulação do Problema Direto I, sendo que os valores de potenciais medidos experimentalmente $\left(\phi_{m e d}\right)$ foram simulados com base no seguinte perfil de velocidade: 


$$
\begin{gathered}
v(r, \theta)=\alpha\left(1-r^{n}\right)\left[1+(r \cos (\theta)-a)^{2}\right] \\
D_{v}=[0,1] \times[0,2 \pi], \quad \alpha, n \in \Re, \quad \alpha \in(0,2], \quad n \in[1,3] \quad \text { e } \quad a \in[0,1]
\end{gathered}
$$

para os seguintes parâmetros de referência:

$$
\alpha_{\text {ref }}=1.0, \quad n_{\text {ref }}=2.0 \quad \text { e } \quad a_{\text {ref }}=0.5
$$

As medidas de potenciais aproximadas $\phi_{\text {aprox }}$ são obtidas conforme descrito no Problema Direto I, considerando perturbações nos parâmetros $\alpha, n$ e $a$. A seguir são apresentados os gráficos referentes as curvas de nível do perfil de velocidade, equação 7.2, para determinadas perturbações nos parâmetros $\alpha, n$ e $a$.
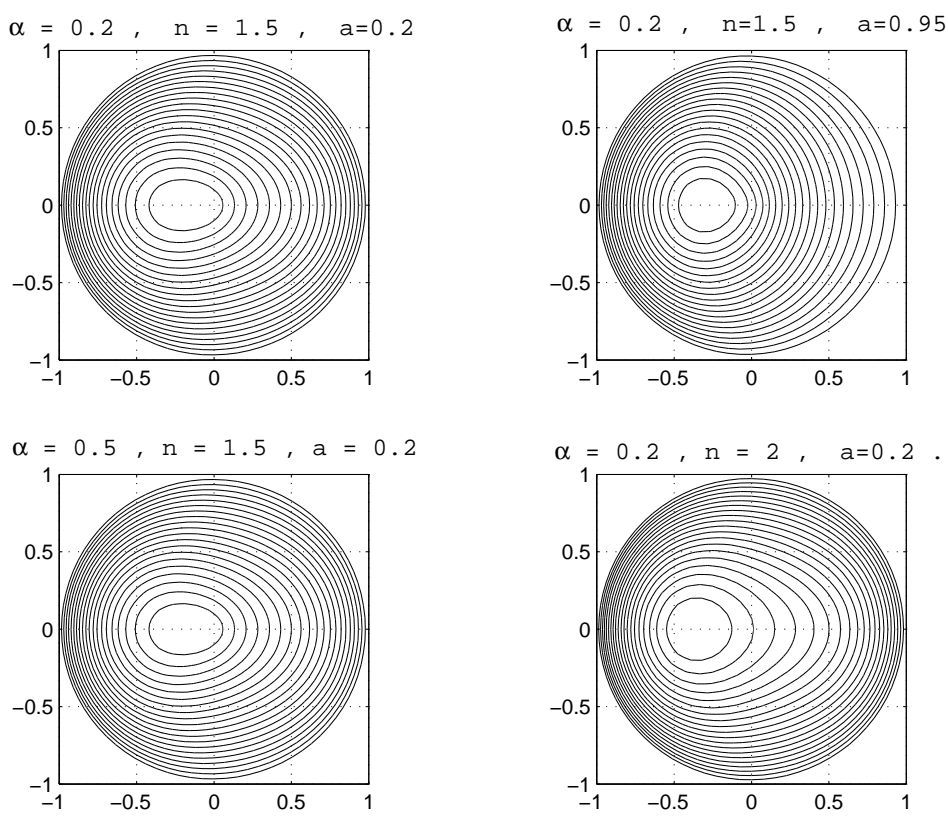

FIGURA 7.7: Influência dos parâmetros $\alpha, n$ e $a$ 


\subsection{Problema de Otimização II}

$$
\begin{aligned}
& \operatorname{Min}[e(\alpha, n, a)] \\
& 0.0<\alpha \leq 2.0 \\
& 1.0 \leq n \leq 3.0 \\
& 0.0 \leq a \leq 1.0
\end{aligned}
$$

$\mathrm{Na}$ resolução deste problema de otimização utilizou-se o $G E O_{\text {var }}$ para $\tau=1.5$ e $p=10^{-12}$.

O objetivo é encontrar $\alpha, n$ e $a$ parâmetros ótimos da velocidade $v(r, \theta)=$ $\alpha\left(1-r^{n}\right)\left[1+(r \cos (\theta)-a)^{2}\right]$, através dos quais $e(\alpha, n, a) \rightarrow 0$.

\subsubsection{Resultados da aplicação do $\mathrm{GEO}_{v a r}$ - Algoritmo de Otimização Extrema Generalizado para $\tau=1.5$}

A tabela 7.3 apresenta a convergência dos parâmetros $\alpha, n$ e $a$ para os seus valores ótimos, ou seja, valores para os quais a função de fitness (e) assume o menor valor. Nestes valores ótimos das variáveis $\alpha, n$ e $a$ a função deve atingir o critério de parada imposto pelo problema, ou seja, o processo de busca pára quando a função de fitness (e) ou funcional de erro atingir um valor mínimo tendendo a zero com uma precisão da ordem de $10^{-12}$. 
TABELA 7.3: Resultados obtidos com $G E O_{v a r}, \tau=1.5$

\begin{tabular}{|c|c|c|c|c|}
\hline Número de Avaliações & Função de Fitness (e) & $\alpha$ & $n$ & $a$ \\
\hline 1 & $1,218629 \mathrm{E}-01$ & 0,956053300000 & 2,817275000000 & 0,495617300000 \\
\hline 4 & $1,032618 \mathrm{E}-01$ & 0,987303100000 & 1,943251000000 & 0,437054100000 \\
\hline 5 & $8,821744 \mathrm{E}-02$ & 0,995115600000 & 1,974501000000 & 0,437298200000 \\
\hline 6 & $7,921601 \mathrm{E}-03$ & 0,999021900000 & 1,974502000000 & 0,499798200000 \\
\hline 7 & $6,871447 \mathrm{E}-03$ & 0,999998500000 & 1,974517000000 & 0,499859300000 \\
\hline 8 & $2,756809 \mathrm{E}-03$ & 0,999999400000 & 1,990142000000 & 0,499859800000 \\
\hline 9 & $2,756615 \mathrm{E}-03$ & 0,999999500000 & 1,990142000000 & 0,499859800000 \\
\hline 10 & $5,571201 \mathrm{E}-04$ & 1,000000000000 & 1,997955000000 & 0,499981900000 \\
\hline 11 & $4,684734 \mathrm{E}-05$ & 1,000000000000 & 1,999908000000 & 0,499981900000 \\
\hline 12 & $3,102794 \mathrm{E}-05$ & 0,999999900000 & 1,999969000000 & 0,499981900000 \\
\hline 13 & $3,726917 \mathrm{E}-06$ & 1,000000000000 & 2,000000000000 & 0,499997100000 \\
\hline 15 & $1,382030 \mathrm{E}-06$ & 1,000000000000 & 2,000000000000 & 0,499998900000 \\
\hline 309 & $1,586995 \mathrm{E}-16$ & 1,000000000000 & 2,000000000000 & 0,500000000000 \\
\hline
\end{tabular}

Na Tabela 7.3 o funcional de erro (e) ou função de fitness atinge o ponto de mínimo com uma precisão da ordem de $10^{-16}$, ultrapassando a precisão estabelecida na implementação do método. Neste tipo de algoritmo de otimização o processo de busca é aleatório, baseado em uma configuração de bits (codificador dos parâmetros em questão) que altera a cada processo de iteração, segundo uma distribuição de probabilidade que depende da posição de rank de cada bit. Dessa forma, uma configuração de bits pode melhorar muito de uma iteração para a outra ou de um intervalo de iteração para o outro e, nestes casos há a possibilidade de um grande salto do valor da função de fitness. A Tabela 7.3 mostra um exemplo desse fato que ocorre no número de avaliações da função de 15 para 309. No intervalo da iteração 15 para 309 a função de fitness não apresentou um valor ótimo melhor do que na iteração 15, apenas na iteração 309 houve uma melhora satisfatória e superior que a precisão imposta na implementação.

A seguir são apresentados os gráficos referentes aos resultados da Tabela 7.3 . 

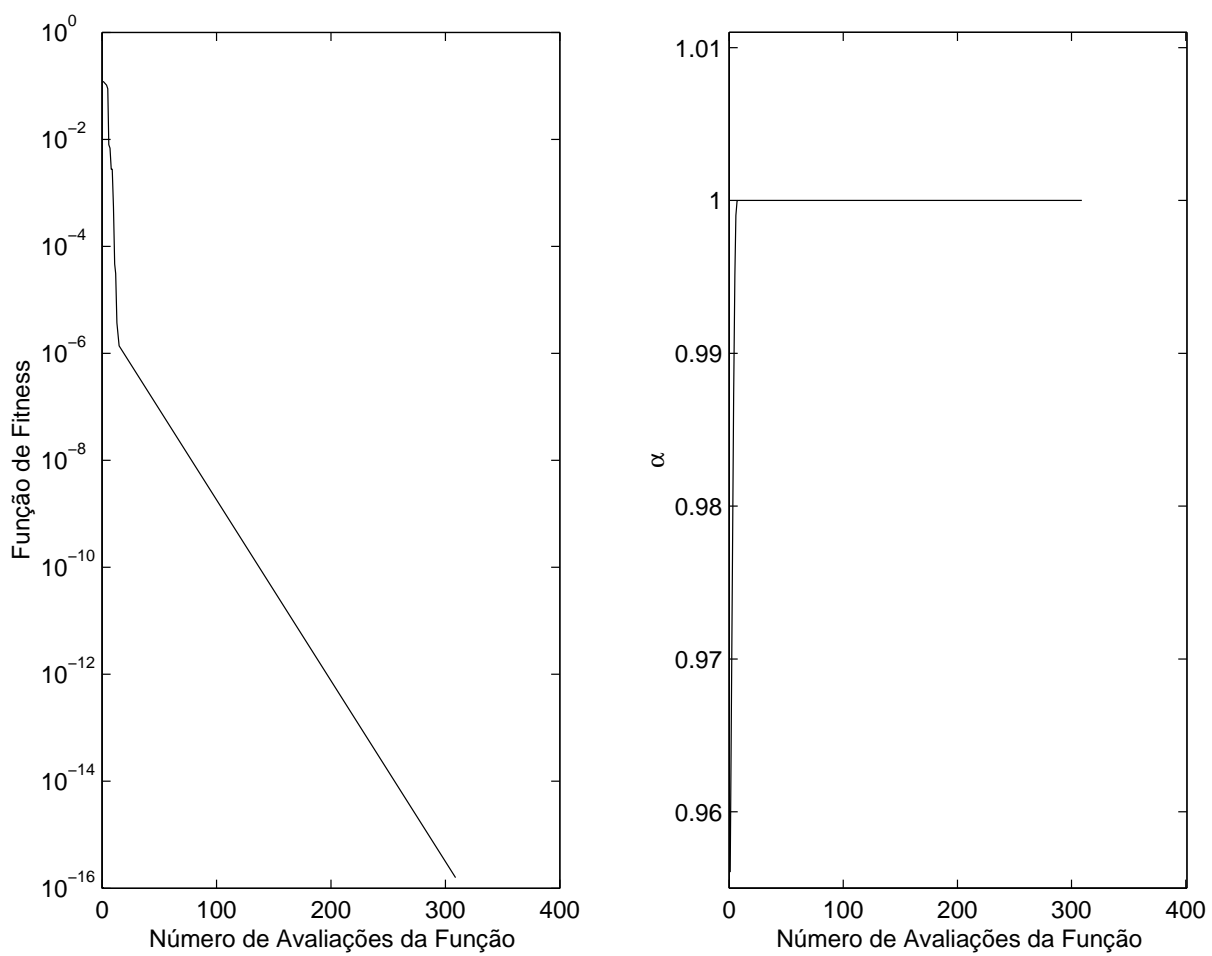

FIGURA 7.8: Resultados ótimos para a função de fitness e e variável $\alpha$
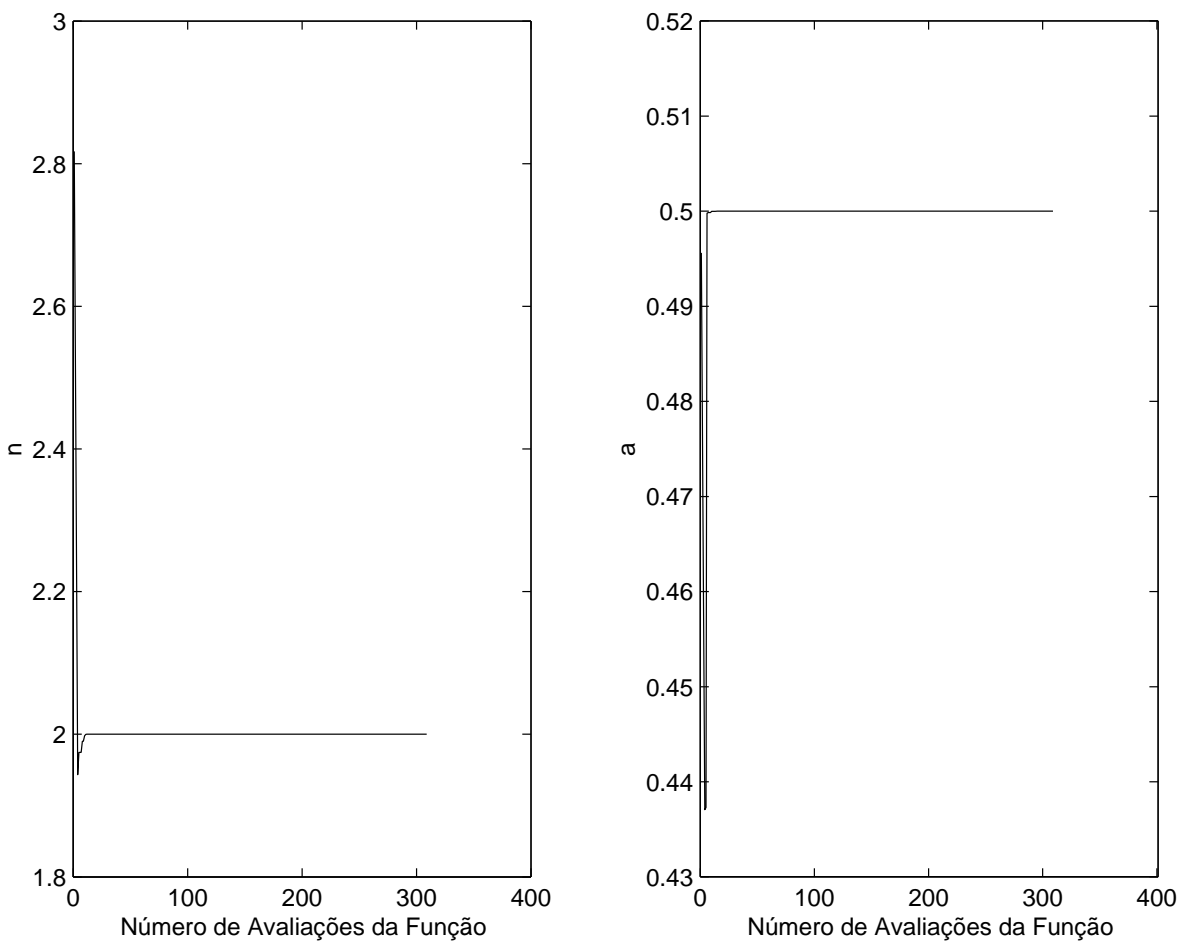

FIGURA 7.9: Resultados ótimos para as variáveis $\mathbf{n}$ e a 
Devido ao aumento no número de variáveis do problema, nota-se através destes resultados que o processo de busca tornou-se um pouco lento se comparado aos resultados do capítulo 7, seção 7.3.2 (Problema de Otimização I). Porém em comparação aos resultados do capítulo 7, seção 7.3.1 houve uma grande redução do tempo computacional e, melhores resultados foram obtidos com relação a precisão do valor ótimo. Uma justificativa para esta ocorrência é que o GEO var apresenta apenas um parâmetro de ajuste, tornando mais fácil este ajuste para um número maior de variáveis, enquanto que nos G.A, o número de parâmetros de ajuste é bem maior e, em alguns casos é necessário recorrer ao G.A híbrido afim de obter um resultado mais satisfatório.

\subsection{Problema Direto III}

Um outro teste foi realizado, sendo que os valores de potenciais medidos experimentalmente $\left(\phi_{m e d}\right)$ foram determinados com base no seguinte perfil de velocidade:

$$
v(r, \theta)=\left(1+f_{1}\right)\left(1-r^{2}\right)\left(1+f_{2}^{2}\right)
$$

onde:

$$
\begin{aligned}
& f_{1}=(r \cos (\theta)-\alpha)^{2}+(r \sin (\theta)-n)^{2} \\
& f_{2}=(r \cos (\theta)-a)^{2}+(r \sin (\theta)-b)^{2}
\end{aligned}
$$

$$
\begin{aligned}
& D_{v}=[0,1] \times[0,2 \pi], \quad \alpha, n \in \Re, \quad \alpha \in[-2.0,2.0], \quad n \in[-1.0,1.0], \quad a \in[-0.5,0.5] \\
& e \quad b \in[-0.25,0.25]
\end{aligned}
$$

para os seguintes parâmetros de referência:

$$
\alpha_{\text {ref }}=0.0, \quad n_{\text {ref }}=0.0, \quad a_{\text {ref }}=0.0 \quad \text { e } \quad b_{\text {ref }}=0.0
$$


As medidas de potenciais aproximadas foram obtidas conforme descrito no Problema Direto I, considerando perturbações nos parâmetros $\alpha, n, a$ e $b$. A seguir são apresentados os gráficos referentes as curvas de nível do perfil de velocidade equação 7.3, para determinadas perturbações nos parâmetros $\alpha, n, a$ e $b$.
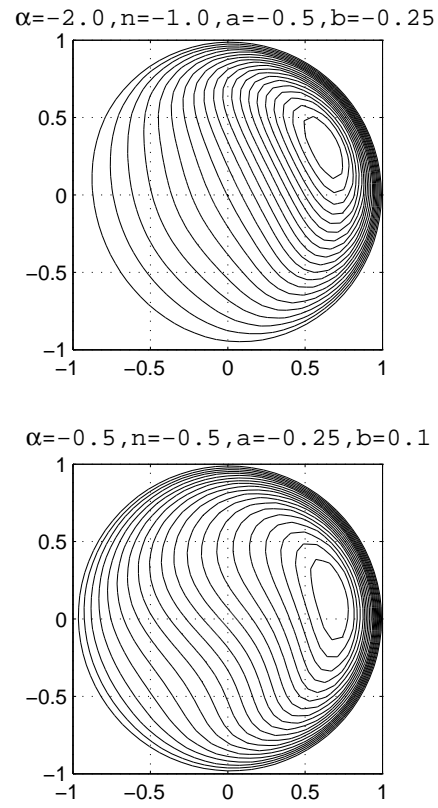
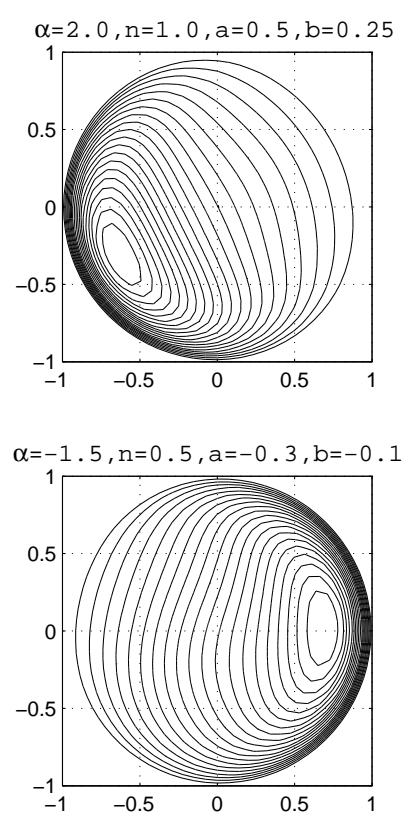

FIGURA 7.10: Influência dos parâmetros $\alpha, n, a$ e $b$

\subsection{Problema de Otimização III}

$$
\begin{aligned}
& \operatorname{Min}[e(\alpha, n, a, b)] \\
& -2.0 \leq \alpha \leq 2.0 \\
& -1.0 \leq n \leq 1.0 \\
& -0.5 \leq a \leq 0.5 \\
& -0.25 \leq b \leq 0.25
\end{aligned}
$$

$\mathrm{Na}$ resolução deste problema de otimização utilizou-se o $G E O_{\text {var }}$ para $p=10^{-12}$ e $\tau=2.0$. 
O objetivo é encontrar $\alpha, n, a$ e $b$ parâmetros ótimos da velocidade $v(r, \theta)=\left(1+f_{1}\right)\left(1-r^{2}\right)\left(1+f_{2}^{2}\right)$, através dos quais $e(\alpha, n, a, b) \rightarrow 0$. $f_{1}$ e $f_{2}$ são definidos na seção 7.6.

\subsubsection{Resultados da aplicação do $\mathrm{GEO}_{v a r}$ - Algoritmo de Otimização Extrema Generalizado para $\tau=2.0$}

A Tabela 7.4 apresenta a convergência dos parâmetros $\alpha, n, a$ e $b$ para os seus valores ótimos, ou seja, valores em que a função objetivo (e) assume o menor valor, estabelecido uma precisão da ordem de $10^{-12}$ imposta na implementação do problema.

TABELA 7.4: Resultados obtidos com $G E O_{v a r}, \tau=2.0$

\begin{tabular}{|c|c|c|c|c|c|}
\hline Número de Avaliações & Função de Fitness $(\mathrm{e})$ & $\alpha$ & $\mathrm{n}$ & $\mathrm{a}$ & $\mathrm{b}$ \\
\hline 1 & $6,867551 \mathrm{E}-01$ & $-1,072268000000$ & 0,634549300000 & $-0,024390370000$ & 0,120817600000 \\
\hline 2 & $5,761763 \mathrm{E}-01$ & $-1,103518000000$ & 0,633572700000 & $-0,028296620000$ & 0,058317600000 \\
\hline 5 & $5,404062 \mathrm{E}-01$ & $-1,095706000000$ & 0,664822700000 & $-0,036109120000$ & 0,062460360000 \\
\hline 11 & $4,543127 \mathrm{E}-01$ & $-1,009767000000$ & 0,557400700000 & $-0,009753375000$ & 0,093740880000 \\
\hline 20 & $4,029080 \mathrm{E}-01$ & $-0,125031500000$ & 0,062401780000 & $-0,283190900000$ & 0,107414200000 \\
\hline 27 & $1,416696 \mathrm{E}-01$ & $-0,000000035046$ & $-0,218846300000$ & $-0,095446740000$ & 0,232414200000 \\
\hline 28 & $1,079482 \mathrm{E}-01$ & $-0,000000005244$ & $-0,156346300000$ & $-0,064196740000$ & 0,248039200000 \\
\hline 32 & $8,276865 \mathrm{E}-02$ & $-0,062500000000$ & $-0,125104000000$ & $-0,032946740000$ & 0,187492300000 \\
\hline 37 & $2,940292 \mathrm{E}-02$ & $-0,000000001518$ & $-0,126019500000$ & $-0,001696735000$ & 0,123039200000 \\
\hline 1475 & $6,407069 \mathrm{E}-03$ & $-0,000000000194$ & $-0,000000000103$ & $-0,003906262000$ & $-0,000000066766$ \\
\hline 1476 & $6,406970 \mathrm{E}-03$ & $-0,000000000427$ & $-0,000000000107$ & $-0,003906254000$ & $-0,000000007162$ \\
\hline 1477 & $1,289089 \mathrm{E}-08$ & $-0,000000000194$ & $-0,000000000049$ & $-0,000000004388$ & $-0,000000003437$ \\
\hline 1478 & $9,468416 \mathrm{E}-09$ & $-0,000000000078$ & $-0,000000000281$ & $-0,000000003922$ & $-0,000000001574$ \\
\hline 1481 & $1,895269 \mathrm{E}-09$ & $-0,000000000001$ & $-0,000000000049$ & $-0,000000000022$ & $-0,000000001108$ \\
\hline 1482 & $3,356779 \mathrm{E}-10$ & $-0,000000000003$ & $-0,000000000020$ & $-0,000000000008$ & $-0,000000000177$ \\
\hline 1483 & $2,353359 \mathrm{E}-10$ & $-0,000000000001$ & $-0,000000000005$ & $-0,000000000022$ & $-0,000000000119$ \\
\hline 1484 & $1,940836 \mathrm{E}-11$ & 0,000000000000 & $-0,000000000001$ & $-0,000000000008$ & $-0,000000000002$ \\
\hline 1486 & $1,196074 \mathrm{E}-11$ & 0,000000000000 & $-0,000000000001$ & $-0,000000000001$ & $-0,000000000004$ \\
\hline 1487 & $1,193410 \mathrm{E}-11$ & $-0,000000000001$ & 0,000000000000 & 0,000000000000 & $-0,000000000005$ \\
\hline 1493 & $9,722396 \mathrm{E}-12$ & $-0,000000000001$ & $-0,000000000003$ & 0,000000000000 & 0,000000000000 \\
\hline 1509 & $9,214441 \mathrm{E}-12$ & $-0,000000000001$ & 0,000000000000 & $-0,000000000003$ & 0,000000000000 \\
\hline
\end{tabular}

Devido ao número de parâmetros a serem ajustados, um número maior de iterações foram necessários, demandando assim um maior tempo computacional. Porém os parâmetros ótimos foram atingidos dentro da ordem de convergência estabelecida pelo problema. A seguir são apresentados os gráficos referentes aos valores apresentados na Tabela 7.4. 

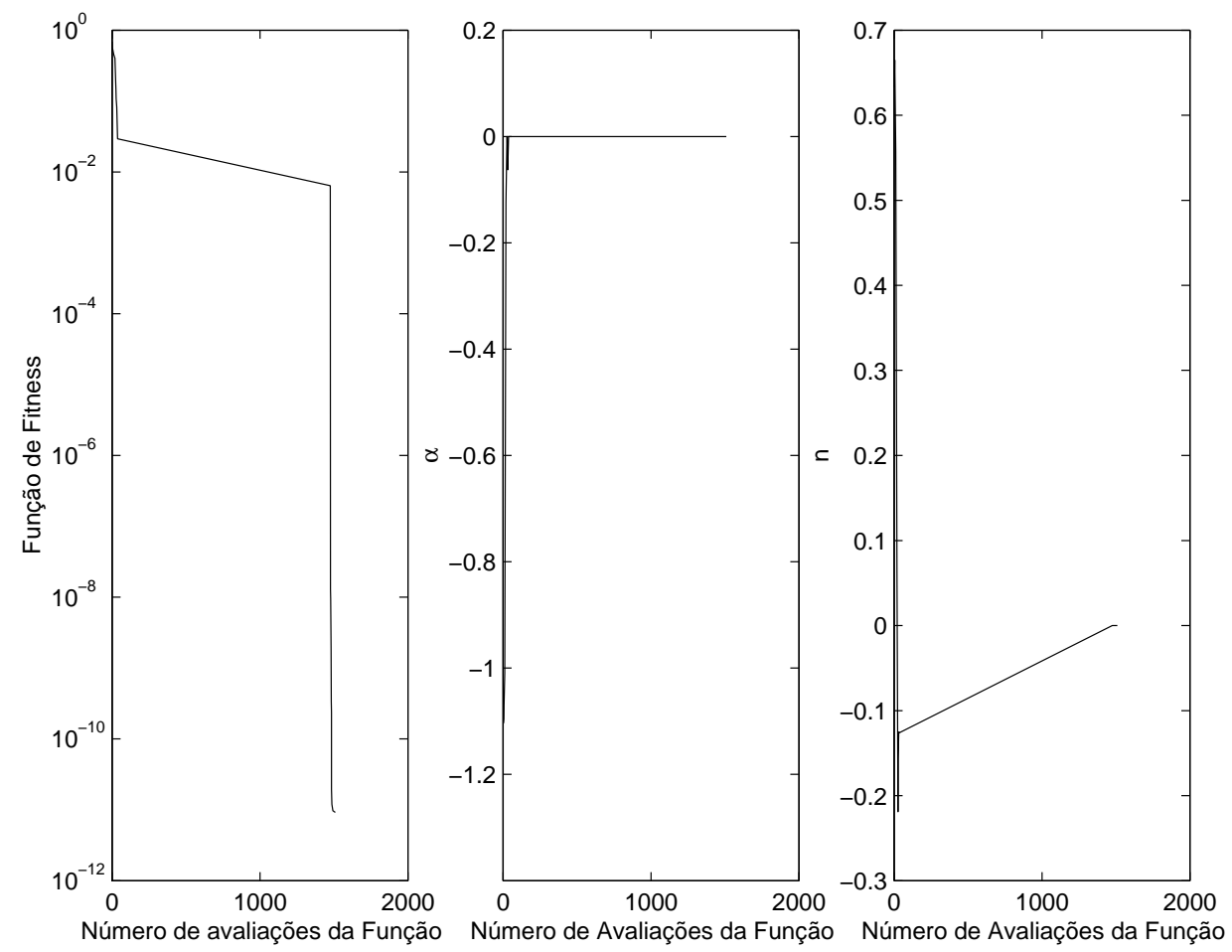

FIGURA 7.11: Resultados ótimos para a função de fitness e, variáveis $\alpha$ e $\mathbf{n}$
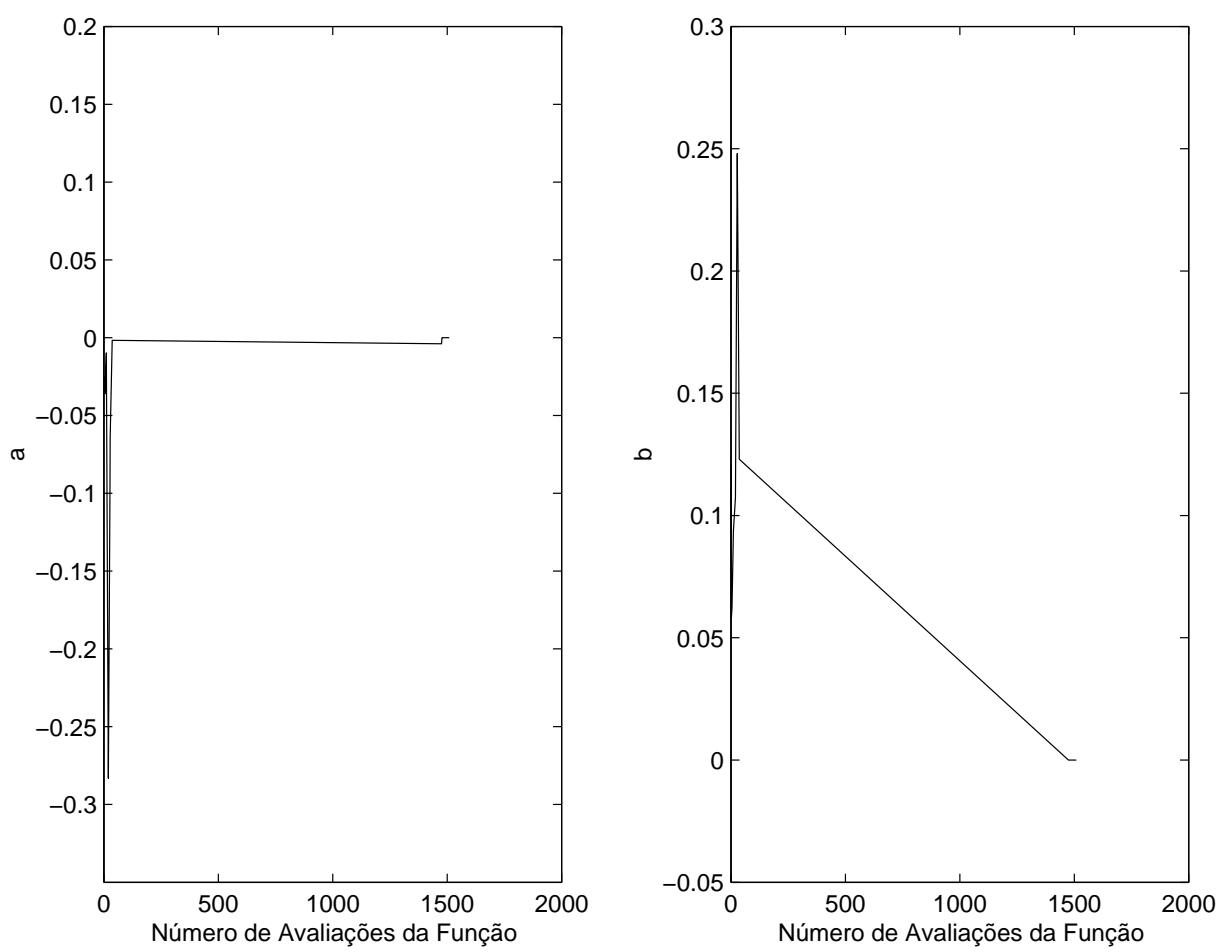

FIGURA 7.12: Resultados ótimos para as variáveis a e b 


\subsection{Resultados Finais}

Os resultados apresentados nesta seção é uma aplicação direta do método de Newton Raphson Linearizado aos Problemas de Otimização I e II.

\subsection{MNRL aplicado ao Problema de Otimização I}

Conforme descrito no capítulo 7, seção 7.3, o Problema de Otimização I consiste na minimização do funcional $e(\alpha, n)$ :

$$
\begin{aligned}
& \operatorname{Min}(e(\alpha, n)) \\
& 0.0<\alpha \leq 2.0 \\
& 1.0 \leq n \leq 3.0
\end{aligned}
$$

onde $\alpha$ e $n$ são parâmetros da velocidade:

$$
v(r, \theta)=\alpha\left(1-r^{n}\right)
$$

\section{Objetivo do Problema de Otimização I:}

Encontrar o ponto ótimo $(\alpha, n)$, ou ponto de mínimo global, que minimiza o funcional de erro (e).

Nesta seção, o processo de busca deste ponto ótimo é realizado utilizandose o Método de Newton-Raphson Linearizado. O desenvolvimento deste processo de busca é descrito a seguir.

\section{MNRL: Aproximação Inicial}

Conforme comentado no capítulo 6, o método de Newton Raphson Linearizado (MNRL) requer uma boa aproximação inicial. Neste trabalho, utilizou-se 
a idéia proposta por Kim et al. (2001), sendo que são necessários neste problema duas aproximações iniciais: uma para a variável $\alpha$ e outra para a variável $n$. Estas aproximações são obtidas através da minimização dos seguintes funcionais de erro:

$$
\begin{aligned}
& \left\|\phi_{\text {med }}-\frac{\alpha_{0}}{\alpha_{r e f}} \phi_{m e d}\right\| \\
& \left\|\phi_{\text {med }}-\frac{n_{0}}{n_{\text {ref }}} \phi_{\text {med }}\right\|
\end{aligned}
$$

Nestes funcionais de erro as tensões de fronteira são decompostas em

$$
\begin{aligned}
& \phi(\alpha, n) \approx \frac{\alpha_{0}}{\alpha_{r e f}} \phi_{m e d} \\
& \phi(\alpha, n) \approx \frac{n_{0}}{n_{r e f}} \phi_{m e d}
\end{aligned}
$$

estabelecendo uma relação linear entre as voltagens de fronteira e os parâmetros $\alpha$ e $n$ da velocidade. A melhor aproximação para $\alpha$ e $n$ é uma constante $\alpha_{0}$ e $n_{0}$ que minimize os funcionais 7.4 e 7.5. Para a minimização destes funcionais utilizou-se o método dos mínimos quadrados ordinários. Como exemplo da utilização deste método, segue o desenvolvimento referente a minimização do funcional descrito na equação 7.4 .

Seja f o funcional a ser minimizado (equação 7.4):

$$
f(\alpha)=\left\|\phi_{m e d}-\frac{\alpha}{\alpha_{r e f}} \phi_{m e d}\right\|
$$

O interesse aqui é ajustar, no sentido dos mínimos quadrados, $f(\alpha)$ por um polinômio $p(\alpha)$ de grau 3 :

$$
p(\alpha)=a_{0}+a_{1} \alpha+a_{2} \alpha^{2}+a_{3} \alpha^{3}
$$




$$
\left\{\begin{array} { l } 
{ p ( \alpha _ { 1 } ) = f ( \alpha _ { 1 } ) } \\
{ p ( \alpha _ { 2 } ) = f ( \alpha _ { 2 } ) } \\
{ p ( \alpha _ { 3 } ) = f ( \alpha _ { 3 } ) } \\
{ p ( \alpha _ { 4 } ) = f ( \alpha _ { 4 } ) } \\
{ \vdots } \\
{ p ( \alpha _ { n } ) = f ( \alpha _ { n } ) }
\end{array} \Rightarrow \left\{\begin{array}{c}
a_{0}+a_{1} \alpha_{1}+a_{2} \alpha_{1}^{2}+a_{3} \alpha_{1}^{3}=f\left(\alpha_{1}\right) \\
a_{0}+a_{1} \alpha_{2}+a_{2} \alpha_{2}^{2}+a_{3} \alpha_{2}^{3}=f\left(\alpha_{2}\right) \\
a_{0}+a_{1} \alpha_{3}+a_{2} \alpha_{3}^{2}+a_{3} \alpha_{3}^{3}=f\left(\alpha_{3}\right) \\
a_{0}+a_{1} \alpha_{4}+a_{2} \alpha_{4}^{2}+a_{3} \alpha_{4}^{3}=f\left(\alpha_{4}\right) \\
\vdots \\
a_{0}+a_{1} \alpha_{n}+a_{2} \alpha_{n}^{2}+a_{3} \alpha_{n}^{3}=f\left(\alpha_{n}\right)
\end{array}\right.\right.
$$

No sistema $7.9, \alpha_{1}, \alpha_{2}, \ldots, \alpha_{n}$ são $n$ pontos do intervalo de interesse, no caso do problema em questão, pontos do intervalo $(0,2]$.

$$
\underbrace{\left[\begin{array}{cccc}
1 & 1 & \ldots & 1 \\
\alpha_{1} & \alpha_{2} & \ldots & \alpha_{n} \\
\alpha_{1}^{2} & \alpha_{2}^{2} & \ldots & \alpha_{n}^{2} \\
\alpha_{1}^{3} & \alpha_{2}^{3} & \ldots & \alpha_{n}^{3}
\end{array}\right]}_{G^{T}} \underbrace{\left[\begin{array}{cccc}
1 & \alpha_{1} & \alpha_{1}^{2} & \alpha_{1}^{3} \\
1 & \alpha_{2} & \alpha_{2}^{2} & \alpha_{2}^{3} \\
1 & \alpha_{3} & \alpha_{3}^{2} & \alpha_{3}^{3} \\
\vdots & \vdots & \vdots & \vdots \\
1 & \alpha_{n} & \alpha_{n}^{2} & \alpha_{n}^{3}
\end{array}\right]}_{G} \underbrace{\left[\begin{array}{c}
a_{0} \\
a_{1} \\
a_{2} \\
\vdots \\
a_{n}
\end{array}\right]}_{\hat{T}}=\underbrace{\left[\begin{array}{cccc}
1 & 1 & \ldots & 1 \\
\alpha_{1} & \alpha_{2} & \ldots & \alpha_{n} \\
\alpha_{1}^{2} & \alpha_{2}^{2} & \ldots & \alpha_{n}^{2} \\
\alpha_{1}^{3} & \alpha_{2}^{3} & \ldots & \alpha_{n}^{3}
\end{array}\right]}_{G^{T}} \underbrace{\left[\begin{array}{c}
f\left(\alpha_{1}\right) \\
f\left(\alpha_{2}\right) \\
f\left(\alpha_{3}\right) \\
\vdots \\
f\left(\alpha_{n}\right)
\end{array}\right]}_{D}
$$

$$
G^{T} G \hat{T}=G^{T} D
$$

A solução do sistema 7.11 fornece os coeficientes do polinômio 7.8, polinômio de grau 3 que melhor se ajusta a $f(\alpha)$ no intervalo em questão, no sentido dos mínimos quadrados. O processo descrito é chamado Método dos Mínimos Quadrados Ordinários.

O valor $\alpha$ no intervalo $(0,2]$ onde $p(\alpha)$ é mínimo será a aproximação inicial.

O mesmo desenvolvimento é utilizado para obter uma aproximação inicial para $n \in[1,3]$. Com isso obteve-se a aproximação inicial $\alpha_{0}$ e $n_{0}$ para o Método de Newton-Raphson Linearizado. 


\section{MNRL: Algoritmo}

Passo 1: Obtenha uma aproximação inicial $x^{0}=\left(\alpha_{0}, n_{0}\right)$, onde $\alpha_{0}$ e $n_{0}$ são parâmetros da velocidade $v(r, \theta)=\alpha_{0}\left(1-r_{0}^{n}\right)$.

Passo 2: Faça $\mathrm{k}=0$ ( $k \rightarrow$ iteração).

Passo 3: Calcule uma aproximação de $\phi\left(x^{k}\right)$ a partir do conjunto de equações 3.9 e 5.1 (Problema Direto).

Passo 4: Calcule a matriz Jacobiana $\left(J=\left(\phi^{\prime}\right)_{i j}=\frac{\partial \phi_{i}}{\partial x_{j}^{k}}\right)$

Passo 5: Calcule a matriz Hessiana Linearizada $A=\left(\phi^{\prime}\right)^{T} \phi^{\prime}=J^{T} J$

Passo 6: Calcule a diferença entre as tensões de referência $\phi_{m e d}\left(\alpha_{r e f}, n_{r e f}\right)$ e a tensão calculada com base na aproximação inicial $\phi\left(x^{k}\right)$, ou seja,

$$
\Delta \phi=\phi_{\text {med }}\left(\alpha_{\text {ref }}, n_{\text {ref }}\right)-\phi\left(x^{k}\right)
$$

Passo 7: Calcule o vetor $b=J^{T} \Delta \phi$

Passo 8: Resolva o sistema linear $A \Delta x^{k}=b$

Passo 9: Atualize de $x^{k+1}=x^{k}+\Delta x^{k}$

Passo 10: Calcule uma aproximação de $\phi\left(x^{k+1}\right)$

Passo 11: Calcule $\epsilon$ definido pela equação 6.9

Passo 12: Se $\epsilon$ satisfizer o critério de parada, a aproximação para a solução ótima é encontrada. Caso contrário, faça $k=k+1$ e retorne ao passo 3 .

\subsubsection{Resultados para o Problema de Otimização I}

A Tabela 7.5 apresenta as aproximações geradas pelo método de NewtonRaphson Linearizado, tendo como aproximação inicial $(\mathrm{k}=0)$ valores obtidos pelo método dos Mínimos Quadrados Ordinário. 
TABELA 7.5: Aproximações geradas pelo MNRL

\begin{tabular}{|c|c|c|c|}
\hline $\mathrm{k}$ & $\alpha$ & $\mathrm{n}$ & $\varepsilon$ \\
\hline 0 & 0,9652063742055 & 2,0005850596211 & \\
\hline 1 & 0,9855925138376 & 2,0594085890329 & $3,465175 \mathrm{E}-02$ \\
\hline 2 & 0,9953468169853 & 2,0178759603564 & $9,385495 \mathrm{E}-05$ \\
\hline 3 & 0,9987078704974 & 2,0050721409120 & $2,017392 \mathrm{E}-04$ \\
\hline 4 & 1,0001741375217 & 1,9992904470199 & $2,081954 \mathrm{E}-05$ \\
\hline 5 & 0,9999519860853 & 2,0001907155746 & $4,223433 \mathrm{E}-06$ \\
\hline 6 & 1,0000733139541 & 1,9997081563705 & $9,484153 \mathrm{E}-08$ \\
\hline 7 & 1,0000210335411 & 1,9999162825446 & $3,209767 \mathrm{E}-08$ \\
\hline 8 & 0,9999959894876 & 2,0000159577665 & $4,126610 \mathrm{E}-09$ \\
\hline 9 & 1,0000003646001 & 1,9999985484689 & $6,252970 \mathrm{E}-10$ \\
\hline 10 & 0,9999999933692 & 2,0000000264231 & $1,455406 \mathrm{E}-10$ \\
\hline 11 & 1,0000000214059 & 1,9999999148110 & $8,881884 \mathrm{E}-12$ \\
\hline 12 & 0,9999999626401 & 2,0000001486821 & $6,983891 \mathrm{E}-13$ \\
\hline
\end{tabular}

Na Tabela 7.5 o valor de $\epsilon$ atinge a precisão imposta na implementação, ou seja, $10^{-13}$. Neste caso, o Método de Newton-Raphson Linearizado apresentou características de um processo que gera a cada iteração um valor ótimo melhor que na iteração anterior. Mas é importante notar que para isso o método requer uma boa aproximação inicial. Caso contrário, existe a possibilidade de estabilização da solução em um determinado intervalo, ou até mesmo oscilações em torno de uma determinada solução ótima, conduzindo a valores de $\epsilon$, ás vezes, maiores que na iteração anterior. Assim como ocorre com o $\mathrm{GEO}_{\text {var }}$, (Tabela 7.2), cujo processo de busca é iterativo e aleatório, onde em cada iteração existe a possibilidade do "suposto" valor ótimo oscilar em torno do valor ótimo da iteração anterior, ou até mesmo essas oscilações podem ser de uma ordem de precisão inferior referente a iteração passada. Perceba que a Tabela 7.2 mostra que no $G E O_{v a r}$ há um salto da iteração 3 para a iteração 8. Esta ocorrência pode ser justificada por ser um processo aleatório e, devido a isso não ter havido nenhuma alteração nas iterações 4,5,6 e 7, ou seja, nessas iterações o processo de mutação não apresentou uma solução melhor que na iteração 3 .

Os resultados da Tabela 7.5 são apresentados nos gráficos a seguir. 

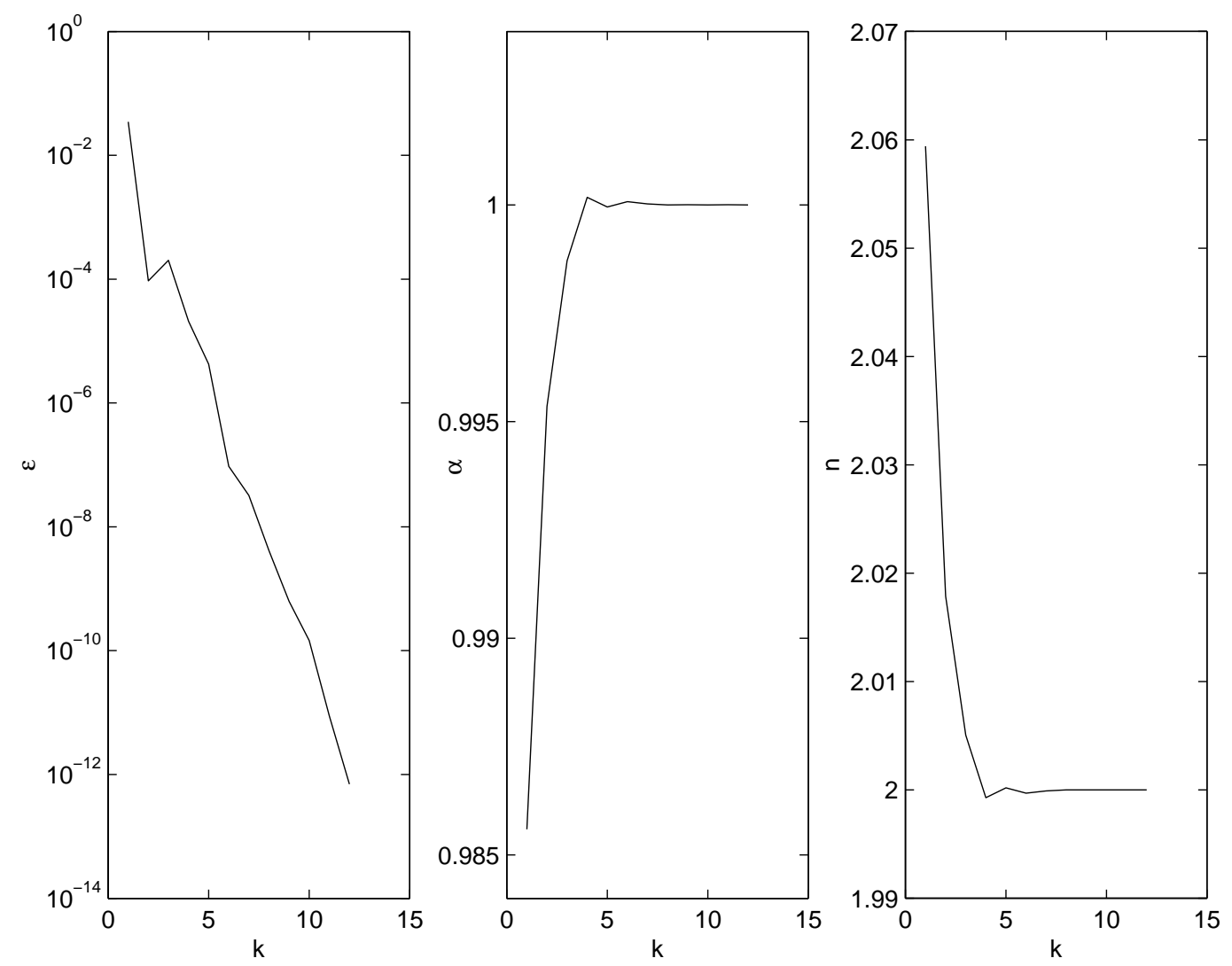

FIGURA 7.13: Resultados gerados pelo MNRL para $\epsilon$, variáveis $\alpha$ e $\mathbf{n}$

Ao comparar os resultados obtidos da aplicação do Método de NewtonRaphson Linearizado (Tabela 7.5) e gráfico (Figura 7.13) com os resultados obtidos da aplicação do algoritmo de Otimização Extrema Generalizado (Tabela 7.2) e gráfico (Figura 7.6) pode-se observar que ambos convergem para a solução ótima, porém no Método de Newton-Raphson Linearizado o tempo de execução é menor.

\subsection{MNRL aplicado ao Problema de Otimização II}

Conforme descrito no capítulo 7, seção 7.5, o Problema de Otimização II consiste na minimização do funcional $e(\alpha, n, a)$ : 


$$
\begin{aligned}
& \operatorname{Min}[e(\alpha, n, a)] \\
& 0.0<\alpha \leq 2.0 \\
& 1.0 \leq n \leq 3.0 \\
& 0.0 \leq a \leq 1.0
\end{aligned}
$$

cujo objetivo é encontrar $\alpha, n$ e $a$ parâmetros ótimos da velocidade $v(r, \theta)=$ $\alpha\left(1-r^{n}\right)\left[1+(r \cos (\theta)-a)^{2}\right]$, através dos quais $e(\alpha, n, a) \rightarrow 0$.

\section{MRL: Aproximação Inicial}

Neste problema de otimização, são necessários três aproximações iniciais: uma para a variável $\alpha$, variável $n$ e variável a. Estas aproximações são obtidas através da minimização dos seguintes funcionais de erro.

$$
\begin{aligned}
& \left\|\phi_{\text {med }}-\frac{\alpha_{0}}{\alpha_{\text {ref }}} \phi_{\text {med }}\right\| \\
& \left\|\phi_{\text {med }}-\frac{n_{0}}{n_{\text {ref }}} \phi_{\text {med }}\right\| \\
& \left\|\phi_{\text {med }}-\frac{a_{0}}{a_{\text {ref }}} \phi_{\text {med }}\right\|
\end{aligned}
$$

Estes funcionais de erro são minimizados utilizando o processo do método dos mínimos quadrados ordinários descrito na seção 7.9 obedecendo o intervalo de busca de cada variável.

\subsubsection{Resultados para o problema de Otimização II}

A Tabela 7.6 apresenta as aproximações geradas pelo método de NewtonRaphson Linearizado, tendo como aproximação inicial $(k=0)$ valores obtidos pelo método dos Mínimos Quadrados Ordinário. 
TABELA 7.6: Aproximações geradas pelo MNRL

\begin{tabular}{|c|c|c|c|c|}
\hline $\mathrm{k}$ & $\alpha$ & $\mathrm{n}$ & $\mathrm{a}$ & $\varepsilon$ \\
\hline 0 & 0,995048903176 & 2,000585328933 & 0,504949564948 & \\
\hline 1 & 1,000062068375 & 1,999840394423 & 0,499971053677 & $1,883714 \mathrm{E}-03$ \\
\hline 2 & 0,999999992602 & 2,000000008746 & 0,500000000052 & $5,162347 \mathrm{E}-06$ \\
\hline 3 & 0,999999999999 & 2,000000000004 & 0,500000000000 & $5,077986 \mathrm{E}-09$ \\
\hline 4 & 0,999999999999 & 2,000000000007 & 0,499999999999 & $1,199164 \mathrm{E}-13$ \\
\hline
\end{tabular}

Os gráficos a seguir apresentam os resultados da Tabela 7.6.
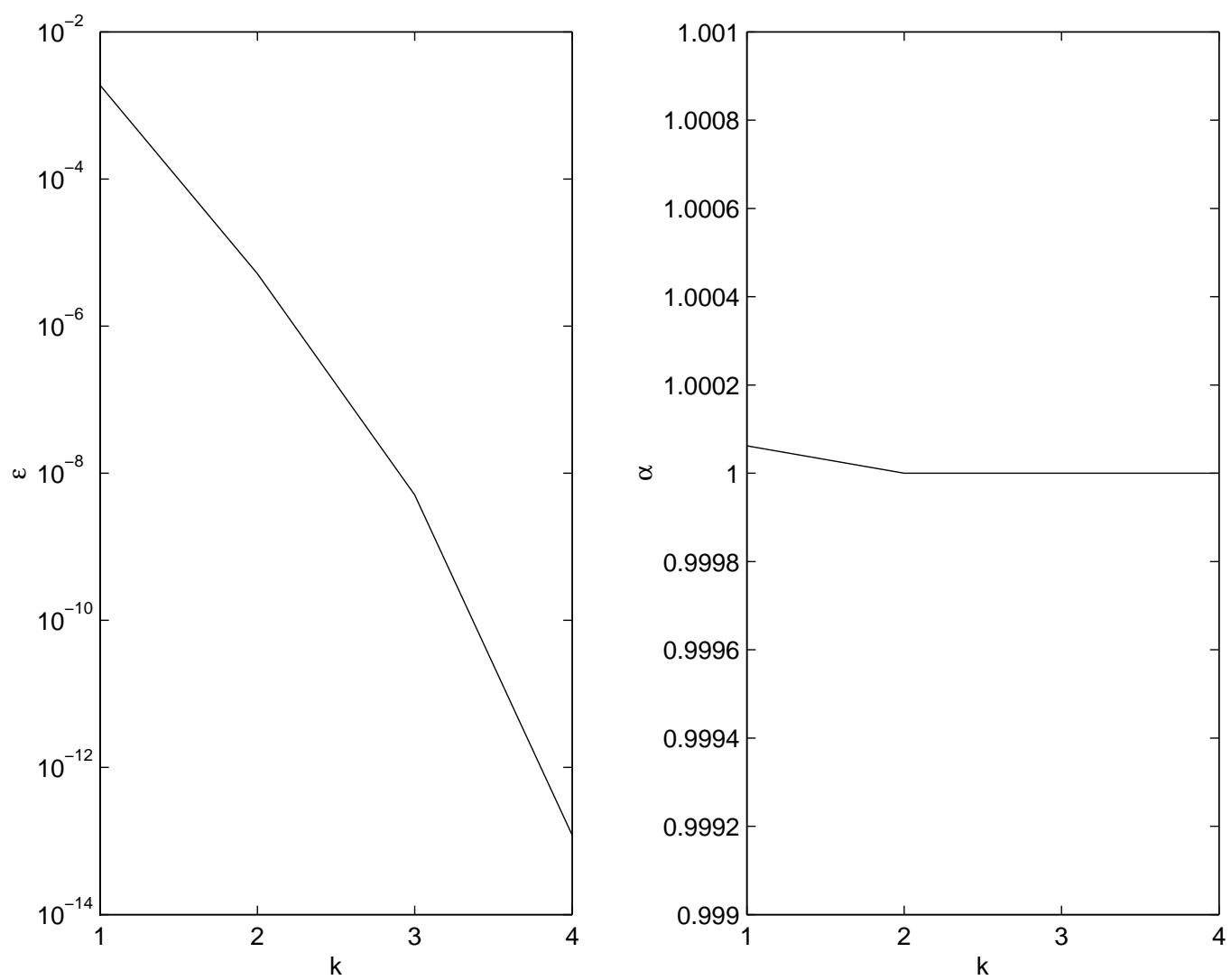

FIGURA 7.14: Resultados gerados pelo MNRL para $\epsilon$ e variável $\alpha$ 

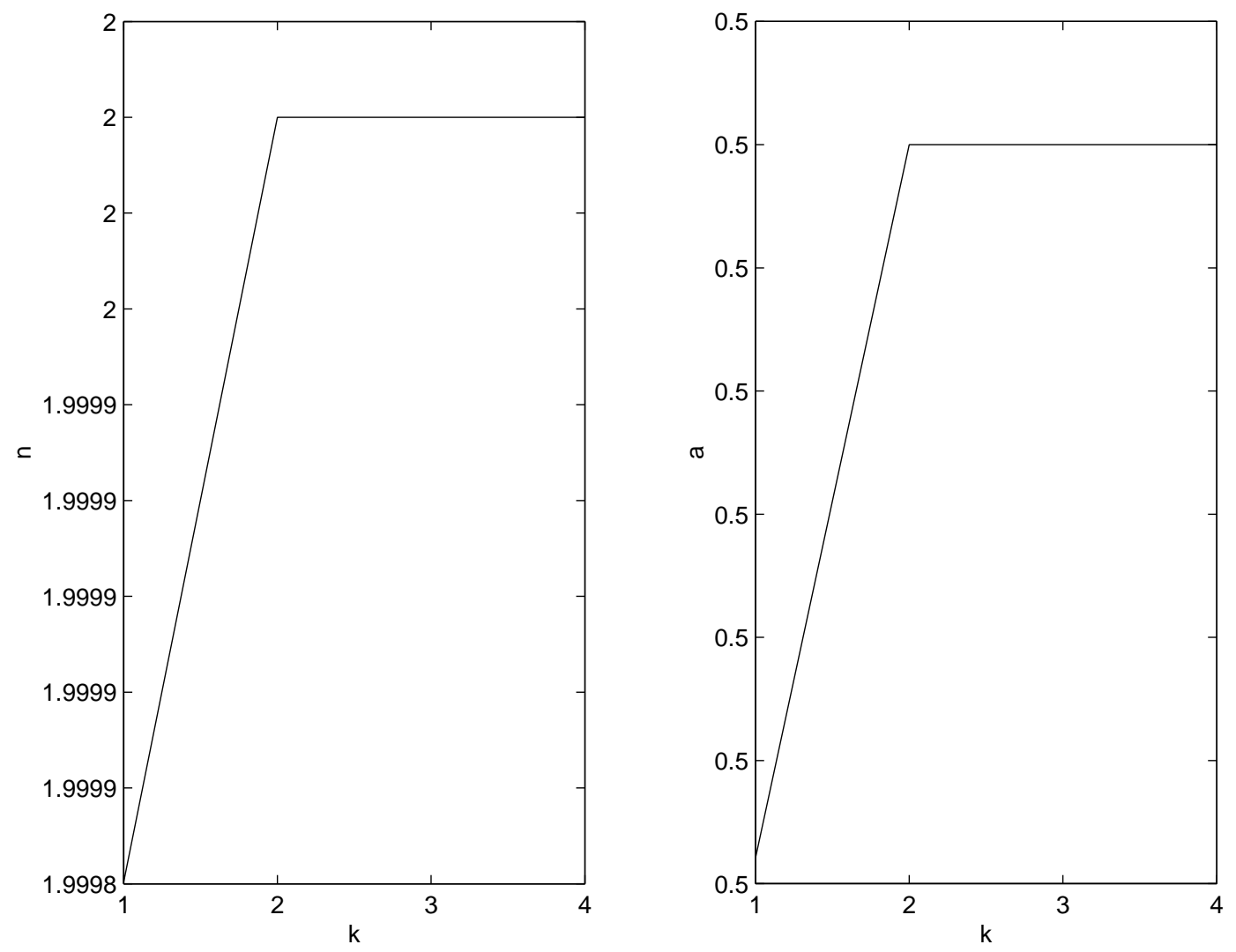

FIGURA 7.15: Resultados gerados pelo MNRL para as variáveis $\mathbf{n}$ e a

A Tabela 7.6 e os gráficos (Figura 7.14 e Figura 7.15) mostram que a velocidade de convergência para os respectivos valores ótimos de $\alpha, n$ e $a$ é bem maior se comparado com o problema de otimização da seção 7.9.1. Um determinante para este fato é que no Método de Newton-Raphson Linearizado um fator importantíssimo para a convergência é a aproximação inicial. O mesmo não ocorre no Método $\mathrm{GEO}_{v a r}$, onde a aproximação inicial é gerada aleatoriamente dentro do intervalo de busca das variáveis. Na tabela 7.3 nota-se as possíveis consequências dessa aleatoriedade, como por exemplo, o salto da iteração 13 para a iteração 15 e outro bem maior da iteração 15 para a iteração 308. Estes intervalos não são intervalos de estabilização e sim intervalos em que o processo busca uma solução melhor que a anterior. Nestes intervalos devem ocorrer soluções piores e estas são descartadas, pois provavelmente o bit escolhido para mutar não satisfaz a distribuição de probabilidade imposta na implementação. Uma grande vantagem dessa aleatoriedade é que o método consegue escapar de mínimos locais e assim 
convergir para a solução ótima, como ocorre nos exemplos das seções 7.3, 7.5 e 7.7 .

\subsection{MNRL aplicado ao Problema de Otimização III}

Conforme descrito no capítulo 7, seção 7.7, o Problema de Otimização III consiste na minimização do funcional $e(\alpha, n, a, b)$.

$$
\begin{gathered}
\operatorname{Min}[e(\alpha, n, a, b)] \\
-1.0 \leq \alpha \leq 1.0 \\
-1.0 \leq n \leq 1.0 \\
-1.0 \leq a \leq 1.0 \\
-1.0 \leq b \leq 1.0
\end{gathered}
$$

cujo objetivo é encontrar $\alpha, n, a$ e $b$ parâmetros ótimos da velocidade $v(r, \theta)=$ $\left(1+f_{1}\right)\left(1-r^{2}\right)\left(1+f_{2}^{2}\right)$, através dos quais $e(\alpha, n, a, b) \rightarrow 0$. Neste caso em específico, alterou-se apenas os intervalos de busca de cada parâmetro e os valores de referência do Problema de Otimização III, fixando-os em

$$
\begin{array}{ll}
\alpha_{\text {ref }}=0.01 & n_{\text {ref }}=0.01 \\
a_{\text {ref }}=0.01 & b_{\text {ref }}=0.01
\end{array}
$$

Essa alteração é realizada porque a aproximação inicial é calculdada a partir da minimização do funcional proposto por Kim (2001). Lembrando que para a construção deste funcional é necessário a decomposição das tensões de fronteira, como por exemplo, nas equações 7.6 e 7.7. Nestas equações pode-se perceber que se o parâmetro de referência for nulo, obtém-se uma divisão por zero. 


\section{MNRL: Aproximação Inicial}

Neste problema de otimização, são necessários quatro aproximações iniciais: uma para a variável $\alpha$, variável $n$, variável a e variável $b$. Estas aproximações são obtidas através da minimização dos seguintes funcionais de erro.

$$
\begin{aligned}
& \left\|\phi_{\text {med }}-\frac{\alpha_{0}}{\alpha_{\text {ref }}} \phi_{\text {med }}\right\| \\
& \left\|\phi_{\text {med }}-\frac{n_{0}}{n_{\text {ref }}} \phi_{\text {med }}\right\| \\
& \left\|\phi_{\text {med }}-\frac{a_{0}}{a_{\text {ref }}} \phi_{\text {med }}\right\| \\
& \left\|\phi_{\text {med }}-\frac{b_{0}}{b_{\text {ref }}} \phi_{\text {med }}\right\|
\end{aligned}
$$

Estes funcionais de erro são minimizados utilizando o processo do Método dos Mínimos Quadrados Ordinários descrito na seção 7.9 obedecendo o intervalo de busca de cada variável.

\subsubsection{Resultados para o problema de Otimização III}

A Tabela 7.7 apresenta as aproximações geradas pelo método de NewtonRaphson Linearizado, tendo como aproximação inicial $(k=0)$ valores obtidos pelo método dos Mínimos Quadrados Ordinário. 
TABELA 7.7: Aproximações geradas pelo MNRL

\begin{tabular}{|c|c|c|c|c|c|}
\hline $\mathrm{k}$ & $\alpha$ & $\mathrm{n}$ & $\mathrm{a}$ & $\mathrm{b}$ & $\varepsilon$ \\
\hline 0 & 0,010301898612 & 0,149999095028 & 0,024733961042 & 0,031226651230 & \\
\hline 1 & 0,007811502119 & $-0,013702136388$ & 0,011878451106 & 0,028896033453 & $5,921963 \mathrm{E}-03$ \\
\hline 2 & 0,009440431484 & $-0,000718229853$ & 0,010464902166 & 0,018532028178 & $8,745961 \mathrm{E}-04$ \\
\hline 3 & 0,009756106045 & 0,005749947745 & 0,010203243460 & 0,013382383905 & $2,032210 \mathrm{E}-04$ \\
\hline 4 & 0,009917503089 & 0,008767500354 & 0,010069142556 & 0,010980911321 & $4,969942 \mathrm{E}-05$ \\
\hline 5 & 0,009986868055 & 0,009838702437 & 0,010011074796 & 0,010128393578 & $1,080925 \mathrm{E}-05$ \\
\hline 6 & 0,009999681548 & 0,009996163880 & 0,010000269458 & 0,010003054141 & $1,357983 \mathrm{E}-06$ \\
\hline 7 & 0,009999999190 & 0,009999980015 & 0,010000000281 & 0,010000015524 & $3,195649 \mathrm{E}-08$ \\
\hline 8 & 0,009999999775 & 0,009999999685 & 0,009999999778 & 0,009999999849 & $1,030608 \mathrm{E}-10$ \\
\hline 9 & 0,009999999777 & 0,009999999776 & 0,009999999776 & 0,009999999777 & $4,195786 \mathrm{E}-13$ \\
\hline
\end{tabular}

A seguir são apresentados os gráficos referentes aos resultados da Tabela 7.7.
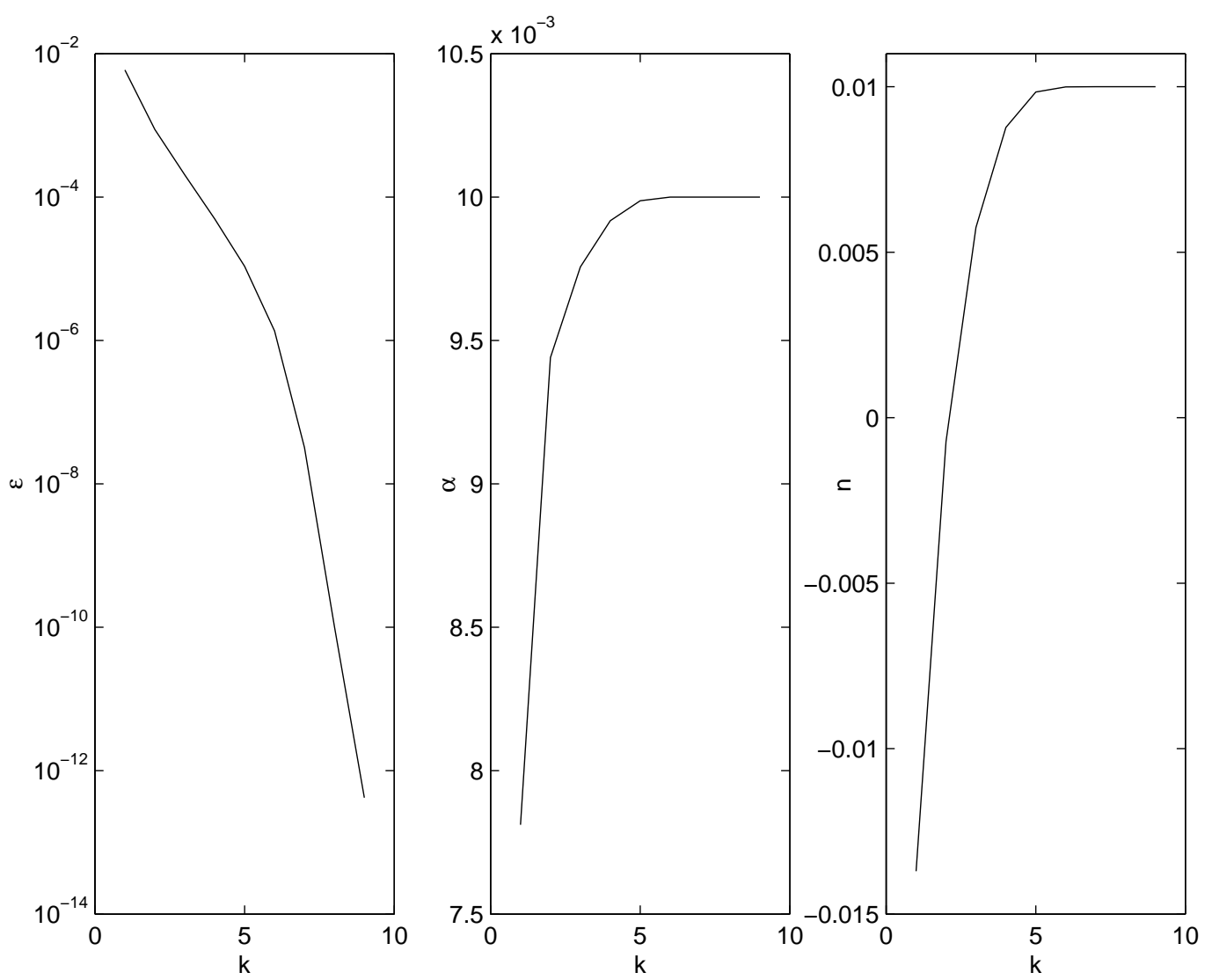

FIGURA 7.16: Resultados gerados pelo MNRL para $\epsilon$, variáveis $\alpha$ e $\mathbf{n}$ 

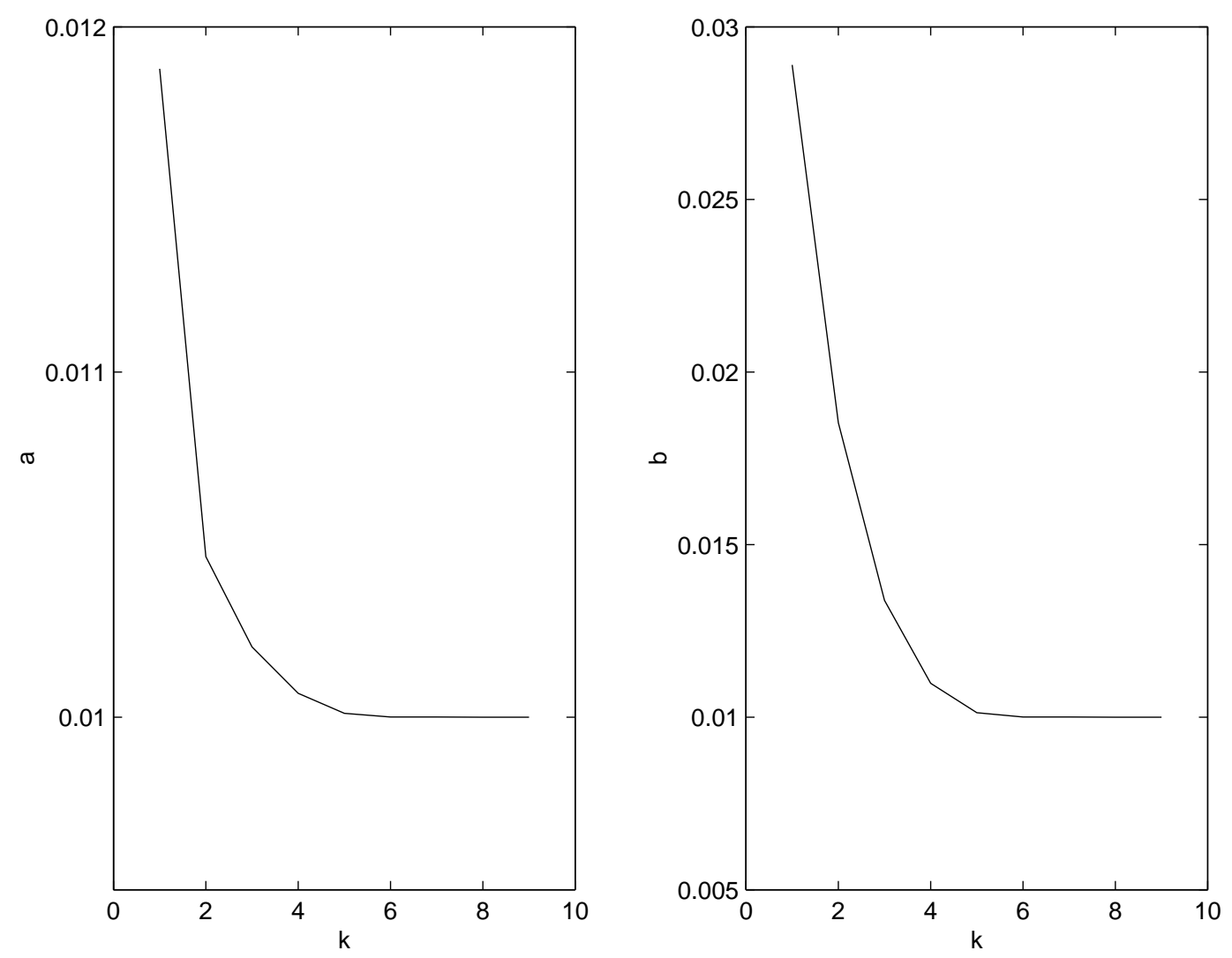

FIGURA 7.17: Resultados gerados pelo MNRL para as variáveis a e b

Os resultados obtidos para este problema de otimização mostram claramente a rapidez de convergência do método se comparado com o GEO var $_{\text {, lem- }}$ brando que para isso é necessário uma boa aproximação inicial. Comparando os resultados de ambos os métodos, pode-se observar na Tabela 7.4 que além da lentidão de convergência do $\mathrm{GEO}_{\text {var }}$ quando comparado ao Método de Newton Raphson Linearizado (Tabela 7.7), a Tabela 7.4 apresenta muitos saltos entre as iterações, o que revela que não foi fácil o ajuste entre os parâmetros procurados durante o processo de busca, levando a um maior número de iterações, ou seja, 1509 . Diferentemente do Método de Newton-Raphson Linearizado que apresentou um número de iterações iguais a 9, o suficiente para alcançar a solução ótima na ordem de precisão imposta na implementação. 


\section{Capítulo 8}

\section{Conclusão}

O objetivo fundamental deste trabalho é o estudo da viabilidade do projeto de um medidor eletromagnético de vazão que atenda as necessidades da empresa de uma forma eficiente, segura e barata. A idéia é calcular a vazão através da reconstrução do perfil de velocidades no interior de uma determinada tubulação. É importante notar que os resultados obtidos são teóricos, baseados no princípio físico de cada técnica utilizada. Neste trabalho é utilizado uma técnica numérica de reconstrução tomográfica eletromagnética baseada na construção de um funcional de erro. Dessa forma, a determinação da vazão provêm do sucesso da resolução de um problema de otimização baseado na busca dos parâmetros da velocidade que minimizem este funcional de erro. Mas o problema não é tão simples, o que pode ser comprovado nos resultados apresentados no capítulo 7. A superfície de erro gerada apresenta uma patologia característica do problema inverso em questão, ou seja, regiões planas, vales com vários mínimos locais e o mínimo global se encontra em um poço bem pronunciado. Sendo assim, o objetivo deste trabalho se resume em resolver um problema de otimização utilizando o menor tempo de execução possível. Para isso vários métodos foram testados e alguns descartados para o problema em questão, como por exemplo, os métodos tradicionais de otimização. A pesquisa direcionou-se na busca de algoritmos evolucionários que melhor se adequassem ao problema e, que apresentassem o menor número de parâmetros possíveis para ajustar. Em princípio utilizou-se os algoritmos genéticos, mas os resultados não foram satisfatórios principalmente 
com relação ao tempo de execução, não viável a uma situação realística, além de possuir vários parâmetros para ajustar. Após pesquisas realizadas, decidiu-se fazer um teste com a utilização do algoritmo de otimização extrema generalizado $\left(\mathrm{GEO}_{\text {var }}\right)$, utilizado por Sousa et al. (2003). Este método apresenta algumas características interessantes, como por exemplo, um parâmetro para ajustar e uma implementação fácil. Além disso, este algoritmo segue a mesma linha dos algoritmos genéticos, ou seja, é fundamentado sob a mesma base teórica. A diferença é que os G.A. trabalham com populações representadas por um conjunto de soluções que coexistem e interagem em um processo de busca. Enquanto que o $\mathrm{GEO}_{\text {var }}$ trabalha com uma população de bits representando somente uma solução do problema em cada iteração. Em G.A. a população evolui através de seleção, mutação, crossover, enquanto que no $\mathrm{GEO}_{\text {var }}$ evolui apenas através de mutação. Os resultados obtidos com o $\mathrm{GEO}_{v a r}$ foram satisfatório se comparados com os G.A., mas dependendo do número de parâmetros ótimos a serem encontrados foram necessários um número de iterações maior não correspondendo aos resultados esperados. Porém ambos os métodos evoluem em um processo de busca aleatório, escapando na maioria das vezes de mínimos locais. Novamente através de pesquisas em busca de outro método de otimização, optou-se pela aplicação do Método de Newton-Raphson Linearizado utilizado por Kim et al. (2001) em um problema de tomografia de impedância elétrica. O desenvolvimento deste método introduz um efeito de regularização do problema em questão. Os testes realizados apresentaram resultados satisfatórios se comparados com os métodos anteriores. Mas o único problema é com relação a aproximação inicial. Kim et al. (2001) propõe um meio de encontrá-la através da minimização de um funcional. O que ocorre e, pode ser observado nos resultados apresentados nas tabelas referentes as seções 7.9.1, 7.10.1 e 7.11.1. é que as aproximações provenientes da minimização destes funcionais apresentam valores bem próximos ou em uma região próxima do mínimo global. Dessa forma, a rapidez de convergência do método para o mínimo global é bem maior se comparado com os métodos anteriores. Em todo caso, pode-se concluir que o estudo apresenta resultados satisfatórios principalmente por se tratar de um problema mal-condicionado. Dessa forma, a idéia do 
projeto de um medidor eletromagnético "inteligente" de vazão é uma proposta viável comprovada nos resultados teóricos obtidos, proporcionando experiência e base teórica para estudos posteriores a essa linha de pesquisa. Uma proposta para um projeto futuro é utilizar como meta uma aplicação em específico, definindo o regime de operação, afim de realizar testes com resultados experimentais em uma plataforma online, por exemplo. 


\section{Referências Bibliográficas}

AHN, Y., DO OH, B. e KIM, M. H. (2003), A current-sensing electromagnetic flow meter for two-phase flow and numerical simulation of the three-dimensional virtual potential distribution: I. Fundamentals and annular flow, Measure-ment Science Technology, v.14, pp.239-250.

ARNOLD, J. S. (1950), An Electromagnetic Flowmeter for Transient Flow Studies, The Review of Scientific Instruments, v.22, No.1, New Mexico, pp.43-47.

BAK, P. e SNEPPEN, K. (1993), Punctuated Equilibruium and Criticality in a Simple Model of Evolution, Physical Review Letters, v.71, No.24, pp.4083-4086.

BATES, C.J. e FRANKLIN, B. (2004), The performance characteristics of a novel multi-electrode electromagnetic flowmeter, Measurement, v.35, pp.389 $-397$

BATES, C. J. e TURNER, R.B. (2002), Fluid flow studies associated with a new electromagnetic flowmeter, Measurement, v.33, pp.85-94.

BEAN, H. S. (1971). Fluid Meters: Their Theory and Aplication. American Society of Mechanical Engineers, New York.

BECK, M. S. e WILLIAMS, R. A. (1996). Process Tomography: a European Innovation and its Applications. Measurement Science Technology, v.7, pp.215-224, march.

BENEDICT, R. P. (1977). Measurement of Temperature, Pressure and Flow. Wiley, New York.

BEVIR, M. K. (1970), The Theory of Induced Voltage Electromagnetic 
Flowmeters, Journal Fluid Mech., v.43, part 3, pp.577-590.

BEVIR, M. K. (1971), The Predicted Effects of Red Blood Cells on Electromagnetic Flow Meter Sensitivity, J. Phys. D: Appl. Phys, v.4, pp. 387-399.

BEVIR, M. K. (1972), The Effects Conducting Pipe Connections and Surrounding Liquid on the Sensitivity of Electromagnetic Flow Meters, $J$. Phys. D: Appl. Phys, v.5, pp. 717-729.

BEVIR, M. K., O’SUllivAN, V. T. e WYATT, D. G. (1981), Computation of Electromagnetic Flowmeter Characteristics from Magnetic Field Data, J. Phys. D: App. Phys., v.14, pp.373-378.

BOETTCHER, S. and PERCUS, A. G. (2001), Optimization with Extremal Dynamics, Physical Review Letters, v.86, pp.5211-5214.

BOYER, C. e LEMONNIER, H. (1996), Design of a flow metering process for two-phase dispersed flows, International Journal of Multiphase Flow, v.22, $n^{0} .1$, august.

CONEY, M.W.E. (1973), The theory and application of conductance probes for the measurement of liquid film thickness in two-phase flow, J. Phys. E: Science Instrument,v.6, pp.903-911.

DAVIS, G. DE VAHL (1979), A Note on a Mesh for use with Polar Coordenates, Numerical Heat Transfer, v.2, pp.261-266.

DAVIS, L. (1991), Handbook of Genetic Algorithm, Van Nostrand Reinhold, New York.

DICKIN, F. J. et al (1992). Tomographic Imaging of Industrial Process Equipment: Techniques and Applications. IEE Proceedings, v.139, $n^{0} .1$, february.

ENGL, H. W., HANKE, M. e NEUBAUER, A. (1996), Regularization of Inverse Problems: Mathematics and its Applications, Kluwer.

GALLI, M. e ONOFRE, R., Sinopse sobre medição de vazão, Escola SENAI "Antonio Souza Noschese", Santos-S.P.

GEN, M. e CHENG, R. (1997). Genetic Algorithms and Engineering Design. Wiley-Interscience Publication. 
GOLDBERG, D. E. (1989). Genetic Algorithms in Search Optimization and Machine Learning. Addison-Wesley Co. Massachusets.

GOLDSTEIN, R. J. (1983). Fluid Mechanics Measurement. Hemisphere Publishing, New York.

HEMP, J. (1975), Improved Magnetic Field for an Electromagnetic Flow Meter with Point Electrodes, J. Phys. D: Appl. Phys, v.8, pp.983-1002.

HERVIEU, E. e SELEGHIM, P. Jr. (1995), Characterization of gas-liquid two-phase flow pattern transition by analysis of the instantaneous frequency, Proceedings of the Second International Conference on Multiphase Flow, FT1-25, v.3, Kyoto, A. Serizawa, T. Fukano \& J. Bataile Eds.

HOLLAND, J. H.(1975), Adaptation in Natural and Artificial Systems, Ann Arbor: University of Michigan Press.

HORNER, B., MESCH, F. (1995), An Induction Flow Meter Insensitive to Asymmetric Flow Profiles Meter Insensitive to Asymmetric Flow Profiles. European Concerted Action on Process Tomography Conf.(Bergen Norway), ISBN 0952316528 pp. 321-30

HORNER, B., MESCH, F. and TRACHTLER, A. (1996), A Multi-Sensor Induction Flow meter Reducing Errors due to Non-Axisymmetric Flow Profiles, Measurement Science Technology, v.7,pp.354-360.

JANILOW, C. e MICHALEWICZ, Z. (1991), An Experimental Comparison of Binary and Floating Point Representation in Genetic Algorithms, The Fourth International Conference on Genetic Algorithms

KARISSON, B. (1998), Fuzzy measures for sensor data fusion in industrial recycling, Measurement Science Technology, v.9, pp.907-912.

KIM, M.C. (2001), Regularization methods in electrical impedance tomography technique for the two-phase flow visualization. In: INTERNATIONAL CONFERENCE HEAT MASS TRANSFER, v.28, $n^{0}$ 6, pp.773-782.

KIM, M. H. et al (2004), Advanced electromagnetic flowmetry for slug flow: numerical signal prediction and calibration, International Journal of Multiphase Flow, v.30, pp.585-614.

KIM, J. et al (2005), Real time measurement of gas and liquid flow rates in 
two-phase slug flow by an advanced electromagnetic flowmeter and conductance probes. In: $11 \underline{a}$ INTERNATIONAL TOPICAL MEETING ON NUCLEAR REACTOR THERMAL-HYDRAULICS (NURETH-11), 2-6 october.

KNOWLES, I. (1998), A Variational Algorithm for Electrical Impedance Tomography. Inverse Problem, v.14, pp.1513-1525.

KOLIN, A. (1945), An Alternating Field Induction Flow Meter of High Sensitivity, The Review of Scientific Instruments, v.16, No.5, pp.109-116.

KÜHN, F. T. et al (1996), Analysis of Chaos in Fluidization using Electrical Capacitance Tomography. Measurement Science Technology, v.7, $n^{0} .3$, pp.361-368.

LEMKE, J. (2004), Novas Tecnologias Patenteadas Combinando Placa de Orifício e Retificador de Fluxo: O problema de trecho reto, Revista Controle \& Instrumentação, edição $n^{0} 95$, agosto.

LIN, C.Y. e HAJELA, P. (1992), Genetic Algorithms in Optimization Problems with Discret and Integer Design Variables, Engeneering Optimization, v.19, pp.309-327.

MICHALEWICZ, Z. (1996), Genetic Algorithms + Data Structures = Evolution Programs, New York:Springer-Verlag Berlin Heidelberg.

MICHALEWICZ, Z., LOGAN, T. e SWAMINATHAN, S. (1994), Evolutionary Operators for Continuous Convex Parameter Space. Proceedings of the Third Annual Conference on Evolutionary Programming.

O’SULLIVAN, V. T. e WYATT, D.G. (1983), Computation of electromagnetic flowmeter characteristics from magnetic field data: III. Rectilinear weight functions, J. Phys. D: Appl. Phys., v.16, pp.1461-1476.

PEYTON et al (1996), An Overview of Electromagnetic Indutance tomography: description of three different system, Measurement Science Technology, v.7, pp.261-271.

PRESS, W. H. et al (1992), Numerical Recipes in Fortran: The Art of Scientific Computing, 2nd ed. Cambridge [England]; New york, NY, USA: Cambridge University Press. 
SCAIFE, J. M., TOZER, R.C. e FREESTON, I. L. (1994), Conductivity and Permitivity Images from an Induced Current Electrical Impedance Tomography System, IEE Proc. A. 141, pp. 356-62.

SHERCLIFF, J. A. (1954), Relation between the Velocity Profile and the Sensitivity of Electromagnetic Flowmeters, J. Appl. Phys., v.25, pp.817818.

SHERCLIFF, J. A. (1955), Experiments on the Dependence of Sensitivity on Velocity Profile in Electromagnetic Flowmeters, Journal Scientific Instruments, v.32, pp.441-442.

SHERCLIFF, J. A. (1962), The Theory of Electromagnetic Flow-Measurement, Cambridge University Press.

SOUSA, L. F. et al (2003), New Stochastic Algorithm for Design Optimization, AIAA Journal, v.41, No.9, pp.1808-1818.

SPITZER, D. W. (1991). Flow Measurement: Pratical Guides for Measurement and Control, Instrument Society of America. Research Triangle Park, North Carolina.

TOKATY, G. A. (1971). History and Philosophy of Fluidmechanics. Oxfordshire: G.T. Foulis.

XIE, C. G. et al (1989), Mass-flow measurements of solids using electrodynamic and capacitance transducers, J. Phys. E: Science Instrument, v.22, pp.712-719.

XIE, C. G. et al (1992), Electrical Capacitance Tomography for Flow Imaging: System Model for Developmemt of Image Reconstruction Algorithms and Primary Sensors. IEE Proc. G, v.139, pp.89-98.

XU et al (2001), Optimum Estimation of the Mean Flow Velocity for the Multi-Electrode Inductance Flowmeter, Measurement Science Technology, v.12, pp.1139-1146.

YAN, W. Q. (1996), Charge injection compensation for charge/discharge capacitance measuring circuits used in tomography systems, Measurement Science and Technology, v.17, pp.1073-1078.

ZHANG, X. (1997), The effect of the phase distribution on the weight function 
of an electromagnetic flow meter in 2D and in the annular domain, Measurement Science Technology, v.8, pp.1285-1288.

ZHANG, X. (1998), 2D analysis for the virtual current distribution in an electromagnetic flow meter with a bubble at various axis positions, Measurement Science Technology, v.9, pp.1501-1505.

ZHANG, X. (1999), On finding the virtual current in an electromagnetic flow meter containing a number of bubbles by two-dimensional analysis, Measurement Science Technology, v.10, pp.1087-1091. 